Aplicação da metodologia AIM-CID no conteúdo da disciplina sistemas operacionais

Roni Guillermo Apaza Aceituno 



\title{
Aplicação da metodologia AIM-CID no conteúdo da disciplina sistemas operacionais
}

\author{
Roni Guillermo Apaza Aceituno
}

Orientadora: Profa. Dra. Sarita Mazzini Bruschi

\begin{abstract}
Dissertação apresentada ao Instituto de Ciências Matemáticas e de Computação - ICMC-USP, como parte dos requisitos para obtenção do título de Mestre em Ciências - Ciências de Computação e Matemática Computacional. VERSÃO REVISADA
\end{abstract}


Ficha catalográfica elaborada pela Biblioteca Prof. Achille Bassi e Seção Técnica de Informática, ICMC/USP, com os dados fornecidos pelo(a) autor(a)

\begin{tabular}{|l} 
AAP639 Apaza Aceituno, Roni Guillermo \\
Aplicação da metodologia AlM-CID no conteúdo da \\
a disciplina sistemas operacionais / Roni Guilermo \\
Apaza Aceituno; orientador Sarita Mazzini Bruschi. - \\
- São Carlos, 2013. \\
87 p. \\
Dissertação (Mestrado - Programa de Pós-Graduação en -- \\
Ciências de Computação e Matemática Computacional), \\
Universidade de São Paulo, 2013. \\
1. AlM-CID. 2. So. 3. Metodología. I. Mazzini \\
Bruschi, Sarita, orient. II. Título.
\end{tabular}




\section{Agradecimentos}

Agradeço sinceramente aos meus pais Santos Guillermo Apaza Huanca e Angélica Aceituna de Apaza por me dar tudo aquilo que precisava e tirar de mim tudo aquilo que não precisava, a toda a família Aceituna de origem Cuzquenha e a família Apaza de origem Punenha, a minha prezada terra Arequipa por dar-me uma história tão rica e costumes tão bons, agradeço a meu querido Perú por deixar um legado que posso chamar de mim e com muito orgulho e humildade chamar-la de o antigo império incaico.

Meus profundos agradecimentos ao povo brasileiro que me acolheu com muita alegria e carinho, minha gratidão ao trem mineiro, a querência tri-legal gaúcha, ao paulistas e paulistanos, ao quente Pará, ao misterioso Acre, ao Mato Grosso do Sul, a Amazônia por descobrir, ao Paraná abençoado, agradeço aos brasileiros em geral o pouco que eu conheci e são lembranças levarei em meu coração até o dia da minha morte.

Especiais agradecimentos a minha Orientadora Doutora Professora Sarita Mazzini Bruschi, a quem peço desculpas por não ter contribuído ainda mais neste trabalho e agradeço por ter me ajudado a chegar muito além do que imaginava.

Meus agradecimentos especiais também vão para os professores do LASDPC aos quais tenho uma grande dívida, pelos conhecimentos passados e pelos conselhos ministrados. Meus agradecimentos aos três Luiz, aos quatro Brunos, aos dois Paulos, Lourenço, Douglas, Vinicius, Fausto, Edvard, Elvis, Geraldo, Helder, Ariel, Edwin, os dois Pedros, Osvaldo, Thiago, Rene, Dionísio e Maycon.

Também agradeço aos gaúchos Daniel e João Paulo por me falarem de sua terra, a qual tive a oportunidade de apreciar com meus olhos. Agradeço também a Emily, a Fernanda e a Geniana umas lindas gaúchas que eu conheci em minha viagem.

Agradeço aos meus prezados amigos do cantinho fraterno por ter-me deixado conhecer pessoas tão especiais e lindas, especialmente a Terezinha, o Cidão e o Paulinho. Meu agradecimento também é para Alvaro e Jean Pierre que me acolheram na sua casa, para Raúl por sua ajuda em tudo o que eu precisava, aos meninos com quem eu morei Breno, Édrian, Vinícius, Cassia, Shen, Karina, Ciza, José Maria, Hugo e Fabiano.

Agradeço ao Alexander Benavides por ter me acolhido na sua casa e mostrar-me Porto Alegre uma cidade muito bonita. Agradecimentos especiais também a Noemi Rocha, Dayse de Almeida, 
Lilian Berton, Valeria Carvalho, Aline de Albuquerque, Lhais Oliveira e Monique Gasparotto. Quero também agradecer a Patricia Figueira Goldberg e Murieli Pereira Tiengo por tudo o que me ensinaram. Conhecimentos que não serão apagados nunca.

Por fim mas não menos importante quero agradecer a Deus todo-poderoso por ter-me deixado chegar até São Carlos e permanecer aqui e a São João Bosco por me dar um modelo a seguir como professor.

Agradeço a CAPES pelo financiamento deste projeto. 
M algumas disciplinas dos cursos de computação, a quantidade excessiva de conteúdo torna mais difícil o ensino dos conceitos. A disciplina de Sistemas Operacionais é um exemplo deste tipo de disciplina e objetivando facilitar o aprendizado, podese fazer uso de diversas técnicas, ferramentas e metodologias, como por exemplo, a AIM-CID (Abordagem Integrada de Modelos Conceitual, Instrucional e Didático). Este projeto de mestrado tem como objetivo principal a aplicação da metodologia AIM-CID sobre os tópicos abordados no ensino de Sistemas Operacionais. Este trabalho foi desenvolvido para ajudar os professores dessa disciplina no ordenamento dos conceitos a serem ensinados. Um objetivo secundário é utilizar os resultados do uso da metodologia para criar a base para o desenvolvimento de materiais educativos visando o ensino do sistemas operacionais. Desse modo, a contribuição deste trabalho permite a criação de elementos que auxiliem os alunos na fixação dos conteúdos da disciplina. Uma vez aplicada a metodologia AIM-CID sobre o conteúdo da disciplina de Sistemas Operacionais, foi utilizada uma metodologia que avalia a usabilidade de softwares pedagógicos, e obteve-se um resultado que valida o modelo desenvolvido neste projeto. 

N some courses of Computer Science programs, the excessive amount of content makes it harder to teach the concepts. The Operating Systems course is an example of this kind of course and aiming to facilitate the learning, it is possible to use several techniques, tools and methodologies, such as the AIM-CID (Integrated Approach of Models - Conceptual, Instructional and Didactic). This master's project has as main objective the application of the methodology AIM-CID on the topics covered by the Operating Systems course. This work was developed to help teachers of this course in planning the concepts to be taught. A secondary goal is to use the results of the use of the methodology to create the basis for the development of educational materials aiming at operating systems teaching. Thus, the contribution of this work allows the creation of elements that assist students in setting the course content. Once applied the methodology AIM-CID on the content of the Operating Systems course, it was used a methodology that assesses the usability of educational software, and it was obtained a result that validates the model developed in this project. 



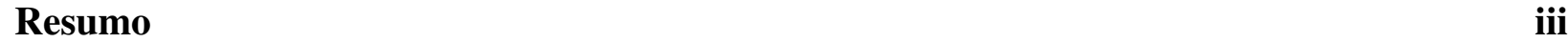

$\begin{array}{lll}\text { Abstract } & \text { v }\end{array}$

1 Introdução $\quad 1$

1.1 Motivação e objetivos . . . . . . . . . . . . . . . . . . . 1

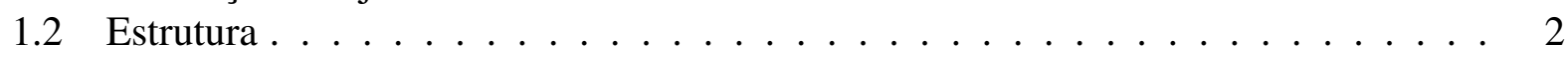

2 Revisão conceitual de Sistemas Operacionais 3

2.1 Considerações Iniciais . . . . . . . . . . . . . . . . . . . . . . . . . . . . . . . . .

2.2 Definição de Sistema Operacional . . . . . . . . . . . . . . . . . . . . 3

2.3 Definição de kernel . . . . . . . . . . . . . . . . . . . . . . 4

2.3.1 Estrutura Monolítica . . . . . . . . . . . . . . . . . . . 4

2.3.2 Estrutura Microkernel . . . . . . . . . . . . . . . . 4

2.4 Gerenciamento de Processos . . . . . . . . . . . . . . . . . . . 5

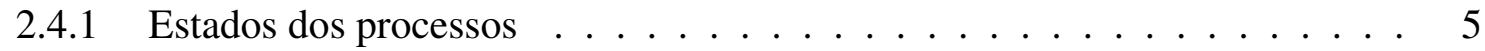

2.4.2 Bloco de controle de processos . . . . . . . . . . . . . 6

2.4 .3 Chamadas ao sistema . . . . . . . . . . . . . . . 7

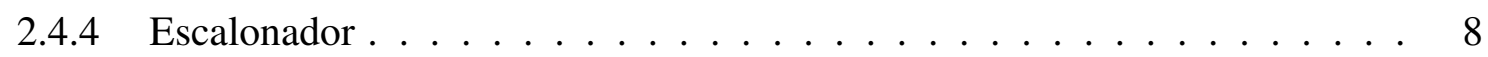

2.5 Gerenciamento de Memória . . . . . . . . . . . . . . . . . . . 9

2.5 .1 Swapping . . . . . . . . . . . . . . . . 9

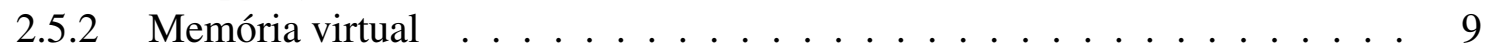

2.5.3 Paginação da Memória Virtual . . . . . . . . . . . . . . . . . . 10

2.5.4 Algoritmos de substituição de páginas na paginação . . . . . . . . . . . . 11

2.5.5 Segmentação da Memória Virtual . . . . . . . . . . . . . . . . . . 12

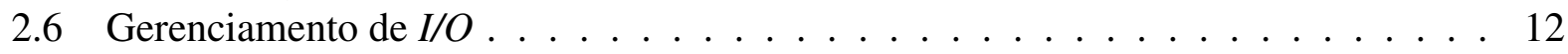

2.6 .1 Interrupções . . . . . . . . . . . . . . . . . . . . . . 12

2.6.2 Tratadores de interrupção . . . . . . . . . . . . . . . . . 13

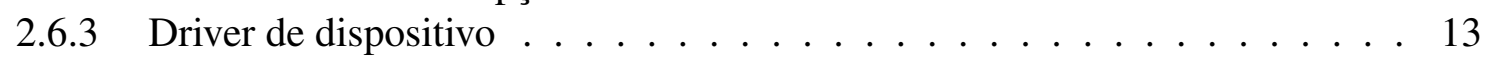

2.6.4 Software de E/S independente de disposítivo . . . . . . . . . . . . . . 13

2.6.5 Software de E/S do espaço de usuário . . . . . . . . . . . . . . . . . . . . 14

2.7 Sistema de arquivos . . . . . . . . . . . . . . . . . . . . . . . . . 14

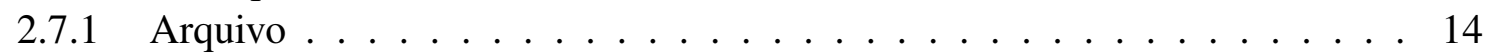

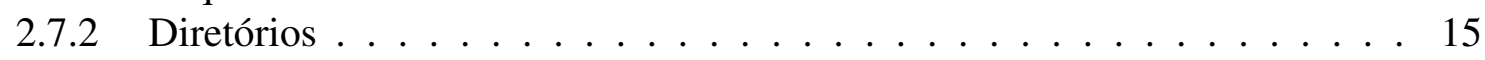

2.7.3 Gerência de Espaço livre em Disco . . . . . . . . . . . . . 15 
2.7.4 Gerência de Alocação de Espaço em Disco . . . . . . . . . . . . . . . . . 15

2.8 Considerações finais . . . . . . . . . . . . . . . . . . 15

3 Metodologia para construção de módulos educacionais 17

3.1 Considerações Iniciais . . . . . . . . . . . . . . . . . . . . 17

3.2 Objetos educacionais . . . . . . . . . . . . . . . . . 17

3.3 Processos para o desenvolvimento dos módulos educacionais . . . . . . . . . . 20

3.3.1 Processos fundamentais . . . . . . . . . . . . . . 20

3.3 .2 Processos de apoio . . . . . . . . . . . . . . 22

3.3.3 Processos organizacionais . . . . . . . . . . . . 23

3.4 Modelagem de módulos educacionais . . . . . . . . . . . . . . . 25

3.4.1 Requisitos para Modelagem de conteúdos educacionais . . . . . . . . . . 25

3.4.2 Modelos genéricos para representação de conteúdos educacionais . . . . . 26

3.4.3 Abordagem Integrada para Modelagem de Conteúdos Educacionais . . . . 29

3.5 Considerações finais . . . . . . . . . . . . . . . . . 32

4 Modelagem de conteúdos em domínio de Sistemas Operacionais 33

4.1 Considerações Iniciais $\ldots \ldots \ldots 33$

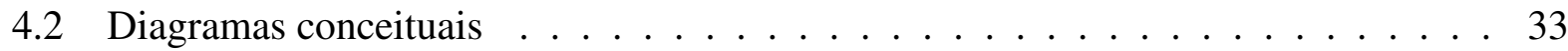

4.3 Diagramas instrucionais . . . . . . . . . . . . . . . . . 42

4.4 Diagrama didáticos . . . . . . . . . . . . . . . . . 53

4.5 Considerações Finais . . . . . . . . . . . . . . . . . . . 59

5 Validação dos modelos gerados $\quad 61$

5.1 Considerações inicias . . . . . . . . . . . . . . . . . . . . 61

5.2 Desenvolvimento de material educativo . . . . . . . . . . . . . . 61

5.3 Sistema Avaliador de Usabilidade em Softwares Pedagógicos . . . . . . . . . . . 62

5.4 Adequação da metodologia . . . . . . . . . . . . . . . . . . . . . . 64

5.5 Instruções para o preenchimento do questionário . . . . . . . . . . . . . . 66

5.6 Conclusões dos questionários . . . . . . . . . . . . . . . . . . 67

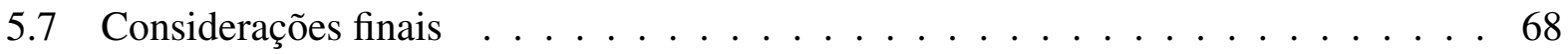

6 Conclusões e Trabalhos Futuros $\quad 69$

6.1 Conclusões . . . . . . . . . . . . . . . . . . . . . . . . 69

6.2 Publicações . . . . . . . . . . . . . . . . . . 71

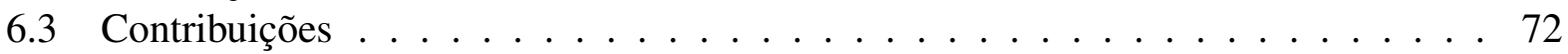

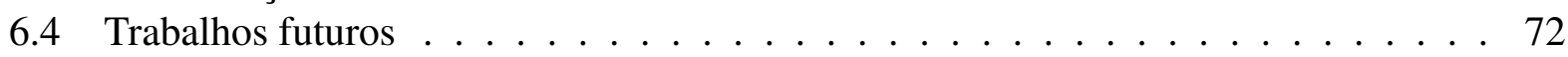




\section{Lista de Figuras}

2.1 Arquitetura Monolítica $($ Roch, 2004) . . . . . . . . . . . . . . . . . . . . 4

2.2 Arquitetura Microkernel (Roch, 2004) . . . . . . . . . . . . . . . . . 5

2.3 Estados de um processo . . . . . . . . . . . . . . . . . . . . . 6

2.4 Estrutura do bloco de controle (Machado e Maia, 2002) . . . . . . . . . . . . . 7

2.5 Representação da chamada ao sistema (Abraham Silberschatz e Gagme, 2009) . . . 8

4.1 Diagrama conceitual de Sistemas Operacionais . . . . . . . . . . . . . 35

4.2 Diagrama conceitual do gerenciador de conceitos. . . . . . . . . . . . . . . 36

4.3 Diagrama conceitual do gerenciador de memória . . . . . . . . . . . . . . . . . . . . . . 38

4.4 Diagrama conceitual do gerenciador de $\mathrm{E} / \mathrm{S} \ldots \ldots \ldots$. . . . . . . . . . . . . . . . 39

4.5 Diagrama conceitual de sistema de arquivos . . . . . . . . . . . . . . . 41

4.6 Diagrama instrucional de Sistemas Operacionais . . . . . . . . . . . . . . . . 42

4.7 Diagrama instrucional do gerenciador de processos . . . . . . . . . . . . . . . . 45

4.8 Diagrama instrucional do gerenciador de memória . . . . . . . . . . . . . . . . . 47

4.9 Diagrama instrucional do gerenciador de $\mathrm{E} / \mathrm{S} \ldots \ldots \ldots$. . . . . . . . . . . 50

4.10 Diagrama instrucional do sistema de arquivos . . . . . . . . . . . . . 52

4.11 Diagrama didático de sistemas operacionais . . . . . . . . . . . . . 53

4.12 Diagrama didático do gerenciador de processos . . . . . . . . . . . . . . . 55

4.13 Diagrama didático do gerenciador de memória . . . . . . . . . . . . . . . 56

4.14 Diagrama didático do gerenciador de E/S . . . . . . . . . . . . . . . 57

4.15 Diagrama didático do gerenciador de sistema de arquivos . . . . . . . . . . . 58

5.1 Exemplo de um slide do material didático . . . . . . . . . . . . . . . . 62

5.2 Exemplo do questionário a ser aplicado . . . . . . . . . . . . 66 



\section{Lista de Tabelas}

5.1 Perguntas referentes a usabilidade didática. . . . . . . . . . . . . . . 65

5.2 Perguntas referentes a usabilidade geral. . . . . . . . . . . . . . . 65

5.3 Respostas referentes a usabilidade didática. . . . . . . . . . . . . . . . . . 67

5.4 Respostas referentes a usabilidade geral. . . . . . . . . . . . . . . 67 


\subsection{Motivação e objetivos}

Os sistemas operacionais fazem parte da grade curricular de diversos curso de computação: Ciências, Engenharia e Sistemas de Informação.

As constantes mudanças na área tecnológica, relacionadas tanto a software quanto a hardware, têm tornado o mercado exigente na qualificação e preparação acadêmica dos profissionais desta área. No âmbito didático em geral, novos métodos são fundamentais para extrair maior eficiência e resultados no ensino. Uma maneira de alcançar esta melhora é buscar transformar os conceitos abstratos apresentados em objetos concretos. O ministério da Educação e Cultura (MEC), através da Secretaria de Educação à distancia (Seed) promove a incorporação de técnicas de educação à distancia e tecnologias de informação nos processos de ensino e aprendizagem (Reis e Costa, 2009).

Tradicionalmente, o professor segue um modelo para prover ao aluno os conhecimentos necessários e exigidos pela respectiva disciplina. Este modelo se baseia em uma bibliografia e um cronograma rígido de ensino (Maia, 2001).

A complexidade de uma disciplina pode levar a dificuldades no ensino da mesma. Esta dificuldade se vê acrescida pela quantidade de informação que está presente em outros meios, como nos livros ou até mesmo na internet. As grades curriculares de cada um dos cursos de Ciências de Computação podem ter objetivos divergentes e, por tanto, o conteúdo a ser ministrado deve adequar-se à grade curricular. 
Para auxiliar no ensino, o professor pode fazer o uso de determinadas ferramentas. Uma destas ferramentas é o software educacional. Porém, para desenvolver um software deste tipo é necessário uma metodologia adequada.

O objetivo principal de este projeto é a aplicação de uma metodologia para o desenvolvimento de módulos educacionais. Esta metodologia tem o nome de Abordagem Integrada de Modelos Conceitual, instrucional e Didática, também conhecida como metodologia AIM-CID. A metodologia AIM-CID será aplicada no conjunto de conceitos presentes na disciplina de Sistemas Operacionais. Será utilizado como base os conceitos abordados no livro Sistemas Operacionais Modernos, de A. S. Tanenbaum (Tanenbaum, 2009)), onde os tópicos são divididos em quatro partes:

- Gerenciamento de processo;

- Gerenciamento de memória;

- Gerenciamento de entrada e saída;

- Sistema de arquivos.

\subsection{Estrutura}

Este documento está organizado em seis capítulos: o capítulo 1 contém a introdução.

O capítulo 2 apresenta a revisão teórica de Sistemas Operacionais baseada nos tópicos abordados em (Tanenbaum, 2009).

O capítulo 3 discute a Metodologia para construção de módulos educacionais. Também serão apresentados os conceitos mais importantes da metodologia AIM-CID.

O capítulo 4 aborda a aplicação da metodologia AIM-CID sobre os conteúdos do domínio de Sistemas Operacionais. O resultado da aplicação desta metodologia será um conjunto de diagramas estabelecidos no formato da metodologia mencionada no capítulo 3.

O capitulo 5 apresenta a metodologia utilizada para a validação dos modelos gerados no capítulo 4, e a avaliação da metodologia.

O Capítulo 6 descreve as conclusões finais do projeto. 


\section{Revisão conceitual de Sistemas \\ Operacionais}

\subsection{Considerações Iniciais}

Os tópicos descritos neste capítulo abordam os conceitos básicos de sistemas operacionais, tendo como objetivo facilitar o entendimento dos conceitos que serão a base para a modelagem do conteúdo educacional proposta neste trabalho.

\subsection{Definição de Sistema Operacional}

Antes de definir o que é um Sistema Operacional (SO), é importante pensar no que aconteceria se ele não existisse. Em primeiro lugar, a interação entre os dispositivos e o usuário final poderia ser muito complexa, dependendo da quantidade e da diversidade dos dispositivos. Em segundo lugar, também seria mais complexo escrever um programa devido a essa interação existente entre as diversas partes do computador para executar alguma tarefa. O mais provável é que aconteceriam outros problemas causados pela falta de um Sistema Operacional. Nessa linha de raciocínio, pode-se dizer que os sistemas operacionais podem ser vistos de duas maneiras. A primeira é enxergar o SO como um gerenciador de recursos, capaz de lidar com as informações referentes aos dispositivos pertencentes ao computador. A segunda é a visão de máquina estendida, em que o SO oferece para o usuário uma abstração do hardware, permitindo uma interface mais amigável. 


\subsection{Definição de kernel}

O kernel é o núcleo do sistema operacional (Stallings, 2005), e também pode ser considerado como um pequeno sistema operacional (Paul J. Deitel e Choffnes, 2005). Baseado na premissa que ele pode ser um gerenciador de recursos, neste caso os recursos mais importantes são memória, processador (Central Unit Process CPU), entrada e saída $(I / O)$ e sistema de arquivos. A estrutura do kernel é complexa pela quantidade de iterações que ele tem em seu interior, por isso mesmo é de difícil entendimento e compreensão. Além disso, ele também gerencia as threads de usuário e de núcleo e o escalonamento de processos.

Em relação à execução dos processos, a maioria dos sistemas operacionais define dois modos de operação (quando suportados pela arquitetura do processador): o espaço de kernel, onde o código executado possui privilégio (acesso) total sobre o hardware, e o espaço do usuário, onde o código (programa) executado possui acesso restrito ao hardware, sendo necessário recorrer ao kernel quando necessário (através de funções denominadas chamadas ao sistema). Apesar da existência de diversas abordagens estruturais de núcleo, apenas duas serão detalhadas: a estrutura microkernel e a estrutura monolítica.

\subsubsection{Estrutura Monolítica}

A estrutura monolítica (Tanenbaum, 2009) tem a característica de ter uma interface bem definida para cada rotina, com o objetivo de que uma possa chamar a outra sem restrições sendo todo o kernel executado no mesmo nível de privilégio, ou seja, com acesso total ao hardware. Além disso, não há apenas uma rotina com sua interface neste sistema, existem muitas rotinas que comunicam-se umas com as outras, podendo criar um sistema caótico. Este tipo de estrutura de kernel é ilustrado na Figura 2.1.

\begin{tabular}{|c|c|}
\hline \multirow{2}{*}{ Espaço de Usuário } & Aplicaçōes \\
\cline { 2 - 2 } & Bibliotecas \\
\hline \multirow{2}{*}{ Kernel } & Comunicaçāo entre processsos \\
\cline { 2 - 2 } & I/O e Gerenciamento de drivers \\
\cline { 2 - 2 } & Gerenciamento fundamental de processsos \\
\hline \multicolumn{2}{|c|}{ Hardware } \\
\hline
\end{tabular}

Figura 2.1: Arquitetura Monolítica (Roch, 2004)

A origem do termo monolítico vem do grego Monólithos que significa pedra única. No contexto de sistemas operacionais, entende-se a estrutura de kernel monolítico como uma compilação das partes em uma unidade, ou seja, o kernel inteiro em apenas um programa(Tanenbaum, 2009).

\subsubsection{Estrutura Microkernel}

A estrutura monolítica possui boa performance uma vez que todos os drivers e subsistemas do kernel são executados no mesmo nível de privilégio. Entretanto, agregar todo o kernel em um só 
programa pode levar a uma menor confiabilidade, já que uma falha em qualquer driver ou subsistema pode ocasionar o travamento total do sistema. Uma forma de contornar esta limitação é utilizar o conceito de microkernel. Esta abordagem consiste em um kernel pequeno, o qual é reduzido para ter somente um processo básico de comunicação e controle de entrada/saída, deixando os demais serviços no espaço de usuário na forma de processos simples. Para executar instruções pertencentes ao espaço do Kernel é necessário o uso de chamadas ao sistema que são previstas por bibliotecas e que são inicializadas no espaço de usuário. Para atender uma requisição de um cliente é preciso usar servidores que estão no espaço do usuário; há um servidor para gerenciar a memória, outro para os processos, um para os drivers, e assim por diante. Estes servidores devem ter um mecanismo de comunicação com o microkernel para poder executar as tarefas que eles oferecem. Esta estrutura funciona através de um modelo de comunicação, como se observa na Figura 2.2.

\begin{tabular}{|c|c|c|c|c|c|}
\hline \multirow{3}{*}{ Espaço de usuario } & \multicolumn{5}{|c|}{ Aplicaçōes } \\
\hline & \multicolumn{5}{|c|}{ Bibliotecas } \\
\hline & $\begin{array}{l}\text { Sistema } \\
\text { de } \\
\text { Arquivos }\end{array}$ & $\begin{array}{l}\text { Servidor } \\
\text { de } \\
\text { Processos }\end{array}$ & Paginador & Drives & $\cdots$ \\
\hline Kernel & \multicolumn{5}{|c|}{ Microkernel } \\
\hline \multicolumn{6}{|c|}{ Hardware } \\
\hline
\end{tabular}

Figura 2.2: Arquitetura Microkernel (Roch, 2004)

\subsection{Gerenciamento de Processos}

Um processo é a instância de um programa em execução e, como qualquer programa, requer recursos que podem ser: CPU, memória, arquivos e dispositivos de $I / O$.

Neste escopo, o sistema operacional é responsável pelo seguinte (Abraham Silberschatz e Gagme, 2004):

- Criar, bloquear e remover processos do sistema;

- Fornecer uma estrutura para sincronização e comunicação entre processos;

- Prover mecanismos para o tratamento de deadlocks.

\subsubsection{Estados dos processos}

Considera-se cinco estados (Abraham Silberschatz e Gagme, 2004) básicos para a execução dos processos:

- Início: Nascimento de um processo, gerado pelo computador;

- Execução: O processo é executado pelo processador; 
- Bloqueio: O processo é bloqueado por alguma razão;

- Pronto: O processo pronto para execução, espera para usar o processador;

- Fim: Uma vez realizadas as tarefas, o processo dá sua execução por terminada.

A Figura 2.3 ilustra a interação entre os estados do processo.

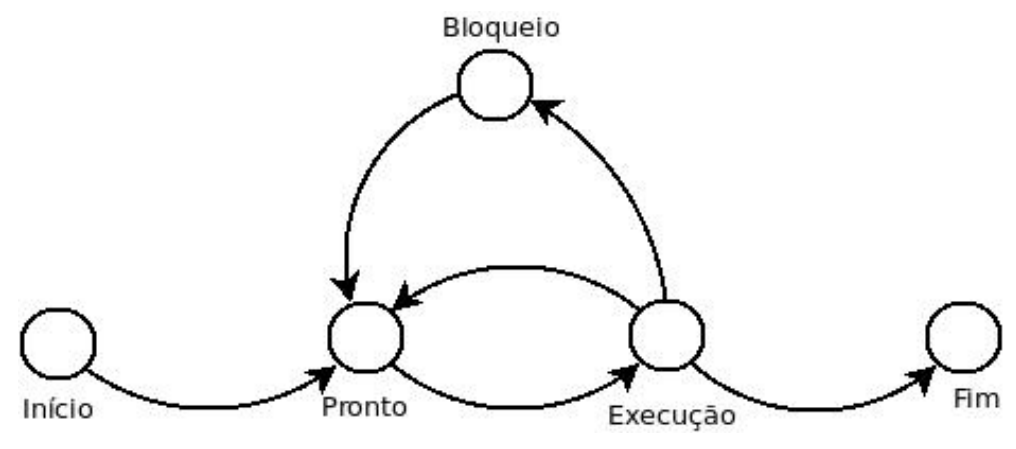

Figura 2.3: Estados de um processo

As mudanças de estados são assim definidas:

- Inicio - Pronto: O processo muda do estado Inicio para Pronto no momento da criação do processo e pode passar à fila de prontos;

- Pronto - Execução: O processo muda do estado Pronto para Execução ao ser escolhido pelo escalonador para sua execução;

- Execução - Fim: Um processo depois de terminar sua execução muda para o estado Fim para finalizar seu ciclo de vida;

- Execução - Pronto: Um processo no estado Execução muda para o estado Pronto por eventos gerados pelo próprio sistema;

- Bloqueio - Pronto: Um processo muda de estado Bloqueio para o estado Pronto, no momento que o processo recebe um dado ou aconteceu um evento especial;

- Execução - Bloqueio: Um processo no estado Execução muda para o estado Bloqueio quando o processo necessita de algum dado especial de E/S.

\subsubsection{Bloco de controle de processos}

O bloco de controle de processos, também conhecido como bloco de controle de tarefas (Abraham Silberschatz e Gagme, 2004), representa as várias informações pertencentes a um processo. A Figura 2.4 ilustra resumidamente os elementos de um bloco de controle (Abraham Silberschatz e Gagme, 2004; Stallings, 2005) que, neste exemplo, podem ser: 
- PID (Process Identifier): Identificador único do processo;

- Estado: A utilidade deste dado é armazenar em que estado está o processo no ciclo de vida do processo (Início, bloqueio, pronto, execução, fim);

- Informação para escalonamento: Inclui informação da prioridade do processo, ponteiros para as filas de escalonamento e outros parâmetros necessários para o escalonamento;

- Contador do programa: Indica o endereço da próxima instrução a ser executada no processo;

- Registradores da CPU: São acumuladores, registradores, ponteiros e outros, os quais dependem da arquitetura do computador e da informação que requer o processo;

- Informação de gerência de memória: Podem conter dados da tabela de páginas, a tabela de segmentos ou outros, dependendo do sistema operacional;

- Informação do estado de Entrada/Saída: Informação dos dispositivos e arquivos usados pelo processo;

- Informação contábil: Informação contábil da CPU e do processo, bem como outro tipo de informação fornecida pelo sistema operacional.

\begin{tabular}{|c|c|c|c|}
\hline \multicolumn{4}{|c|}{ Identificador do Processo } \\
\hline \multicolumn{4}{|c|}{ Estado do Processo } \\
\hline Prioridade & Ponte & & Outros \\
\hline \multicolumn{4}{|c|}{ Contador do programa } \\
\hline Acumuladores & Registradores & Ponteiros & Outros \\
\hline $\begin{array}{c}\text { Tabela de } \\
\text { páginas }\end{array}$ & \multicolumn{2}{|c|}{\begin{tabular}{|c|c|}
$\begin{array}{c}\text { Tabela de } \\
\text { segmentos }\end{array}$ & \\
\end{tabular}} & Outros \\
\hline \multicolumn{4}{|c|}{ Entrada/Saída } \\
\hline \multicolumn{4}{|c|}{ Informação contábil } \\
\hline \multicolumn{4}{|c|}{ Outros } \\
\hline
\end{tabular}

Figura 2.4: Estrutura do bloco de controle (Machado e Maia, 2002)

\subsubsection{Chamadas ao sistema}

As chamadas ao sistema (System calls, em inglês ) são um conjunto de funções oferecidas pelo sistema operacional, disponíveis como uma interface ao programa do usuário, permitindo acesso ao espaço do kernel. Estas chamadas ao sistema podem ser agrupadas em (Abraham Silberschatz e Gagme, 2004): controle de processos, gerenciamento de arquivos, gerenciamento de dispositivos, manutenção de informações, comunicações.

Não é necessário que este conjunto de funções seja conhecido em detalhes pelo programador para ser aplicado no desenvolvimento de aplicativos, uma vez que bibliotecas (como por exemplo a 
biblioteca C) podem abstrair estas funções em uma API (Application Programming Interface) mais fácil de ser utilizada. Alguns padrões também definem uma API para as chamadas ao sistemas, neste caso, de acordo com (Abraham Silberschatz e Gagme, 2009) as APIs mais conhecidas são:

- Win32 API para sistemas Windows;

- POSIX API para sistemas baseados no padrão POSIX (Portable Operating System Interface $X$ - Interface de Sistema Operacional Portável, sendo o X uma referência ao Unix);

- Java API para programas executados na máquina virtual java.

O sistema de suporte em tempo de execução para algumas linguagens de programação provê uma interface para as chamada ao sistema e as linguagens de programação provêm um enlace para as chamadas ao sistema habilitadas pelo sistema operacional. Esta interface associa cada chamada de sistema a um número que é alocado em uma tabela e depois invocado pelo kernel do sistema operacional. A relação entre o sistema operacional, a interface de chamada de sistema e as chamadas ao sistema, pode ser visualizada na Figura 2.5 (Abraham Silberschatz e Gagme, 2009).

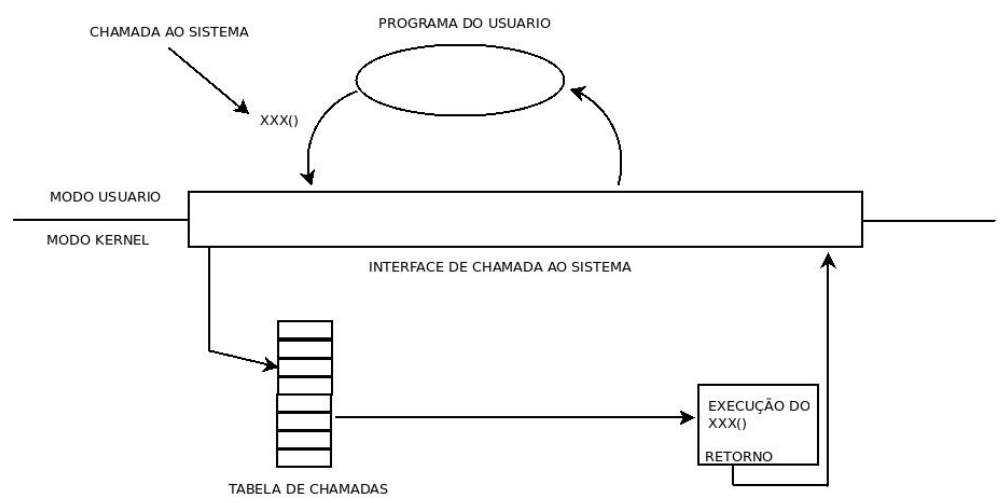

Figura 2.5: Representação da chamada ao sistema (Abraham Silberschatz e Gagme, 2009)

O padrão POSIX (Lewine, 1991) foi desenvolvido para que todos os programas feitos no UNIX fossem compatíveis com todas as vertentes deste SO.

\subsubsection{Escalonador}

O escalonador é responsável por fazer a seleção dos processos, com o único objetivo de aumentar a eficiência do uso da CPU, alternando entre os processos, de acordo com uma política de escalonamento, permitindo ainda que os programas de usuário possam interagir com outros processos enquanto ele ainda está na CPU (Abraham Silberschatz e Gagme, 2004).

Os principais algoritmos de escalonamento são (Abraham Silberschatz e Gagme, 2004):

- Escalonamento First-Come First-Served - FCFS: O processo que requisita a CPU em primeiro lugar recebe a CPU primeiro; 
- Escalonamento Shortest Job First- SJF: Seleciona-se o processo à espera com o menor tempo de execução estimado até a sua conclusão;

- Escalonamento por prioridade: Uma prioridade é associada a cada processo, e é alocado o processo com a maior prioridade na CPU;

- Escalonamento Round Robin: A cada processo é atribuído um intervalo de tempo, o quantum, no qual ele é permitido executar. Se, ao final do quantum o processo estiver ainda executando, o processo sofrerá preempção e a CPU será dada a outro processo. Se o processo foi bloqueado ou terminou antes que o quantum tenha decorrido, o próximo processo é alocado na CPU pelo escalonador.

\subsection{Gerenciamento de Memória}

Uma das funções mais importantes do sistema operacional é o gerenciamento de memória, que tem como objetivo controlar a memória no SO através de funções de gerenciamento, tais como alocar processos na memória principal, determinar quanto espaço há disponível e como responder às mudanças na utilização da memória de um processo. O gerenciador de memória interage com o hardware de gerenciamento de memória específicos (Paul J. Deitel e Choffnes, 2005). Seja memória principal, memória cache ou memória secundária, o sistema operacional precisa de uma estratégia de gerenciamento de memória.

Se o computador pudesse ter uma quantidade de memória ilimitada, não seria preciso estabelecer métodos para gerenciar-la. Sendo ela um recurso limitado, precisa de métodos de troca tais como swapping e memória virtual.

\subsubsection{Swapping}

O método de swapping, conhecido também como troca de processos, consiste em trocar processos inteiros da memória para o disco (memória secundária) e do disco para a memória para ser executado. O método de alocação de memória gera espaços, os quais precisam também serem gerenciados através de algum método, por exemplo:

- Mapa de bit;

- Lista encadeada.

\subsubsection{Memória virtual}

O tamanho total do programa - ou seja o código executável, a pilha e seus dados - pode exceder o limite da memória real. Com a utilização de memória virtual, partes ativas do programa podem ser mantidas na memória e partes em disco (Paul J. Deitel e Choffnes, 2005). 
Neste contexto, há dois tipos de endereços: os referenciados por processos (denominados endereços virtuais) e os disponíveis na memória principal (denominados endereços físicos ou reais). A tradução do endereço virtual para o endereço real é feita por um tipo de hardware, denominado MMU(Memory Management Unit, Unidade de gerenciamento de memória) (Paul J. Deitel e Choffnes, 2005).

Para indicar o espaço de endereçamento virtual de um processo é feito o agrupamento dos endereços em páginas ou segmentos; assim, o sistema monitora onde cada página ou segmento de memória virtual foi posicionado na memória principal (Paul J. Deitel e Choffnes, 2005). Se os endereços virtuais são agrupados em páginas tem-se a técnica conhecida como paginação. Caso os endereços sejam agrupados em segmentos, tem-se a segmentação.

\subsubsection{Paginação da Memória Virtual}

A paginação é uma das possíveis técnicas utilizadas nos sistemas que apresentam memória virtual. São utilizados endereços virtuais, formando um espaço de endereçamento virtual. O espaço do endereçamento virtual é composto por páginas (pages) e o espaço correspondente a esta página na memória real é a moldura de página (Page frame). A página e a moldura de página têm igual tamanho (Tanenbaum, 2003).

No momento que a MMU detecta que uma página no endereçamento virtual não está alocada em um endereçamento real, ela faz uma interrupção gerenciada pelo sistema operacional, chamada falta de página.

Escolhe-se uma moldura de página pouco usada e esta é enviada para o disco, depois carrega a página que gerou a interrupção, atualiza a tabela de páginas e reinicia o processo que solicitou a página. A ação de levar uma página a uma moldura de página será chamada de mapear.

O endereço virtual é formado por um número de página virtual, que indica a posição da página em relação ao início da tabela de páginas, e um deslocamento, que indica a posição que tem o endereço virtual em relação com a página na qual encontra-se. O endereço físico é obtido através de uma combinação do endereço da página real e o deslocamento da página virtual (Machado e Maia, 2002).

Uma estrutura útil dentro da paginação é a tabela de páginas (Tanenbaum, 2003). Ela faz a tradução de um endereço virtual em um endereço real através de uma operação que pode ser considerada tradutora.

Para não armazenar toda a tabela (que pode ser grande na memória), alguns sistemas operacionais geram múltiplos níveis de tabelas de memória para não criar toda a tabela de página. A ideia principal é ter uma tabela de páginas com as características de um diretório, o qual aloja outras tabelas de páginas. Assim por exemplo, para ter um uma memória com dois níveis de tabelas de páginas (neste caso há uma estrutura de páginas de dois níveis), haverá uma tabela que armazene os endereços de todas as tabelas de página. Isto é conhecido como Tabelas de páginas multiníveis (Tanenbaum, 2003). 
Os detalhes de uma entrada para tabela de página variam de máquina para máquina, mas as informações presentes na entrada são quase as mesmas, podendo ser (Tanenbaum, 2003):

- Número de moldura de página: o número mais importante da entrada numa tabela de página é o número traduzido pela tabela de páginas de um endereço virtual a um endereço real. $\mathrm{Na}$ paginação, este valor é importante, já que sem ele, é impossível alocar o endereço da página virtual na memória real, utilizando a abordagem da paginação.

- Bit presente/ausente: este bit serve para saber se a página está ou não está na memória principal.

- Bit de proteção: indica se o tipo de acesso a página na memória é somente para escrita, leitura ou execução ou uma combinação delas.

- Bits modificados e referenciados: servem para indicar o uso da página. O bit modificado também é chamado de bit sujo. O bit de referenciado é utilizado para indicar quando uma página física é referenciada.

- Bit cache desabilitado: utilizado para desabilitar a propriedade de cache de alguma página.

\subsubsection{Algoritmos de substituição de páginas na paginação}

Ao acontecer uma falta de página e trazer uma página para a memória real, esta página pode ser requisitada muitas vezes ou pode ser requisitada poucas vezes ou talvez nenhuma vez. Para atingir o objetivo de determinar que página tem menos possibilidades de voltar a gerar uma falta de página, são implementados os algoritmos de substituição de páginas, apresentados a seguir (Tanenbaum, 2003):

- Página ótima;

- Páginas não usadas recentemente (NUR);

- Primeira a entrar, primeira a sair (FIFO - First-In-First-Out);

- Segunda chance (SC);

- Relógio;

- Menos recentemente usada (MRU);

- Não usada freqüentemente (NUF);

- Conjunto de trabalho (WS-Working Set);

- WSClock (Working Set Clock) (Tanenbaum, 2003). 


\subsubsection{Segmentação da Memória Virtual}

Durante a execução de um programa uma parcela de páginas na memória pode ter um crescimento alto. Uma solução para esse crescimento é o uso de segmentação (Tanenbaum, 2003).

A segmentação propõe o uso de segmentos que são espaços de endereçamento sem relacionamento um com o outro. Cada segmento tem uma sequência linear de endereços, que vai de um valor mínimo a um valor máximo. Além da sequência de endereços, o tamanho dos segmentos pode ser variável para um conjunto de segmentos de número também variável (Tanenbaum, 2003).

Para fornecer um endereço de segmentação é necessário ter um número de segmento e um endereço dentro do segmento escolhido (Tanenbaum, 2003).

\subsection{Gerenciamento de $I / O$}

A tarefa da gerência de I/O é ocultar as peculiaridades dos dispositivos de entrada e saída e fornecer uma interface aos usuários, consistindo nas seguintes tarefas (Abraham Silberschatz e Gagme, 2004):

- Um componente de gerência de memória que inclui o uso de buffers, caches e spools;

- Uma interface para controladores de dispositivos;

- Drivers para dispositivos de hardware específicos.

A implementação do gerenciador do I/O é feita utilizando camadas. A camada de mais baixo nivel oculta características do dispositivo das camadas alocadas mais para cima, isto para dar ao usuário uma interface fácil de utilizar. Para ter um melhor gerenciamento da diversidade de dispositivos existentes, são definidas as camadas de: tratadores de interrupção, Drivers do dispositivo, Software do Sistema Operacional independente do dispositivo e Software de E/S no nível de usuário, os quais fornecem uma interface flexível para gerenciamento dos dispositivos no Sistema Operacional. Assim, nesta abordagem de camadas, tem-se uma visão dos dispositivos como um todo, importante para os usuários, e tem-se uma visão de diversos controladores para cada dispositivo, que é para a camada de mais baixo nível (Machado e Maia, 2002).

\subsubsection{Interrupções}

Uma interrupção é definida como um evento que altera a sequência das instruções executadas pelo processador. O sinal é enviado ao processador quando um dispositivo muda de status (Paul J. Deitel e Choffnes, 2005).

As interrupções podem ser um evento relacionado ao hardware e também ao software e podem ser divididas em síncronas e assíncronas (Bovet e Cesati, 2000): 
- Interrupções síncronas: São aquelas que estão em sincronia com o processo (Paul J. Deitel e Choffnes, 2005).

- Interrupções assíncronas: São interrupções causadas por algum evento que não tenha relação com o processo atual (Paul J. Deitel e Choffnes, 2005).

\subsubsection{Tratadores de interrupção}

Segundo (Tanenbaum, 2009), no funcionamento de um computador ao acontecer uma interrupção, o sistema operacional responde através de uma função que resolve aquela interrupção. Essa função (rotina de manipulação de interrupção ) pode ser simples ou pode ser muito complexa, dependendo da interrupção e a interação que ela tem com outros dispositivos.

\subsubsection{Driver de dispositivo}

Cada dispositivo de E/S tem um conjunto de registradores que são gerenciados pelo controlador para ler os dados do dispositivo ou saber o estado do dispositivo ou as duas coisas. Para fazer isso é preciso um código especial, fornecido pelo fabricante do dispositivo, que pode ser diferente para cada sistema operacional. Para gerenciar um dispositivo é preciso ler os registradores do dispositivo para ser utilizado pelo computador. A leitura dos registradores é feito pelo driver do dispositivo (Tanenbaum, 2009). Cada driver pode tratar um dispositivo ou uma família de dispositivos para utilizar os elementos de hardware do dispositivo.

Uma forma de classificação dos dispositivos é pela maneira com que os dados são transferidos (Abraham Silberschatz e Gagme, 2009):

- Dispositivo de bloco.

A interface de dispositivo de bloco captura todos os aspectos necessários para acessar unidades de disco e outros dispositivos orientados ao bloco. Espera-se que os dispositivos interpretem comandos como write (), read () ou seek () (Abraham Silberschatz e Gagme, 2009).

- Dispositivo de caractere

A interface destes dispositivos permite capturar um caractere. O teclado é um exemplo deste tipo de dispositivo, que está habilitado para aplicações que usem get () ou put () (Abraham Silberschatz e Gagme, 2004).

\subsubsection{Software de E/S independente de disposítivo}

Segundo a utilização do software que interage com a E/S do computador, pode-se dizer que há dois tipos de software: um é o driver e outro é o software independente de dispositivo. A 
diferenciação entre eles depende do Sistema Operacional. O Sistema Operacional geralmente faz essa divisão por razões de eficiência. Algumas funções básicas do software de E/S independente de dispositivo são (Tanenbaum, 2009):

- Interface uniforme para os drivers de dispositivos;

- Utilização de buffer;

- Relatório de erros;

- Alocação e liberação de dispositivos dedicados;

- Tamanho de bloco independente de dispositivos.

\subsubsection{Software de E/S do espaço de usuário}

A maior parte do gerenciador de E/S está no Sistema Operacional, mas em alguns programas existem bibliotecas ligadas a estes programas, com rotinas que fazem chamadas ao sistema. Este conjunto de rotinas não faz parte do estudo do gerenciador de $\mathrm{E} / \mathrm{S}$, sendo que algumas utilizam a interface das chamadas de sistemas, e outras fazem uma tarefa mais complexa, como por exemplo: o printf e o scanf. Outra parte do sistema de E/S é o spooling, sendo o spool uma maneira de tratar os dispositivos dedicados de E/S no caso de multiprogramação. A maneira de trabalhar do spool é através de um processo especial chamado Daemon e de um diretório especial chamado Diretório de spool. O processo Daemon é dono do dispositivo e somente o usará em caso de ter um arquivo no diretório de spool que precise desse dispositivo.

\subsection{Sistema de arquivos}

Nos Sistemas Operacionais o armazenamento da informação é um fator importante e possui características de persistência e concorrência. O lugar onde se armazena as informações é uma estrutura abstrata que tem uma representação física no computador, armazenando um conjunto de informações e recebendo o nome de arquivo.

Podemos definir o sistema de arquivos como aquele que dá um nome, cria uma estrutura, cria um modo de acesso, dá proteção e programa os tipos de arquivos, dependendo das necessidades do usuário final (Tanenbaum, 2003).

\subsubsection{Arquivo}

Um arquivo é uma unidade de informação que pode conter dados ou instruções. As principais características dos arquivos são (Tanenbaum, 2003): nomeação de arquivos; estrutura do arquivo; tipos de arquivos; acessos ao disco; atributos de arquivos e operações com arquivos. 


\subsubsection{Diretórios}

Para poder gerar uma ordem e um controle sobre os arquivos, o sistema operacional cria um arquivo especial, o diretório, onde encontram-se não somente os arquivos, mas também informações como localização física, nome, organização e outras informações (Machado e Maia, 2002). As implementações de diretórios podem ser: nivel único; estrutura de dois níveis e estrutura em árvore.

\subsubsection{Gerência de Espaço livre em Disco}

Para criar arquivos ou diretórios o sistema operacional deve ter a informação de quanto espaço há no disco rígido e para fazer isto é necessária uma estrutura de dados que permita salvar estas informações. O Sistema Operacional deve ter a capacidade de criar um espaço para um arquivo e depois fazer que este espaço não seja outra vez escrito (Machado e Maia, 2002). Para alcançar este objetivo pode-se implementar um mapa de bit (bit map), o qual associa cada bloco do disco rígido a uma entrada na tabela, sendo o valor que pode tomar de 0 se o bloco está livre ou de 1 se o bloco está alocado. Para um disco rígido pequeno é uma boa opção, mas ao ter um disco rígido maior o problema se apresenta na memória, que é onde se aloja a tabela. Outra opção poderia ser uma lista encadeada de blocos livres no disco rígido, onde cada bloco tem um endereço do seguinte bloco, dentro da lista encadeada. O problema agora é a forma em como se vai procurar cada bloco dentro desta lista encadeada, já que a pesquisa seria de uma forma sequencial.

Uma outra opção baseia-se no fato de que um bloco geralmente é liberado com outros blocos, assim se faz uma tabela que tem o endereço do primeiro bloco liberado e a quantidade de blocos que foram liberados com ele. Este método tem o nome de tabela de blocos livres.

\subsubsection{Gerência de Alocação de Espaço em Disco}

Uma vez criados os arquivos e os diretórios, estes ocupam um espaço, o qual também deve ser gerenciado pelo sistema de arquivos. Apresenta-se as principais técnicas de alocação (Machado e Maia, 2002): alocação contigua; alocação encadeada e alocação indexada.

\subsection{Considerações finais}

Uma vez abordados os conceitos básicos de sistemas operacionais, deve-se entender que a separação dos tópicos teóricos é apenas conceitual, pois em uma implementação real dificilmente esta divisão é encontrada ou até mesmo passível de ser alcançada. Os conceitos apresentados seguem a mesma divisão de alguns livros textos da área. A verdadeira interação entre os componentes dentro de um sistema operacional pode chegar a uma estrutura complexa e até mesmo caótica para qualquer indivíduo que nunca tenha estudado estes conceitos antes, dificultando o en- 
tendimento das ideias relacionadas aos sistemas operacionais através da leitura de códigos fonte. Assim, é importante facilitar o entendimento desses conceitos e a interação entre eles. O próximo capítulo descreve uma metodologia de modelagem de conteúdo educacional que foi utilizada com o objetivo de auxiliar no ensino dos conceitos de Sistemas Operacionais. 


\section{Metodologia para construção de módulos educacionais}

\subsection{Considerações Iniciais}

Este capítulo tem como objetivo contextualizar o conceito de objetos educacionais (do inglês Learning Objects), além de fornecer uma breve revisão de como é desenvolvido um módulo educacional utilizando um conjunto de processos padronizados (Barbosa et al., 2003).

\subsection{Objetos educacionais}

A definição de objeto educacional diz respeito a qualquer recurso utilizado no processo de aprendizagem. Este termo é utilizado para definir materiais educacionais desenvolvidos para maximizar o aprendizado (Tarouco et al., 2003).

Segundo Gama(2007) os objetos educacionais têm as seguintes características:

- Reusabilidade: é uma das características mais importantes dos objetos educacionais segundo (Lopes, 2010), pois pode ser utilizado em um contexto distinto daquele imaginado ou projetado pelo desenvolvedor. Para que esta característica seja alcançada é preciso que cada objeto seja independente, isto é, que ela faça sentido por si mesmo;

- Adaptabilidade: é a característica que permite a flexibilidade dos objetos educacionais para serem modificados de acordo com as necessidades do aluno. Do ponto de vista tecnológico, 
é preciso que a ferramenta possa ser reaproveitada sem necessidade de uma adaptação. Mas esta mesma ferramenta deve proporcionar a capacidade de construção de conteúdo de acordo com as necessidades dos alunos, satisfazendo as variáveis de tempo e conteúdo programado (Lopes, 2010);

- Granularidade: é a habilidade que indica quanto esses objetos podem ser segmentados, em relação ao tamanho e o conteúdo desse objeto (Lopes, 2010);

- Acessibilidade ${ }^{1}$ : é capacidade de oferecer um objeto accessível através do uso de um meio de comunicação como, por exemplo, a Internet, para seu uso em diferentes locais;

- Durabilidade: é a capacidade de que seu uso perdure independente das mudanças de tecnologia (Nienow e Bez, 2010);

- Interoperabilidade: é a capacidade de oferecer uma comunicação transparente para o usuário entre sistemas, sem que o usuário tenha que desenvolver novos elementos de um sistema para adaptar aos outros (Lopes, 2010);

- Metadados: é a capacidade do objeto possuir informações que descrevem suas características, como por exemplo: título, assunto, data, autor (Lopes, 2010).

Segundo Gama(2007), os objetos educacionais podem ser classificados em:

- Objetos de Instrução: têm o objetivo de dar apoio ao aprendizagem e são divididos em:

- Objetos de lição: combinação de textos, imagens, filmes, vídeos, perguntas e exercícios;

- Objetos workshop: apresentações, videoconferência e outras ferramentas de colaboração geral;

- Objetos seminários: oferece uma comunicação síncrona entre aprendizes, por meio de áudio, vídeo, intercâmbio de mensagens, etc;

- Objetos artigos: incluem material de estudo, gráficos, tabelas, etc;

- Objetos White papers: baseados em textos com detalhes de tópicos completos;

- Objetos caso de estudo: objetos baseados na análise de implementações de produtos educacionais, de experiências pedagógicas, etc.

- Objetos de colaboração: objetos com o objetivo de prover comunicação em ambientes de aprendizagem colaborativa:

- Objetos monitores de exercícios: objetos gerados pelo intercâmbio entre aprendiz ou aprendizes e o monitor;

\footnotetext{
${ }^{1}$ Acessibilidade, facilidade para o acesso ao software independentemente da plataforma na qual se encontra, (Gama, 2007)
} 
- Objetos chats: com ajuda de uma comunicação síncrona, os aprendizes podem trocar conhecimentos e compartilhar experiências ente eles;

- Objetos fórum: similar aos objetos chats, com a diferença de ser uma comunicação assíncrona;

- Objetos de reuniões on-line: são desde documentos até computadores utilizados com o objetivo de compartilhar os conhecimentos.

- Objetos de prática: com o objetivo de auto-aprendizado, apresentam uma alta interação:

- Simulação de jogo de interpretação de personagens (Role Playing Game): com o objetivo de avaliar os conhecimentos e habilidades do aprendiz em uma simulação de situação real.

- Simulação de software: usa ambientes gráficos para praticar tarefas completas;

- Simulação de hardware: usa objetos de hardware simulado para praticar determinadas tarefas;

- Simulação de códigos: tem por objetivo o aprendizado de técnicas completas de codificação de software;

- Simulação conceitual: conceitos são relacionados utilizando-se exercícios práticos;

- Simulação de modelos de negócios: tem por objetivo administrar uma situação real, utilizando, para isso, um conjunto de varáveis em uma empresa virtual;

- Laboratórios on-line: esses objetos apresentam características relacionadas à tecnologia de informação;

- Projetos de investigação: têm como objetivo impulsar o aprendizado através de exercícios com áreas bem específicas.

- Objetos de Avaliação: apresentam os limites do conhecimento do aprendiz:

- Pré-avaliação: servem para avaliar os conhecimentos dos aprendizes antes de começar o processo de aprendizado;

- Avaliação de proficiência: servem para verificar se o conhecimento obtido pelo aprendiz até o momento é suficiente para se continuar o processo de aprendizado;

- Testes de rendimentos: têm o objetivo de avaliar o aprendiz em uma tarefa específica;

- Pré-teste de certificação: tem o objetivo de avaliar o aprendiz de acordo com as modalidades de estudo e certificação. 


\subsection{Processos para o desenvolvimento dos módulos edu- cacionais}

Segundo Barbosa (2004), os módulos educacionais são unidades para o ensino constituídos por teorias que incorporam atividades práticas e avaliações. Para disponibilizar estes conteúdos educacionais pode-se utilizar elementos tecnológicos e computacionais.

Define-se módulos educacionais como sendo unidades de estudo que integram conteúdos teóricos, atividades práticas e avaliações, recursos tecnológicos e computacionais que são disponibilizados aos alunos.

Segundo Barbosa (2004), os módulos educacionais são desenvolvidos por meio da construção de um conjunto de blocos de conteúdo, com a capacidade de reutilização e interação com outros objetos. Estes blocos são geralmente denominados como objetos de aprendizado (learning object), mas também podem ser conhecidos como; objetos educacionais, componentes de ensino, objetos de educação, entre outros termos.

Segundo Barbosa (2004), a característica principal dos objetos de aprendizado é sua capacidade de dividir os conteúdos em pedaços pequenos reutilizáveis aos diferentes ambientes de ensino e treinamento, descantado se assim as características de reusabilidade, interoperabilidade, acessibilidade e extensibilidade. Estabelecendo uma comparação entre os termos, os módulos educacionais podem ser definidos como o todo, enquanto os objetos de aprendizado constituem uma parte indivisível.

Segundo Barbosa e Maldonado (2003), para construir um módulo educacional podem ser seguidos os processos descritos a seguir, os quais foram modificados do padrão ISO/IEC 12270.

\subsubsection{Processos fundamentais}

Nestes processos estabelecem-se tarefas e atividades a serem aplicadas durante o ciclo de vida do módulo educacional, o qual pode também ser chamado de produto de software. Como produto de software pode-se usar vários modelos de construção de software como por exemplo: Cascata, Prototipagem ou Incremental. Os processos modificados do padrão ISSO/IEC 12270 são descritos a seguir:

- Processo de aquisição: este processo estabelece o contrato de desenvolvimento e as tarefas a serem realizadas pelo adquirente (comprador, cliente, proprietário ou usuário), com o objetivo de desenvolver ou melhorar um módulo educacional. Tem como atividades: (1) preparação do pedido de proposta; (2) preparação e atualização do contrato; (3) monitoramento do fornecedor; (4) documentação do processo de aquisição e (5) aceitação e conclusão.

- Processo de definição: neste processo identifica-se o problema de aprendizado a ser solucionado, identificando as necessidades da pessoa adquirente e os requisitos a serem satisfeitos. 
Este processo pode ser aplicado isoladamente ou acompanhado do processo de aquisição. As atividades pertencentes a este processo: (1) definição do problema e das necessidades de aprendizado; (2) Definição inicial dos requisitos; (3) Análise da viabilidade do projeto; (4) Determinação do escopo do módulo; (5) Construção do repositório de terminologias; (6) Documentação do processo de definição; (7) Revisão e aprovação.

- Processo de fornecimento: as atividades deste processo têm relação com o fornecedor do módulo educacional, especialmente com o contrato e a execução de planos de projeto elaborados no processo de planejamento. As atividades definidas para este processo são: (1) iniciação; (2) preparação da resposta; (3) contrato; (4) execução e controle; (5) revisão e avaliação; (6) documentação do processo de fornecimento e (7) entrega e conclusão.

- Processo de planejamento: neste processo define-se a estrutura geral do módulo e revisa-se os requisitos deste. Também são estabelecidos os planos a serem utilizados para gerenciar e garantir a qualidade do projeto. As atividades definidas para este processo são: (1) especificação inicial; (2) determinação dos componentes do módulo educacional; (3) planejamento; (4) determinação de padrões; (5) documentação do processo de planejamento e (6) revisão e aprovação.

- Processo de desenvolvimento: neste processo tratam-se as atividades pertencentes ao ciclo de vida de desenvolvimento do módulo educacional. As atividades deste processo são: (1) implantação do processo; (2) análise; (3) projeto; (4) implementação e integração; (5) teste; (6) instalação do módulo no ambiente educacional; (7) construção e atualização de metadatos; (8) atualização do repositório de terminologias; (9) documentação do processo de desenvolvimento e (10) apoio à aceitação do módulo.

- Processo de operação: as atividades deste processo abrangem a operação do módulo educacional e o suporte operacional aos usuários (instrutores/mediadores, aprendizes e outros desenvolvedores), as quais são realizadas pelo operador. As atividades definidas para este processo são: (1) implantação do processo; (2) teste operacional; (3) operação de módulo; (4) suporte operacional; (5) identificação de problemas e melhorias e (6) documentação de processo de operação.

- Processo de disponibilização: as atividades neste processo são as referidas ao instrutor/mediador do módulo educacional. Este processo foi proposto por (Barbosa et al., 2003) especificamente para o contexto de produção de módulos educacionais. As atividades definidas para este processo são: (1) iniciação; (2) disponibilização do módulo; (3) acompanhamento e suporte instrucional; (4) identificação de problemas e melhorias e (5) documentação do processo de disponibilização.

- Processo de manutenção: neste processo as atividades são pertencentes ao mantenedor do módulo educacional, no sentido de correção de problemas, incorporação de novos conheci- 
mentos e possíveis adaptações a mudanças tecnológicas. As atividades definidas para este processo são: (1) implantação do processo; (2) análise do problema e da modificação; (3) implementação da modificação; (4) revisão/aceitação; (5) manutenção do repositório de terminologias; (6) manutenção de meta-datos; (7) migração; (8) documentação do processo de manutenção e (9) descontinuação do módulo.

\subsubsection{Processos de apoio}

Estes processos apoiam os outros processos do ciclo de vida dos módulos educacionais, assegurando o sucesso e a qualidade do produto de software. Os processos modificados do padrão ISO/IEC 12270 são descritos a seguir:

- Processos de documentação: neste processo as atividades têm o objetivo de registrar as informações geradas no ciclo de vida do módulo educacional. As atividades deste processo são: (1) implementação do processo; (2) projeto e desenvolvimento; (3) produção e (4) manutenção.

- Processo de publicação dos resultados: o objetivo deste processo é apresentar os resultados obtidos ao longo do ciclo de vida do módulo educacional. As atividades relacionadas com este processo são: (1) implantação do processo; (2) projeto e (3) distribuição.

- Processo de gerência de configuração: o objetivo deste processo é estabelecer os itens de configuração de módulo (isto corresponde a um item produzido no processo de desenvolvimento do módulo educacional). Para isso aplicam-se procedimentos técnicos e administrativos com o objetivo de controlar as versões e modificações, registrando e relatando todo o que aconteça com estes itens. Controla-se também o armazenamento, manipulação e entrega dos mesmos. Também tem o objetivo de garantir completude, consistência e corretude dos itens. As atividades associadas a estes processo são: (1) implantação do processo; (2) identificação da configuração; (3) determinação de responsabilidades; (4) controle de configuração; (5) avaliação de configuração e (6) entrega e gerência de configuração.

- Processo de gerência do conhecimento: neste processo vão tratar-se os aspectos relacionados ao controle e gerenciamento do conhecimento sob o qual o módulo educacional foi desenvolvido. As atividades deste processo são: (1) implantação do processo; (2) identificação de itens de conhecimento; (3) determinação dos itens de configuração associados; (4) determinação de responsabilidades; (5) controle de itens de conhecimento; (6) avaliação de itens de conhecimento e (7) entrega e gerência do conhecimento.

- Processo de garantia de qualidade: as atividades deste processo estabelecem uma conformidade entre os requisitos especificados e os planos estabelecidos e os processos e produtos do módulo educacional. As atividades relacionadas com este processo são: (1) implantação do 
processo; (2) determinação de responsabilidades; (3) projeto; (4) garantia de produtos e (5) garantia de processos.

- Processo de verificação: neste processo estabelecem-se atividades referidas à verificação do módulo educacional, usando-se para determinar se os sub-produtos atendem completamente aos requisitos e às condições impostas em atividades anteriores incluindo análises, revisões e testes. As atividades deste processo são: (1) implantação do processo; (2) determinação de responsabilidades; (3) projeto e (4) verificação.

- Processo de validação: as atividades deste processo servem para estabelecer se o produto final conseguiu atingir os requisitos especificados. As atividades deste processo são: (1) implantação do processo; (2) determinação de responsabilidades; (3) projeto e (4) validação.

- Processo de revisão conjunta: as atividades deste processo avaliam o estado de um atividade e também os sub-produtos desta, fazendo parte deste processo alguns aspectos técnicos e gerencias. As atividades deste processo são: (1) implementação do processo; (2) determinação de responsabilidades; (3) projeto; (4) revisões gerenciais e (5) revisões técnicas.

- Processo de Auditoria: as atividades deste processo estabelecem quão adequado é o módulo com os requisitos, os planos e o contrato do módulo educacional. As atividades deste processo são: (1) implantação do processo e (2) auditoria.

- Processo de Resolução de problemas: neste processo estabelecem-se as atividades para resolver e analisar problemas que ocorrem na execução dos outros processos e também as tendências de novas ocorrências. As atividades deste processo são: (1) implantação do processo, (2) determinação de responsabilidades e (3) resolução de problemas.

\subsubsection{Processos organizacionais}

Os processos organizacionais têm relação com as organizações que desenvolvem os módulos educacionais, analisando suas características, capacitação, recursos e infra-estrutura, para estabelecer uma estrutura onde as tarefas estabelecidas por outros processos sejam conduzidas. Definem-se também atividades de melhoria dos recursos humanos e a melhoria do próprio processo de desenvolvimento dos módulos.

- Processo de capacitação: neste processo, com a identificação de recursos humanos, computacionais e econômicos, determina-se e avalia-se a capacidade de cada equipe de desenvolvimento. As atividades pertinentes a este processo são: (1) implantação do processo; (2) coleta de dados e (3) determinação de capacidades.

- Processo de comunicação: as atividades deste processo referem-se aos aspectos do desenvolvimento com troca de informações entre equipes de trabalho. Têm-se as seguintes atividades: (1) implantação do processo e (2) determinação dos meios e protocolos de comunicação. 
- Processo de gerência: neste processo são estabelecidas as atividades aplicadas para o gerenciamento de um determinado processo estas atividades são genéricas, as atividades deste processo são: (1) início e definição do escopo; (2) planejamento e (3) execução e controle.

- Processo de coordenação: as atividades deste processo servem para coordenar as equipes de desenvolvimento. Estabelece-se um coordenador que é responsável por um produto ou uma tarefa feita por uma equipe. As seguintes atividades compõem este processo: (1) inicio e definição do escopo; (2) planejamento e (3) execução e controle.

- Processo de controle de artefatos: as atividades deste processo são estabelecidas para controlar e integrar os sub-produtos (artefatos) desenvolvidos por cada equipe de trabalho. Têm-se neste processo as seguintes atividades: (1) início e definição do escopo; (2) planejamento e (3) execução e controle.

- Processo de infra-estrutura: neste processo são definidas as atividades para estabelecer e manter uma infraestrutura necessária para a execução dos outros processos. Os elementos da infraestrutura são os elementos necessários para o desenvolvimento, operação, disponibilização e manutenção do módulo educacional. As atividades referidas a este processo são: (1) implantação do processo; (2) instalação da infra-estrutura e (3) manutenção da infraestrutura.

- Processo de melhoria: neste processo são estabelecidas as atividades básicas com o objetivo de estabelecer, avaliar, medir, controlar e melhorar os processos do ciclo de vida do módulo educacional. Mudanças dos paradigmas e princípios educacionais devem ser consideradas. As atividades referidas ao processo de melhoria são: (1) determinação do processo; (2) avaliação do processo e (3) melhoria do processo.

- Processo de treinamento: as atividades deste processo têm relação com as habilidades gerencias, técnicas e específicas envolvendo o domínio do conhecimento, e a melhoria desses conhecimentos nas equipes de desenvolvimento. Têm-se as seguintes atividades neste processo: (1) implantação do processo e (2) treinamento.

- Processo de copyright e licença: estabelecem-se neste processo as atividades relacionadas com a utilização, modificação e distribuição do módulo educacional e também sobre a propriedade intelectual desse módulo. Compõem este processo as seguintes atividades: (1) início e definição do escopo; (2) atribuição de direitos autorais e (3) definição dos termos de distribuição.

A modelagem de conteúdo educacional apoia o instrutor no entendimento do conteúdo educacional, facilitando a compreensão das partes principais e as informações adicionais determinadas pela abordagem do instrutor, além de fornecer uma visão ordenada e coerente do conteúdo educacional a serem ensinado ou a serem transmitidos ao aprendiz através de diversos objetos educacionais. 


\subsection{Modelagem de módulos educacionais}

Segundo Barbosa(2004), para entender a organização dos conceitos dentro da metodologia AIM-CID foi necessário definir os requisitos essenciais para modelar conteúdos educacionais. Os modelos que fazem parte da metodologia AIM-CID usam os requisitos antes mencionados para serem definidos e posteriormente para se determinar a abordagem integrada a ser utilizada.

\subsubsection{Requisitos para Modelagem de conteúdos educacionais}

A importância do material didático empregado é fundamental no processo de aprendizado do aluno. Ele pode ser visto como uma composição de elementos teóricos e práticos. A modelagem de conteúdos educacionais ajuda o autor de conteúdos educacionais na estruturação do conteúdo para que se sobressaia o conteúdo essencial no processo de ensino.

Os requisitos sugeridos por Barbosa (2004), são:

- Taxonomia de conceitos: na modelagem descrita, a taxonomia de conceitos é representada utilizando relacionamentos do tipo (type-of), que associam conceitos genéricos com conceitos específicos. É muito utilizada na estruturação de conceitos no conhecimento (Pimentel, 1997).

- Composição de conceitos: alguns conceitos são compreendidos mais claramente se eles são divididos em partes. Relacionamentos que permitem este tipo de divisão são chamados de relacionamentos (part-of) e indicam que um conceito é composto por outros.

- Relacionamentos específicos: importantes dentro do conjunto de conceitos, ideias, exemplos e outros elementos de um tópico, este tipo de relacionamento depende do conjunto antes definido. Estes relacionamentos específicos são complementares aos outros tipos de relacionamentos. Devem ter uma semântica própria que assegure um relacionamento claro e conciso.

- Decomposição Hierárquica (modularização): esta característica permite a divisão dos elementos do modelo, que representa o conjunto de conceitos, ideias, exemplos e outros elementos de um tópico, em módulos. Esta ação se faz para facilitar o entendimento dos elementos deste conjunto mencionado. Os módulos são construídos sobre mecanismos de decomposição hierárquica, ou seja, elementos mais gerais são decompostos em elementos mais específicos. Como consequência, uma análise em diferentes níveis de abstração tornase possível. Esta característica é importante para o reuso do conhecimento.

- Diferenciação entre categorias do conhecimento: outros tipos de informação podem estar representados na modelagem de conteúdos educacionais, segundo Barbosa (2004). Eles têm que se categorizar com o intuito de: (1) melhorar a compreensão do conjunto de conceitos; 
(2) ajudar a visualizar os elementos dentro deste conjunto que podem evoluir; (3) dar suporte a criação de contextos de aprendizado, (4) possibilitar a representação de ferramentas educacionais que sejam consideradas.

- Ordem pedagógica: a sequência de apresentação das informações é uma parte importante dentro da elaboração de conteúdos educacionais, sendo que a liberdade na exploração do conteúdo deve estar garantida para o aluno.

- Contexto de aprendizado: eles são especificados para possibilitar o acesso ao material didático aos aprendizes. Cada contexto de aprendizado pode ter diferentes objetivos. A sequência didática representada em um modelo pode ser vista como um contexto de aprendizado. As maneiras alternativas de acesso às informações, conhecidas como estruturas de acesso (tais como índices, roteiros e visitas guiadas), apoiam os contextos de aprendizado.

- História: os contextos de aprendizado visitados pelo aprendiz, em certos momentos precisam ser recuperados. Esta característica permite uma diminuição no número de transições entre os elementos do domínio de conhecimento.

- Propagação de eventos (Broadcast): os diferentes tipos de mídia podem fazer parte do conteúdo educacional. Mecanismos de propagação de eventos fornecem um suporte para a sincronização dos diversos tipos de mídia. Mecanismos de propagação de eventos são importantes na modelagem de conteúdos educacionais.

\subsubsection{Modelos genéricos para representação de conteúdos educa- cionais}

Os conjuntos de conteúdos educacionais podem ser agrupados de acordo com a descrição de conceitos e informações adicionais sobre um conjunto de conceitos, ideias, exemplos e outros elementos de um tópico e também podem ser agregados elementos complementares a este conjunto. Desse modo, podemos agrupar os conteúdos educacionais em três grupos:

- Modelo conceitual: o modelo conceitual obedece à perspectiva conceitual, que fala dos conceitos mais importantes de um domínio de conhecimento e da forma como os elementos deste modelo conceitual se relacionam uns com outros. Por ser um conjunto de elementos importantes e também por apresentar uma interrelação entre estes elementos, a estrutura presente neste modelo também será importante, já que ela ajudará a compreender o que se vai ensinar. O modelo conceitual é constituído por unidades chamadas conceitos e, segundo Barbosa (2004), as interrelações entre estas unidades são definidas como segue:

- Relacionamentos Estruturais: Apresentam um relacionamento com a possibilidade de inferir algo dele. Pode-se dizer que são relacionamentos mais gerais, como por exemplo, relacionamentos do tipo classificação (type-of) ou do tipo composição (part-of); 
- Relacionamentos Específicos do Domínio: Apresentam um relacionamento mais específico dentro de um domínio de conhecimento. Este relacionamento específico pode variar sua interpretação em outro domínio de conhecimento.

Uma vez identificados os conceitos e suas relações, eles devem ser estruturados com o objetivo de serem entendíveis. Dentro das estruturas que organizam as informações, existem muitas opções dentro das quais, se recomenda utilizar mapas conceituais, por ser o uso desta técnica amplamente aceito (Kawasaki, 1996). O modelo conceitual deve possuir as seguintes características para ser considerado um modelo conceitual:

- Taxonomia de conceitos: deve apresentar a possibilidade de relacionamentos de classificação e deve oferecer elementos suficientes para a representação desta característica;

- Composição de conceitos: deve apresentar a possibilidade de relacionamentos de composição e deve oferecer elementos suficientes para a representação desta característica;

- Relacionamentos específicos: deve apresentar a possibilidade de relacionamentos específicos com uma relação com o conjunto de conceitos, ideias, exemplos e outros elementos de um tópico através de uma semântica;

- Decomposição Hierárquica: deve apresentar a possibilidade de decomposição da estrutura em hierarquias.

- Modelo instrucional: deve possibilitar a adição de informações adicionais e elementos que complementem a informação apresentada pelo modelo conceitual. Segundo Barbosa (2004), este modelo divide-se em duas etapas: o refinamento do modelo conceitual e a definição de elementos instrucionais. Na primeira etapa, baseado no modelo conceitual antes desenvolvido, criar-se-á algumas informações que apoiem estes conceitos. Tais informações serão chamadas, segundo Barbosa (2004), de itens de informação. Para refinar este modelo conceitual, muitas técnicas podem ser utilizadas. Porém, será usada a sugerida por (Reigeluth, 1983) pois ela define os seguintes itens de informação: conceitos (já presentes no diagrama conceitual), fatos, procedimentos e princípios. A segunda etapa define os elementos instrucionais, os quais servem como complemento aos itens de informação definidos na etapa anterior. Tais elementos devem ser representados adequadamente para serem entendidos e, segundo (Barbosa et al., 2002) e (Mayorga et al., 1999), podem ser divididos em três categorias:

- Elementos explanatórios: complementam a informação de um item de informação presente, por exemplo: dicas, sugestões de estudo, referências;

- Elementos exploratórios: os alunos passeiam através dos itens de informação de um domínio de conhecimento nos quais experimentam atividades práticas. Por exemplo, podem ser: exercícios guiados, simulações, hands-on de ferramentas; 
- Elementos de avaliação: possibilitam a avaliação do aprendiz e do conhecimento adquirido por ele. Eles podem ser, por exemplo: avaliações diagnósticas, formativas ou somáticas, na forma questões objetivas e/ou subjetivas.

É importante ressaltar que os elementos instrucionais podem estar ou não presentes no conteúdo, diferentemente dos itens de informação, que sempre se fazem presentes. Tem-se que especificar as relações entre os elementos instrucionais e os itens de informação. Também se tem que especificar as relações entre os elementos instrucionais, porém, deve-se lembrar que não se precisa de dados específicos daquelas relações. Neste modelo, devem-se fornecer elementos para apresentar os diferentes tipos de informação associados aos elementos do domínio do conhecimento. Também deve-se prover elementos que assegurem a decomposição hierárquica.

- Modelo didático: dependendo dos objetivos educacionais, pode-se fazer um modelo didático, sendo uma qualidade do modelo instrucional a variedade de modelos didáticos que se possam derivar dele, dependendo dos objetivos da instituição educativa. São responsáveis pela ordem de precedência dos objetos didáticos a serem apresentados na sala de aula e dos relacionamentos didáticos (complementa, exemplifica, ilustra, motiva, exercita e avalia). Também podem ser usadas estruturas como índices, roteiros e visitas guiadas. Os aspectos comportamentais também podem ser especificados no modelo didático, fazendo dele uma possível ferramenta de auxílio em um ambiente dinâmico, onde alguns relacionamentos podem ser ativados e outros não, dependendo do desenvolvimento do aprendiz. Os seguintes requisitos estarão presentes no modelo (Barbosa, 2004):

- Ordem Pedagógica: devem existir os elementos suficientes para a representação da sequência entre as informações do domínio;

- Contextos de Aprendizado: devem existir os mecanismos suficientes para a representação e dos contextos de aprendizado;

- Histórico: devem existir os elementos suficientes para armazenar os caminhos percorridos das informações do domínio. Também devem existir os elementos suficientes para se recuperar os contextos de aprendizado, antes visitados;

- Propagação de Eventos: devem existir os elementos suficientes que permitam tratar características como concorrência e sincronização, entre as diferentes informações do domínio.

Deve-se assegurar a concordância, consistência e uniformidade do modelo didático em relação aos modelos anteriormente tratados. Por tanto, deve-se garantir a presença de características de diferenciação entre categorias do conhecimento e a decomposição hierárquica. Os paradigmas educacionais, domínios de conhecimentos e outros aspectos pedagógicos devem ser aplicados sobre o modelo didático através das sequências de apresentação das 
informações (também chamadas ordem pedagógica). O modelo didático é independente da abordagem pedagógica e da estratégia adotada e os recursos devem estar disponíveis para se estabelecer a representação da sequência de apresentação.

\subsubsection{Abordagem Integrada para Modelagem de Conteúdos Educa- cionais}

A Abordagem Integrada de Modelagem - Conceitual, Instrucional e Didática (AIM-CID), tem o objetivo de reunir, em uma mesma proposta, os modelos conceitual, instrucional e didático, apresentados anteriormente. Essa abordagem foi proposta por Barbosa (2004), em sua tese de doutorado. A técnica de mapas conceituais (Moreira, 1987; Novak, 1981, 1990; Novak e Gowin, 1984) foi utilizada para a modelagem conceitual no AIM-CID, pelas seguintes razões:

- Representação de conceitos e hierarquia entre eles.

- Facilidade de uso.

- Aceitado amplamente por profissionais em educação e fundamentado em princípios educacionais.

- Adotado por outras modelagens de conteúdos educacionais.

Algumas restrições e/ou extensões foram adicionadas, segundo (Barbosa, 2004):

- Só são representados os conceitos no mapa conceitual.

- Foram incorporadas na representação elementos que ajudem a representar a taxonomia e composição de conceitos.

Foi usado o modelo HMBS (Hypertext Model Based on Statecharts) (Turine et al., 1997; Turine, 1998; Turine et al., 1990) simplificado para a etapa de construção do modelo instrucional. O modelo escolhido dever suportar a representação das distintas categorias do conhecimento, pelo qual deve ter a capacidade de representar elementos tais como: itens de informação (fato, conceito, princípio e procedimento) e elementos instrucionais (explanatórios, exploratórios e de avaliação). Segundo Barbosa (2004), um hiperdocumento H no HMBS é definido como uma 7-upla $H=<S T, P, m, L, p l, a e, N>$, onde:

- $S T$ representa o statechart, definido como uma 11-tupla $S T=<s, \rho, \psi, \gamma, \delta, V, C, E, A, R, T>$ representando, respectivamente, estados, função de hierarquia, função tipo de decomposição, função história, função padrão, conjunto de expressões, conjunto de condições, conjunto de condições, conjunto de eventos, conjunto de ações, conjunto de rótulos e conjunto de transições. 
- P representa o conjunto finito de páginas de informação, que define o conteúdo do documento. $\mathrm{O} p$ está definido pela tripla $\langle c, t, A n c p>$, com $p \in P, p$ representa uma porção de informação, $c$ pode conter mídias estáticas ( texto, gráfico ou imagem) ou dinâmicas ( vídeo, áudio ou animação ), $t$ representa o título da página e Ancp representa a coleção de âncoras contidas na página.

- $m: S s->P$ simboliza uma função, com entrada de estados compostos de tipo $O R$ e estados atômicos do statechart e como saída mapeia-os em páginas. Estados AND não fazem este processo, pois somente especificam concorrência de informações na apresentação.

- $L$ : representa o conjunto de canais de apresentação usados para interpretar e visualizar as informações das páginas.

- $p l: P->L$ é uma função que associa um $p \in P$ com um $l \in L$ para que a página seja interpretada e visualizada.

- $a e: A n c p->E$ função de associação entre âncoras de uma página e eventos do statechart, que também definem as transições a serem disparadas.

- $N$ é um número inteiro que define o nível navegacional, ou de visibilidade do hiperdocumento. Também pode-se utilizar este valor para definir o nível de profundidade hierárquica a ser apresentada durante a navegação.

Segundo Barbosa (2004), para atingir o objetivo de representação de diferentes categorias de informações foi necessário substituir o elemento $C$ da tripla $\langle C, t, A n c p\rangle$ das páginas $P$. $\mathrm{O}$ elemento $C$ passa a representar o conjunto finito de porções de informação, formalizado pela quádrupla $C=<$ Iinfo, Eexplor, Eexplan, Eaval $>$, no qual:

- Iinfo: simboliza o conjunto finito de itens de informação, dos quais a página está composta. Iinfo é a quádrupla; Iinfo $=<F$, Conc, Princ, Proc $>$, no qual:

- $F=f 1, f 2, \ldots, f i, i>=0$ representa o conjunto finito de fatos relacionados com a página;

- Conc $=\operatorname{conc} 1, \operatorname{conc} 2, \ldots, \operatorname{concj}, j>=0$ representa o conjunto finito de conceitos associados com a página;

- Princ $=$ princ $1, \operatorname{princ} 2, \ldots$, princk, $k>=0$ representa o conjunto finito de princípios associados com a página; $\mathrm{e}$

- Proc $=\operatorname{proc} 1, \operatorname{proc} 2, \ldots, \operatorname{procl}, l>=0$ representa o conjunto finito de procedimentos associados com a página.

- Eexplor: simboliza o conjunto finito de elementos exploratórios, dentro do conteúdo da página, esta composta por Eexplo $=<$ Exerc $>$ : 
- Exer $=$ exer 1, exer $2, \ldots$, exeri, $i>=0$ representa o conjunto finito de exercícios.

- Eexplan: simboliza o conjunto finito de elementos explanatórios, e é composto pela tupla Eexplam $=<E x$, Compl $>$, no qual:

- Ex $=$ ex 1, ex $2, \ldots$, exi,$i>=0$ simboliza o conjunto finito de exemplos.

- Compl $=$ compl1, compl $2, \ldots$, complj, $j>=0$ simboliza o conjunto finito de informações complementares.

- Eaval simboliza o conjunto de elementos de avaliação que forma o conteúdo da página, sendo composta pela tripla Eaval $=<A D, A F, A S>$, no qual:

- $A D=a d 1, a d 2, \ldots, a d i, i>=0$ representa o conjunto finito de avaliações diagnósticas.

- $A F=a f 1, a f 2, \ldots, a f j, j>=0$ representa o conjunto finito de avaliações formativas.

- $A S=a s 1, a s 2, \ldots, a s k, k>=0$ representa o conjunto finito de avaliações somativas.

Segundo Barbosa(2004), o modelo HMBS foi modificado para atingir os objetivos da nova metodologia, sendo então chamado de HMBS/Instrucional. Para desenvolver a modelagem didática também se usou o modelo HMBS, que além de ter as características do HMBS/Instrucional, também deverão representar elementos de navegação e aspectos comportamentais do hiperdocumento educacional. As características de mecanismos de história, propagação de eventos e definição de eventos, podem ser tratadas pelo modelo HMBS. A característica de navegação de usuário é essencial na perspectiva didática da modelagem dos conteúdos educacionais, e esta característica também pode ser tratada pelo modelo HMBS. No modelo HMBS modificado para o modelo didático, apresentam-se os estados DD (Dynamically Defined - Definido Dinamicamente) com as seguintes propriedades.

- Um único estado num determinado momento pode ser ativo;

- O estado $D D$ não apresenta estado inicial e ele é definido dinamicamente pelo usuário;

- Num estado $D D$, os sub-estados $O R$ chamam-se estados $O R_{D D}$ estarão totalmente conectados entre eles;

- Um estado $D D\left(X_{D D}\right)$, que representa a saída de quaisquer estado $O R_{D D}$, tem uma saída que pode ativar qualquer estado $O R_{D D}$ da hierarquia de estados-pai- $D D$ de $X_{D D}$, onde um estado $X_{D D}$ representa quaisquer estado de entrada.

Esta última propriedade requer que o modelo HMBS seja estendido, segundo Barbosa (2004). Definimos: 
- $\operatorname{SeqPais}\left(X_{D D}\right)=\operatorname{pai}_{S_{1}}, \operatorname{pai}_{S_{2}}, \operatorname{pai}_{S_{3}}, \ldots p a i_{S_{i}}$ tal que $p a i_{S_{j-1}}$ e $p\left(p a i_{S_{j}}\right), j=1, \ldots i-1$

Onde a sequência SeqPais $\left(X_{D D}\right)$ representa a hierarquia dos estados-pai de um estado $X_{D D}$.

Definimos a hierarquia de estados-pai- $D D$ de um estado $X_{D D}$ com a sequência:

SeqpaisDD $\left(X_{D D}\right)=$ pai $_{S_{1}}$, pai $_{S_{2}}$, pai $_{S_{3}}, \ldots$ pai $_{S_{n}}$

tal que $\forall p a i_{S_{k}}, k=1, \ldots, n: \psi e s t\left(p a i_{S_{k}}\right)=O R_{D D}$ e $p a i_{S_{k-1}} \epsilon p\left(p a i_{S_{k}}\right)$.

Onde $\psi$ define que tipo vai ter cada estado $O R$, com a função:

uest : $S->\left\{O R, O R_{D D}, A N D\right\}$.

Este modelo que é uma extensão do modelo HMBS e foi nomeado como HMBS/Didático. Todas as modificações feitas para o modelo HMBS/Instrucional foram mantidas neste modelo, porém, também foi mantida a estruturação hierárquica dos níveis conceitual e instrucional para atingir o objetivo de uniformidade da abordagem AIM-CID.

\subsection{Considerações finais}

Este capítulo teve como objetivo explicar os objetos educacionais e as ferramentas educacionais, abordando também de forma sumarizada os processos para o desenvolvimento dos módulos educacionais baseados no padrão ISO/IEC 12207, descrevendo os processos fundamentais, os processos organizacionais e os processos de apoio. A metodologia AIM-CID foi detalhada através da definição de três modelos: conceitual, instrucional e didático. O modelo conceitual faz uso de mapas conceituais e os modelos instrucional e didático fazem uso do modelo HMBS modificado, pelo qual se faz uma breve descrição deste modelo e as modificações feitas com o intuito de integrar todos os demais modelos em um modelo unificado. No próximo capítulo será explicado como essa metodologia foi aplicada sobre os conceitos de sistemas operacionais. 


\section{Modelagem de conteúdos em domínio de Sistemas Operacionais}

\subsection{Considerações Iniciais}

Este capítulo apresenta os diagramas referentes a aplicação da metodologia AIM-CID para a modelagem de conteúdos em domínio de sistemas operacionais. Nesta abordagem serão apresentados os diagramas conceituais, os quais mostram uma visão geral dos sistemas operacionais, (primeiro diagrama a ser apresentado neste capítulo). Em seguida e nessa ordem, serão apresentados os diagramas conceituais do gerenciamento de processos, do gerenciamento de memória, do gerenciamento de E/S e do sistema de arquivos. Por fim, seguindo os passos estabelecidos na metodologia, serão apresentados os diagramas instrucionais e didáticos (seguindo a ordem estabelecida nos diagramas conceituais), reforçando que o desenvolvimento destes diagramas mostra a visão do professor encarregado de ministrar a disciplina. Os diagramas conceituais foram desenvolvidos com o software $\mathrm{Yed}^{1}$ e para desenvolver os outros diagramas, foi utilizado o software Microsoft Office Visio $2007^{\circledR}$.

\subsection{Diagramas conceituais}

A Figura 4.1 ilustra o modelo conceitual envolvendo os conceitos de Sistemas Operacionais em alto nível, usando a metodologia AIM-CID. Nesta parte, não foram usados elementos como

\footnotetext{
${ }^{1}$ http : //www.yworks.com/en/products_yed_about.html
} 
exemplos ou exercícios. A seguir serão descritos os relacionamentos entre os estados que fazem parte deste diagrama conceitual.

- Osistema Operacional possui o Gerenciador de processos,o Gerenciador de entrada/saída,o Sistema de arquivos, oGerenciador de memória e uma Estrutura; pode ser visto como uma Máquina estendida; oferece a Chamada de sistema; é acessado via Chamada de Sistema.

- O Gerenciador de recurso gerencia Hardware.

- A Máquina estendida abstrai o Hardware através das Chamadas de Sistema.

- OGerenciador de processos;o Gerenciador de entrada/saída;o Sistema de arquivoseo Gerenciador de memória são acessados via Chamadas de sistema.

- As Aplicações utilizam as Chamadas de sistema para acessar o sistema operacional.

A Figura 4.1 apresenta somente o requisito de composição de conceitos, no conceito de Sistema Operacional, não apresentando requisitos de taxonomia de conceitos (característica dos modelos conceituais). Na figura apresentada observa-se o diagrama conceitual de um sistema operacional. Neste escopo representa-se os conceitos correspondentes à parte introdutória da matéria de Sistemas Operacionais. Dentro deste domínio de conhecimento estabelecido para o diagrama conceitual não estão apresentados todos os conceitos estabelecidos formalmente nos livros escritos para esta matéria, sendo que alguns deles formam parte de outros domínios fora do domínio de conhecimento de sistemas operacionais, enquanto outros referem-se a história dos computadores e a história dos sistemas operacionais. Isso justifica a quantidade de conceitos apresentados no desenho (que são 11 no total). O diagrama conceitual, pela sua natureza subjetiva, pode variar de uma pessoa a outra. Uma outra pessoa poderia adicionar conceitos ou retirá-los, depende da abordagem da pessoa que desenvolve o diagrama conceitual, sendo isto válido para todos os outros diagramas conceituais definidos nesta monografia.

A Figura 4.2 ilustra o modelo conceitual construído para o domínio de conhecimento envolvendo os conceitos de Gerencidador de Processos. Para diferenciar os novos conceitos em relação à Figura 4.1, estes foram destacados na cor azul, enquanto os conceitos originais estão na cor preta. Os diagramas das Figuras 4.3, 4.4 e 4.5 também estão definidos da mesma forma. A seguir serão descritos alguns dos relacionamentos entre os estados que fazem parte deste diagrama conceitual.

- OBloco de controle de processos (BCP) contém Informação de software; contém Informação de Hardware e contém Espaço de endereçamento. 
- O Escalonador de processos requer CPU e implementa Algoritmos de escalonamento.

- Os Algoritmos de escalonamento apresentam Características específicas; apresentam Características gerais e têm Categoria.

- A Categoria pode ser Preemptivo e pode ser Não preemptivo.

- A Justiça; A Políticas de sistema; O Balanceamento são Caracteristicas gerais.

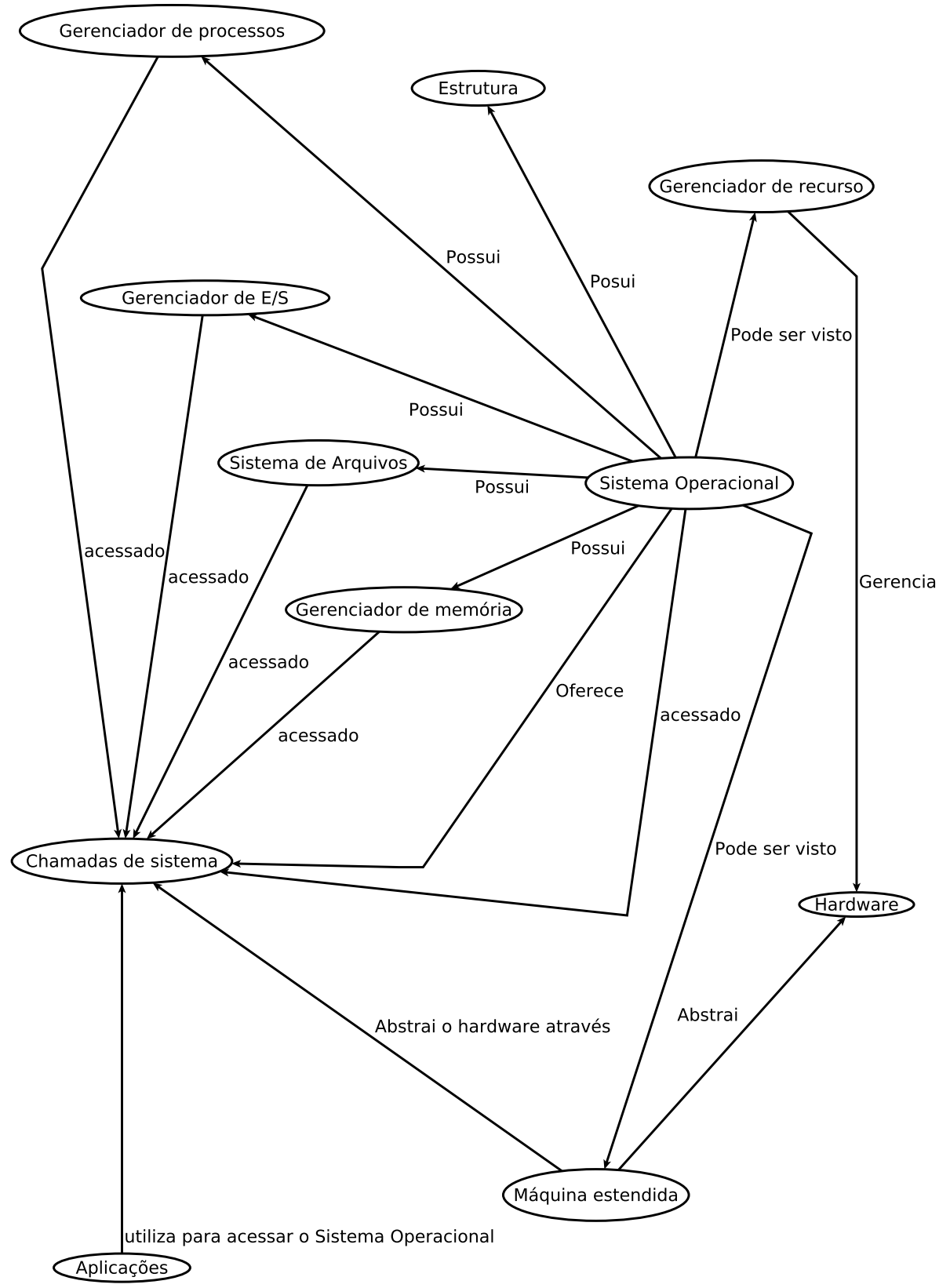

Figura 4.1: Diagrama conceitual de Sistemas Operacionais 


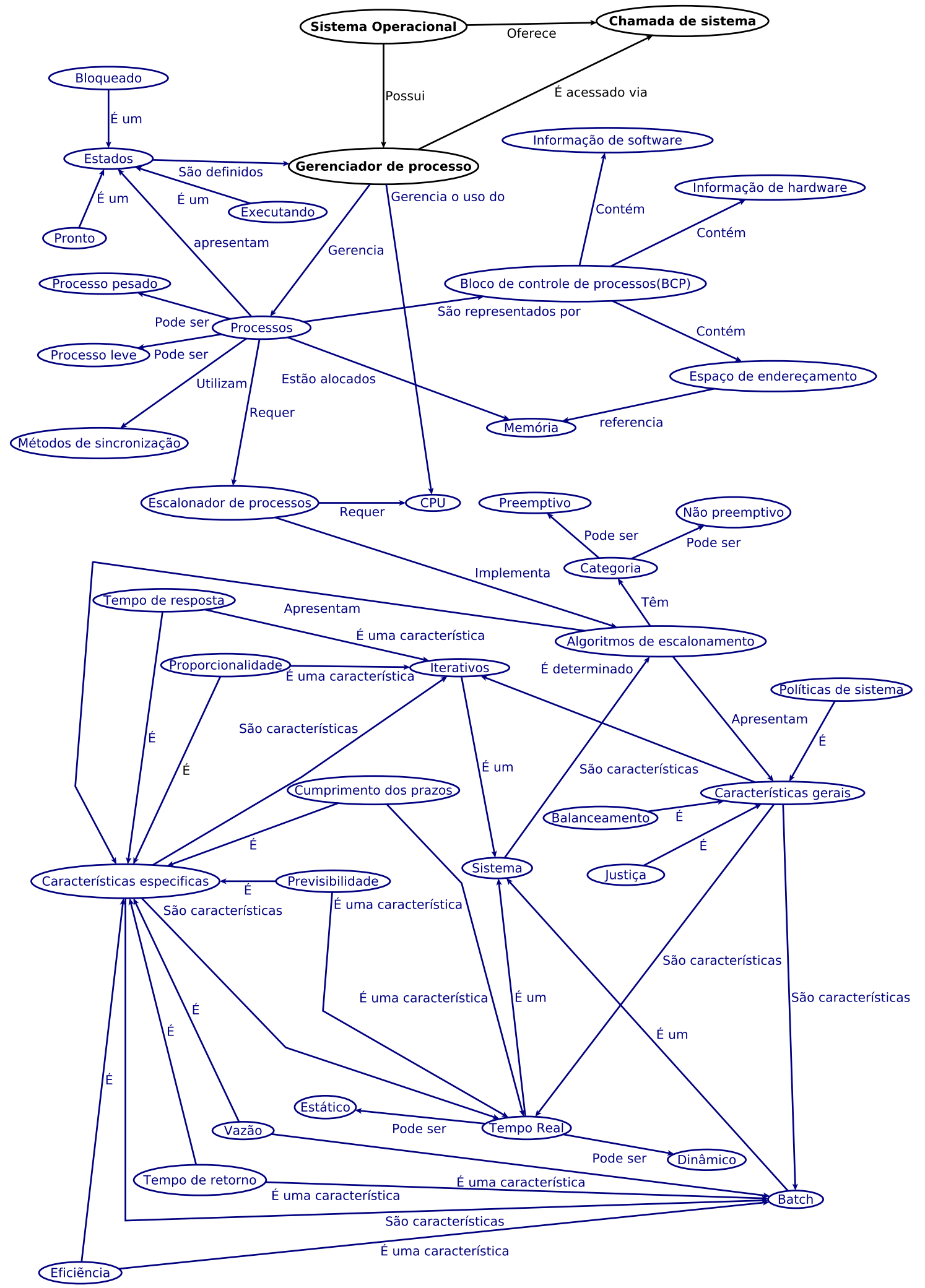

Figura 4.2: Diagrama conceitual do gerenciador de conceitos.

A Figura 4.2 apresenta a característica de taxonomia de conceitos nos conceitos de Estados, de Processos, de Categoria, Características Gerais, Características 
Específicas e Tempo real. Também apresenta a característica de composição de conceitos no Bloco de controle de processos (BCP).

O escopo aqui apresentado limita o domínio do conhecimento aos conceitos mais importantes, segundo o mestrando e seu orientador, dentro desta parte do ensino dos sistemas operacionais.

A Figura 4.3 ilustra o modelo conceitual construído para o domínio do conhecimento envolvendo o critério gerenciador de memória. A seguir serão descritos alguns dos relacionamentos entre os estados que fazem parte deste diagrama conceitual.

- O Com memória virtual gerencia Memória virtual.

- A Memória virtual apresenta Espaço de endereçamento lógico e utiliza Técnica de memória virtual.

- O Espaço de endereçamento lógico utiliza MMU.

- A MMU traduz endereços para o Espaço de endereçamento físico.

- A Técnica de memória virtual pode ser de tipo Segmentação e pode ser de tipo Paginação.

A Figura 4.3 apresenta taxonomia de conceitos nos conceitos de Politica de alocação; Técnica para alocação de páginas por processo; Técnica de memória virtual; Fragmentação; Estratégia; Estrutura chamada filas;

Particionamento e Técnica de gerenciamento de espaço livre. A composição de conceitos acontece nos conceitos de Tabela de páginase Tabela de segmentos.

O diagrama conceitual apresenta um domínio de conhecimento limitado, pelo professor, com o intuito de mostrar os conceitos mais importantes ensinados nesta parte da matéria de sistemas operacionais.

A Figura 4.4 apresenta o modelo conceitual construído para melhor entendimento do critério Gerenciador de Entrada/Saída. A seguir serão descritos alguns dos relacionamentos entre os estados que fazem parte deste diagrama conceitual.

- OGerenciador de E/S possui Procedimento para acessar o dispositivo de E/S; gerencia Dispositivo de E/S e possui Software de $\mathrm{E} / \mathrm{S}$.

- O Software de E/S possui a característica de Tratamento de erros; possui a característica de Independência de dispositivo; possui a característica de Transferência e apresenta Camadas para o uso de dispositivos de $\mathrm{E} / \mathrm{S}$.

- A Independência de dispositivos possui Atribuição uniforme de nomes. 


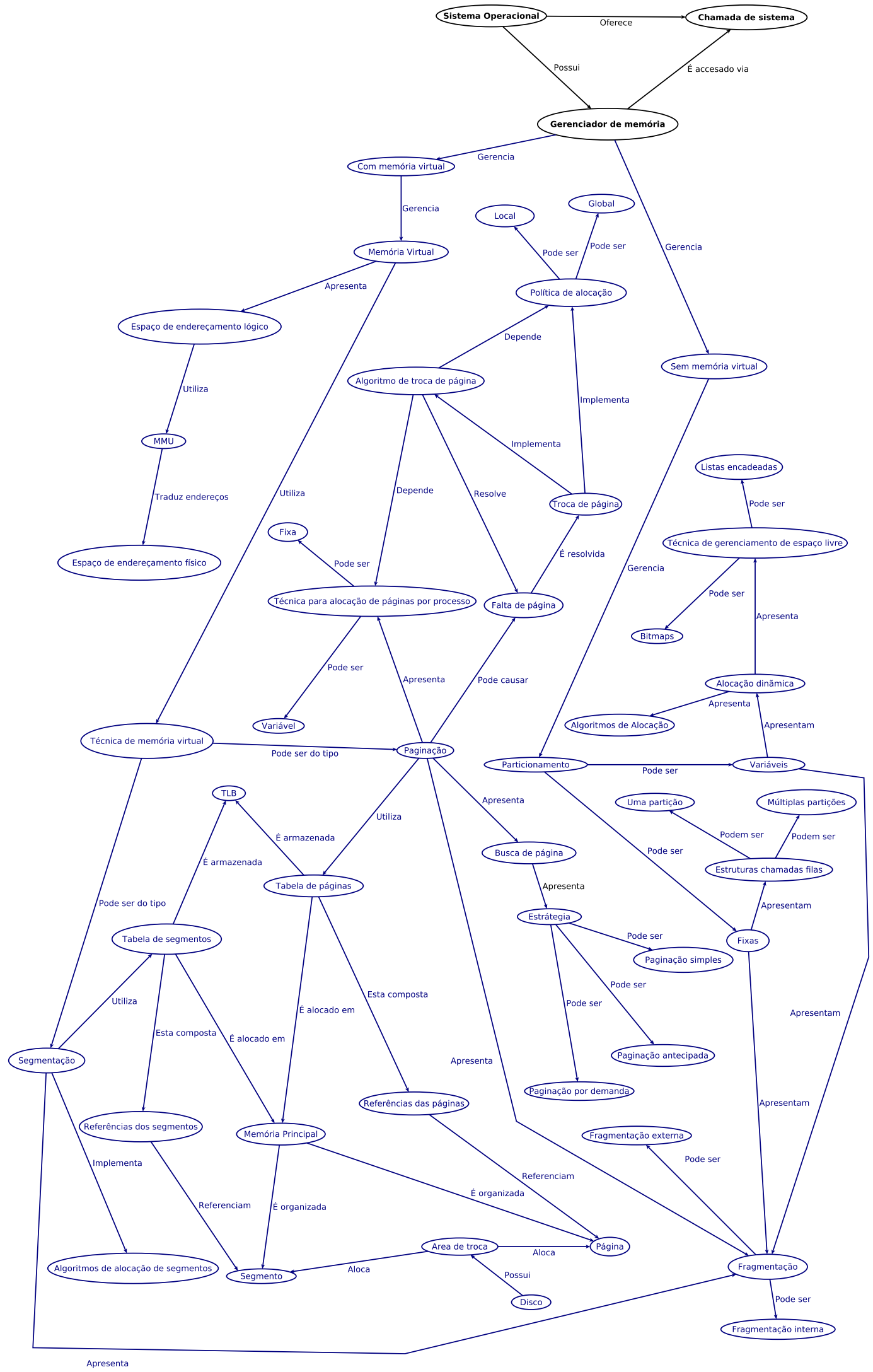

Figura 4.3: Diagrama conceitual do gerenciador de memória 


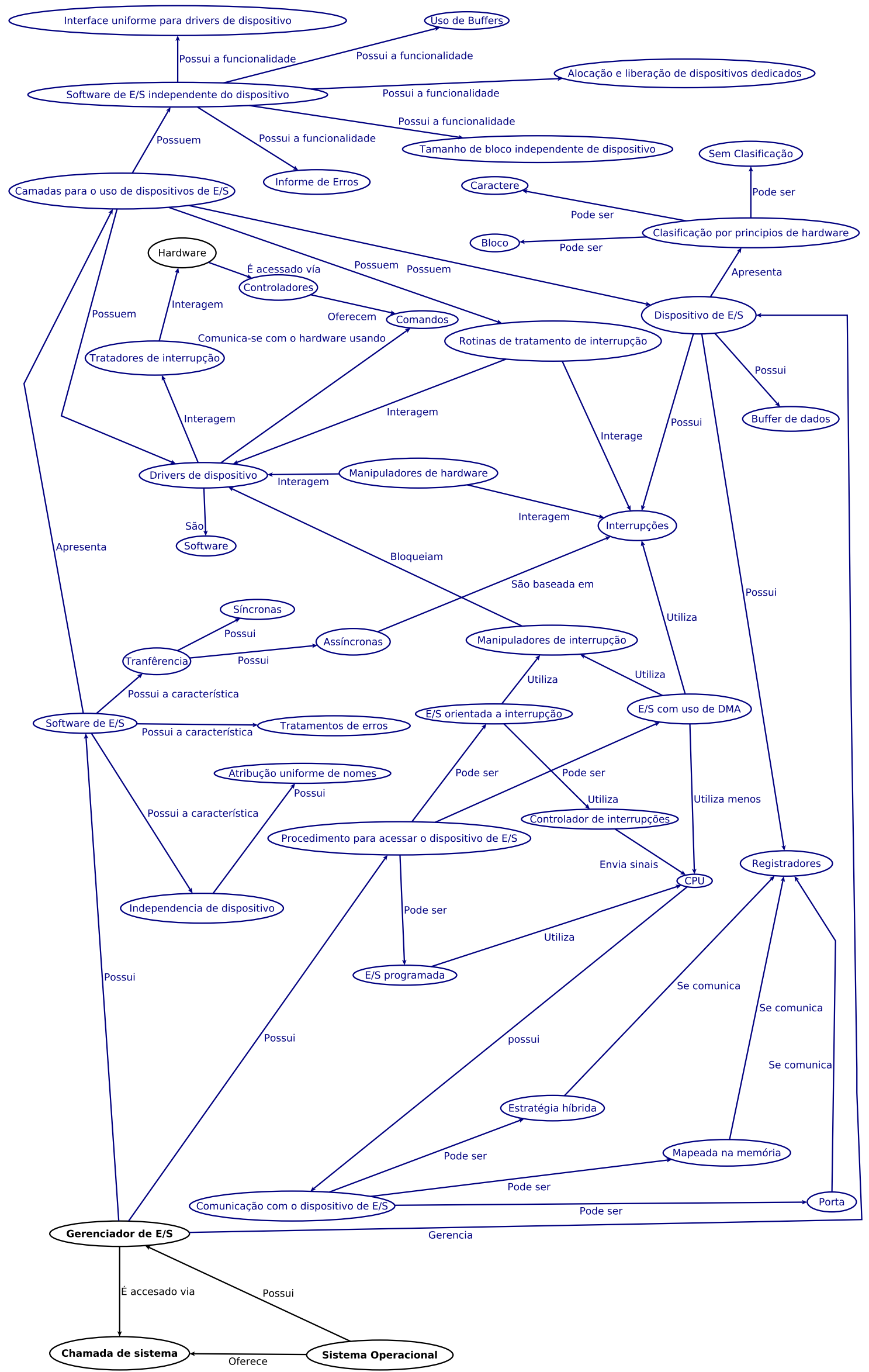

Figura 4.4: Diagrama conceitual do gerenciador de E/S 
- ODispositivo de E/S possui Buffer de dados; possui Interrupções; possui Registradores e apresenta Classificação por princípios de hardware.

- A Classificação por princípios de hardware pode ser por Bloco; pode ser por Caractere e pode ser Sem Classificação.

Neste diagrama conceitual observa-se a característica de taxonomia de conceitos nos conceitos de Classificar por princípios de hardware; Comunicação com o dispositivo de E/S; Procedimento para aceder ao dispositivo de E/Se Transferência. O conceito de Camadas para o uso de dispositivos de E/S apresenta a característica de composição de conceitos. Na figura mostra-se um domínio do conhecimento limitado pela pessoa encarregada de fazê-lo, isto quer dizer que é a visão dele, pode ser variado por outra pessoa com diferente abordagem dos tópicos ensinados no Gerenciador de E/S.

A Figura 4.5 apresenta o modelo conceitual construído para o domínio de conhecimento envolvendo o critério de sistema de arquivos. A seguir serão descritos alguns dos relacionamentos entre os estados que fazem parte deste diagrama conceitual.

- O Arquivo possui Atributo; possui Nome; possui Acesso; possui Estrutura; possui Tipo; possui Operação e se aloca em Disco.

- A Estrutura pode ser por Árvores de registros; pode ser por Sequência não estruturada de bytes e pode ser por Sequência de registros de tamanho fixo.

- O Acesso pode ser Sequencial e pode ser Aleatório.

- O Nome possui Tamanho; pode ser por Extensão e pode ser Sensíveis as Maiúsculas e Minúsculas.

- OTipopode ser Arquivos especiais de bloco; pode ser Arquivos especiais de caractere; pode ser Arquivos regulares e pode ser Diretórios.

- Os Arquivos regulares pode ser ASCII e pode ser Binário.

- Os Diretórios apresentam Serviço de diretório; apresenta Operações; apresenta Tratamento de nomes de arquivos; apresenta Organizaçãoe utiliza uma estrutura de Busca.

Na Figura 4.5 os conceitos com a caraterística de taxonomia de conceitos são Estrutura; Acesso; Tipo; Arquivos regulares; Busca; Organização; Caminho; Tratamento de nomes de arquivose Exemplos de Sistemas de Arquivos. Os conceitos que 
apresentam composição de conceitos são Arqui vo e Nome. O diagrama feito para esta pesquisa não deve considera-se como uma única versão, esta versão pode diferir de um autor para outro.

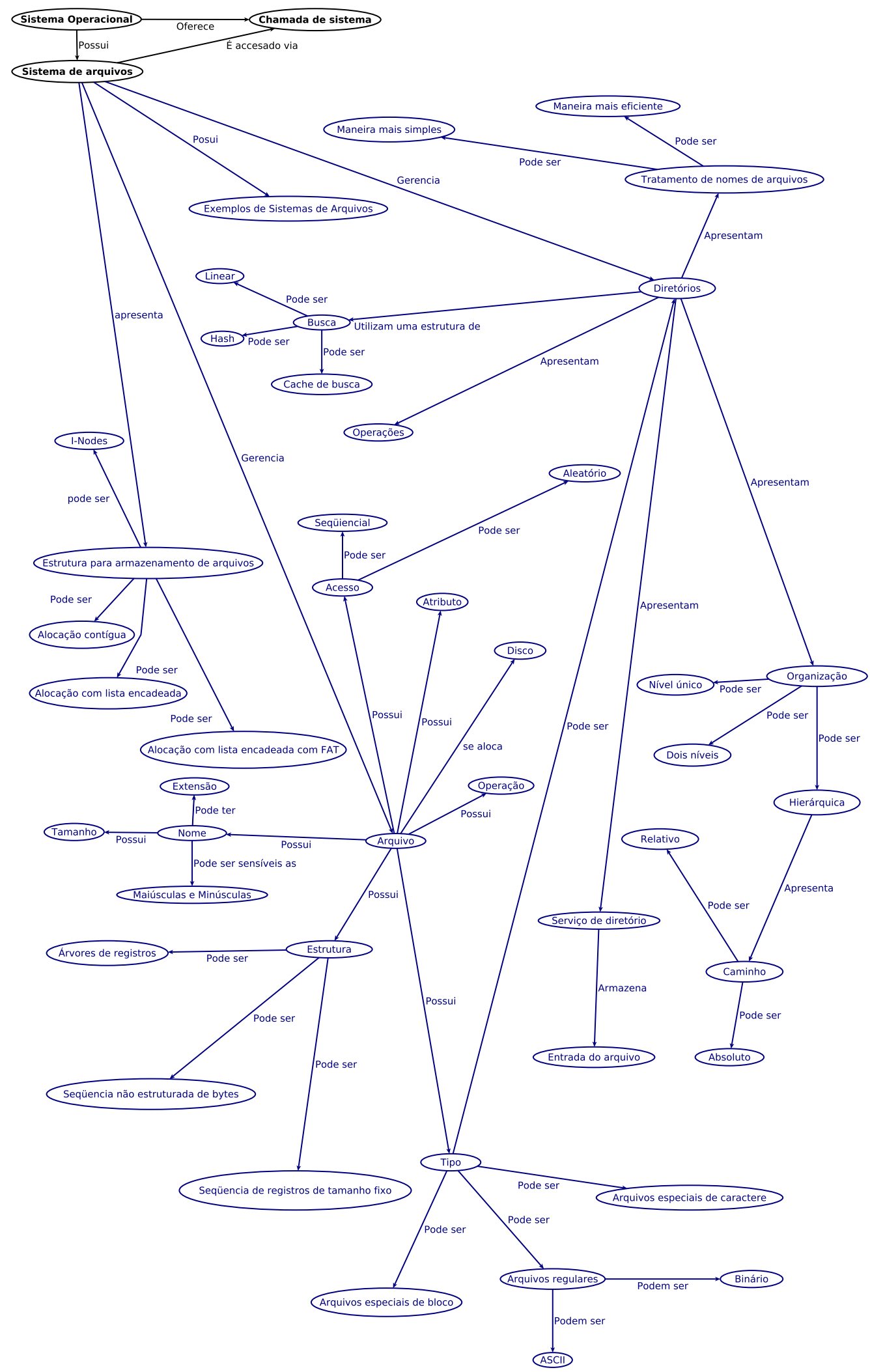

Figura 4.5: Diagrama conceitual de sistema de arquivos 


\subsection{Diagramas instrucionais}

A Figura 4.6 apresenta o modelo instrucional construído para o critério Sistemas Operacionais, utilizando o HMBS/Instrucional introduzido no capítulo anterior e incorporando também elementos que apoiam a compreensão dos conceitos estabelecidos em etapas anteriores. Na primeira etapa de construção do modelo instrucional são identificadas outras informações relevantes que podem ser associadas ao modelo conceitual estabelecido na Figura 4.1. Neste caso, não foi identificada nenhuma informação adicional que pudesse ajudar na compreensão dos conceitos estabelecidos no modelo conceitual. Neste diagrama estabelecem-se associações entre os conceitos de Gerenciador de Recurso e Hardware, e entre os conceitos Chamada de Sistema e Aplicações. Na segunda etapa acrescentam-se os elementos instrucionais (elementos exploratórios, elementos explanatórios e elementos de avaliação) que serão associados aos itens de informação. O diagrama apresentado tem somente elementos explanatórios, os quais possuem uma relação direita com o conceito Estrutura e conceito Sistema Operacional, e estão agrupados num conjunto chamado Exemplos de estrutura e Exemplos de Sistemas Operacionais. Os novos elementos estão destacados com a cor vermelha, sendo que o mesmo procedimento é realizado para as Figuras 4.7, 4.8, 4.9 e 4.10 . O agrupamento de elementos estabelecido para este modelo instrucional se faz com o critério das características de taxonomia de conceitos e decomposição hierárquica do modelo conceitual. As linhas representam as relações entre os elementos deste modelo instrucional.

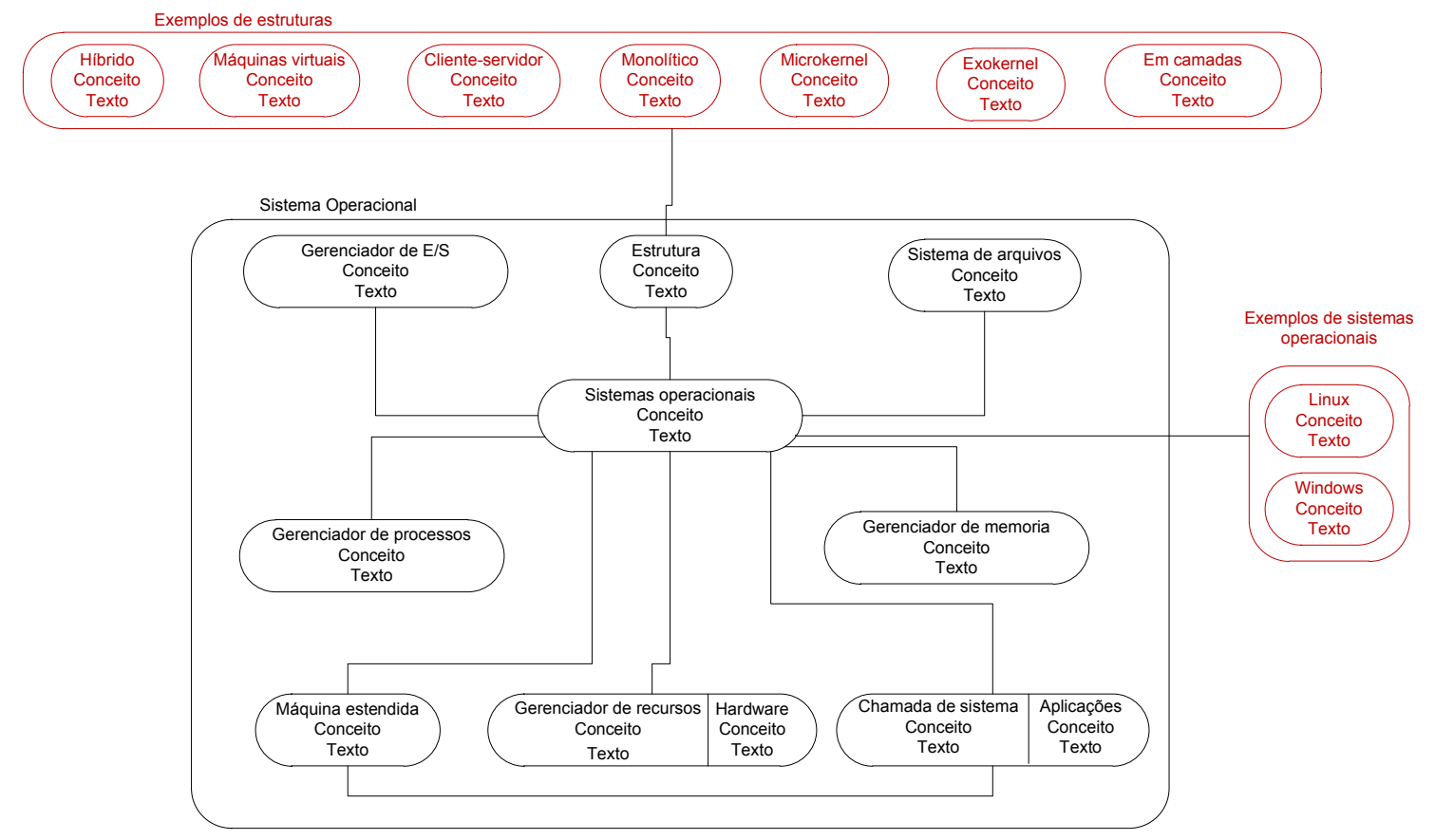

Figura 4.6: Diagrama instrucional de Sistemas Operacionais

A Figura 4.7 apresenta o modelo instrucional construído para o critério de gerenciador de processos. É utilizado o HBMS/instrucional descrito no capítulo anterior, incorporando também ele- 
mentos que apoiam na compreensão dos conceitos estabelecidos em passos anteriores. Na primeira etapa de construção do modelo instrucional, identificamos as seguintes informações relevantes:

1. Mudança de contexto:Conceito:texto;

2. Race conditicion:Conceito:simulação;

3. Race conditicion:Conceito:texto;

4. Comunicações: Conceito:texto;

5. Exclusão mútua:Conceito:texto;

6. Exclusão mútua:Conceito:simulação;

7. Memória:Conceito:simulação;

8. Preemptivo:Conceito:simulação;

9. Algoritmo: Conceito:texto;

10. Não preemptivo:Conceito:simulação.

No diagrama estabelecem-se as próximas associações:

1. Memória:Conceito: simulação e Memória: Conceito:texto²;

2. Processo: Conceito:textoe Processo: Conceito:simulação;

3. Exclusão mútua:Conceito:textoe Exclusão mútua:Conceito:simulação;

4. Race Condition:Conceito:textoe Race Condition:Conceito:simulação;

5. Preemptivo: Conceito:texto, Preemptivo: Conceito: simulaçãoe Algoritmo: Conceito:texto;

6. Não preemptivo:Conceito:texto, Não preemptivo:Conceito:simulação e Algoritmo: Conceito:texto.

Na próxima etapa são acrescentados os elementos explanatórios (elementos instrucionais):

1. Exemplos de informações de hardware:

(a) Registrador: Conceito:texto;

\footnotetext{
${ }^{2} \mathrm{O}$ termo memória faz referencia ao conceito de memória estabelecido no ensino do gerenciamento de processos.
} 
(b) Contador de programa:Conceito:texto;

(c) Stack Pointer:Conceito:texto.

2. Exemplos de informações de software:

(a) Estado de processo:Conceito:texto;

(b) Registrador: Conceito:texto;

(c) Parametros de escalonamento:Conceito:texto;

(d) Identificador de Processos:Conceito:texto.

3. Exemplos de processo leve(Thread:Conceito:texto);

4. Exemplos de métodos de sincronização e comunicação:

(a) Pipes:Conceito:texto;

(b) Monitores:Conceito:texto;

(c) Espera ocupada:Conceito:texto;

(d) Sockets:Conceito:texto;

(e) Semáforo:Conceito:texto;

(f) Primitivas Sleep/Wakeup:Conceito:texto;

(g) RPC:Conceito:texto;

(h) MPI:Conceito:texto;

(i) Web Services:Conceito:texto;

(j) RMI: Conceito:texto.

5. Exemplos de algoritmos interativos:

(a) Round Robin:Exemplo:simulação;

(b) Garantido:Exemplo:simulação;

(c) Shortest Process Next:Exemplo:simulação;

(d) Prioridades:Exemplo:simulação;

(e) Múltiplas filas:Exemplo:simulação;

(f) Fair-share:Exemplo:simulação;

(g) Lotery:Exemplo:simulação. 


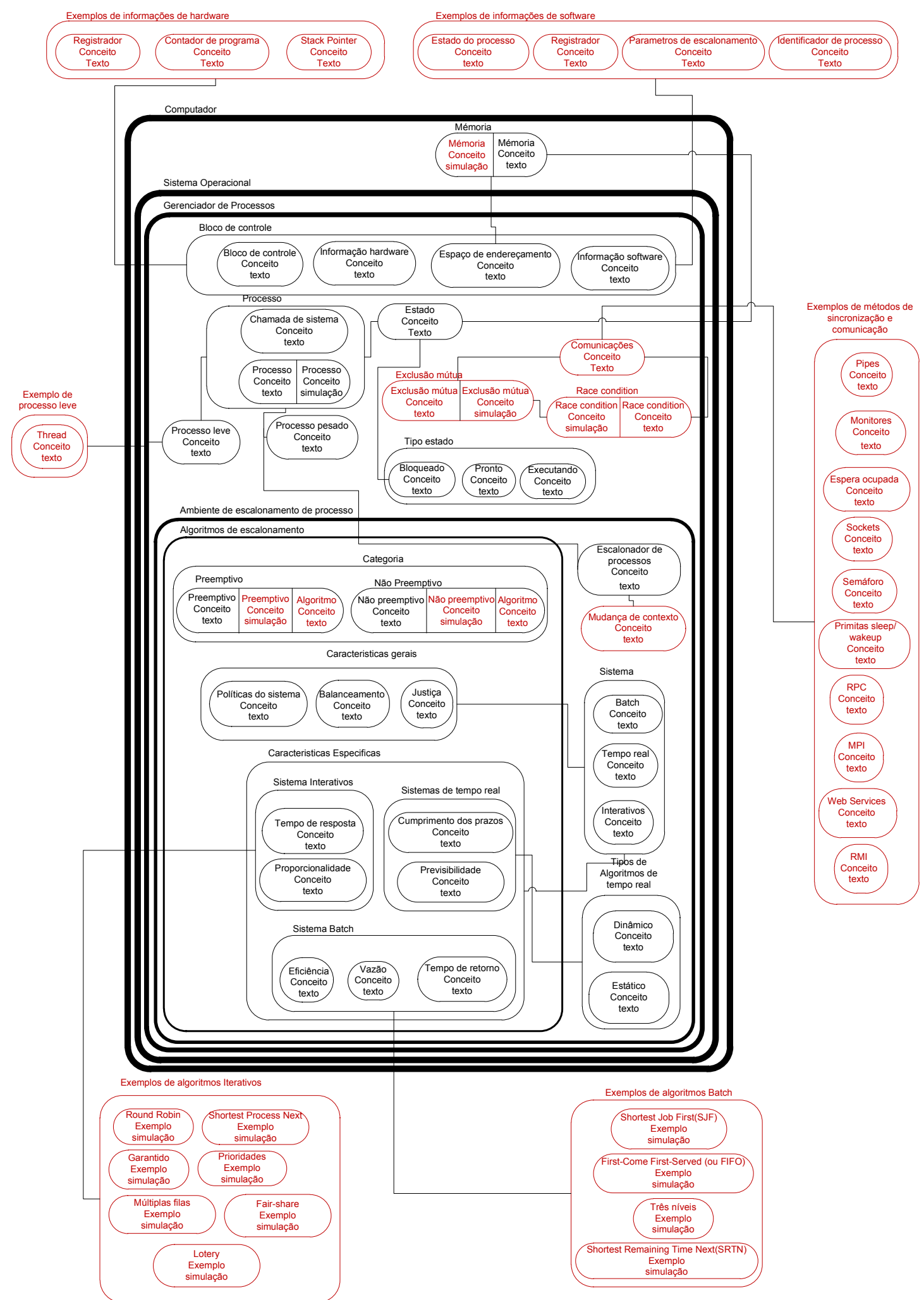

Figura 4.7: Diagrama instrucional do gerenciador de processos

6. Exemplos de algoritmos Batch:

(a) Shortest Job Firts (SJF) : Exemplo:simulação; 
(b) First-Come First-Served (ou FIFO) :Exemplo:simulação;

(c) Três níveis:Exemplo:simulação;

(d) Shortest Remaining Time Next (SRTN) :Exemplo:simulação.

A Figura 4.8 mostra o modelo instrucional construído para o critério gerenciador de memória, utilizando o modelo HBMS/Instrucional descrito anteriormente, incorporando também elementos que apoiam na comprensão dos conceitos estabelecidos em passos anteriores.

Na primeira etapa da construção deste modelo instrucional, foram identificados os seguintes conceitos:

1. Alocação:conceito:texto;

2. Swapping:conceito:texto;

3. Alocação de segmentos:Conceito:texto;

4. Memória real: Conceito:texto;

5. Estratégia de busca de pagina:conceito:texto;

6. Política de substituição:Conceito:texto;

7. Memória:Conceito:texto;

8. Cache: Conceito:texto;

9. RAM: Conceito: texto;

10. Tabela de segmentos:Conceito:Simulação;

11. TLB:Conceito:simulação;

12. Tabelas de páginas:conceito:simulação.

Após a identificação destes elementos definidos pelo aluno de mestrado e seu orientador, eles são adicionados ao modelo instrucional, e posteriormente definidas as associações:

1. Tabela de páginas:Conceito:textoe

Tabela de páginas:Conceito:simulação;

2. TLB:Conceito:texto e TLB:Conceito:simulação;

3. Tabela de segmentos:Conceito:textoe

Tabela de segmentos:Conceito:simulação. 




Figura 4.8: Diagrama instrucional do gerenciador de memória

No passo seguinte são acrescentados os elementos instrucionais:

1. Exemplo de técnica de gerenciamento de espaço livre: 
(a) Bitmaps:Exemplo:texto;

(b) Lista encadeada:Exemplo:texto.

2. Exemplos de algoritmos de alocação:

(a) WORST FIT:Exemplo:texto;

(b) BEST FIT:Exemplo:texto;

(c) NEXT FIT:Exemplo:texto;

(d) FIRST FIT:Exemplo:texto;

(e) QUICK FIT:Exemplo:texto.

3. Exemplos de algoritmos de alocação de segmentos ${ }^{3}$ :
(a) WORST FIT:Exemplo:texto;
(b) BEST FIT:Exemplo:texto;
(c) NEXT FIT:Exemplo:texto;
(d) FIRST FIT:Exemplo:texto;
(e) QUICK FIT:Exemplo:texto.

4. Exemplos de estratégia de busca de página:
(a) Paginação por demanda:Exemplo:texto;
(b) Paginação simples:Exemplo:texto;
(c) Paginação antecipada:Exemplo:texto.

5. Exemplos de técnica para alocação de páginas:

(a) Fixa:Exemplo:texto;

(b) Variável:Exemplo:texto.

6. Exemplos de algoritmo de troca de página:
(a) Ótimo:Exemplo:simulação;
(b) NRU :Exemplo:simulação;
(c) FIFO:Exemplos:simulação;
(d) Segunda chance:Exemplo:simulação;
(e) Relógio:Exemplo:simulação;
(f) LRU:Exemplo:simulação;

\footnotetext{
${ }^{3} \mathrm{~A}$ repetição destes grupos de algoritmos tem o objetivo de melhorar o entendimento do diagrama.
} 
(g) NFU:Exemplo:simulação;

(h) Working set:Exemplo:simulação;

(i) WSClock:Exemplo:texto.

A Figura 4.9 apresenta o modelo instrucional definido para o critério Gerenciamento de E/S, utilizando o modelo HMBS/Instrucional estabelecido no capítulo anterior, adicionando também elementos que apoiam na comprensão dos conceitos estabelecidos em passos anteriores. A identificação de outras informações relevantes é a primeira etapa na construção do modelo instrucional. Com possiblidade de associação ao modelo conceitual estabelecido para o critério de Gerenciamento de E/S, estas informações são:

1. Software de E/S em espaço de usuário:Conceito:texto;

2. Controladora de DMA:Conceito:texto;

3. E/S com uso de DMA:Conceito:simulação;

4. E/S orientada a interrupção:Conceito:simulação;

5. E/S programada:Conceito:simulação.

Estabelecem-se as seguintes associações:

1. E/S programada:Conceito:texto,E/S programada:Conceito:simulação e CPU: Conceito:texto;

2. E/S com uso de DMA:Conceito:textoe E/S com uso de DMA:Conceito:simulação;

3. E/S orientada a interrupção:Conceito:textoe E/S orientada a interrupção:Conceito:simulação.

Na figura também são adicionados os elementos instrucionais do tipo elementos explanatórios, os quais serão associados aos itens de informação correspondentes, sendo:

1. Exemplos de dispositivos de bloco(Disco rígido:Exemplo:texto);

2. Exemplos de dispositivos de caractere:

(a) Impressora:Exemplo:texto;

(b) Interface de Rede:Exemplo:texto;

(c) Placa de Som:Exemplo:texto.

3. Exemplos de dispositivos sem classificação(Clock:Exemplo:texto). 


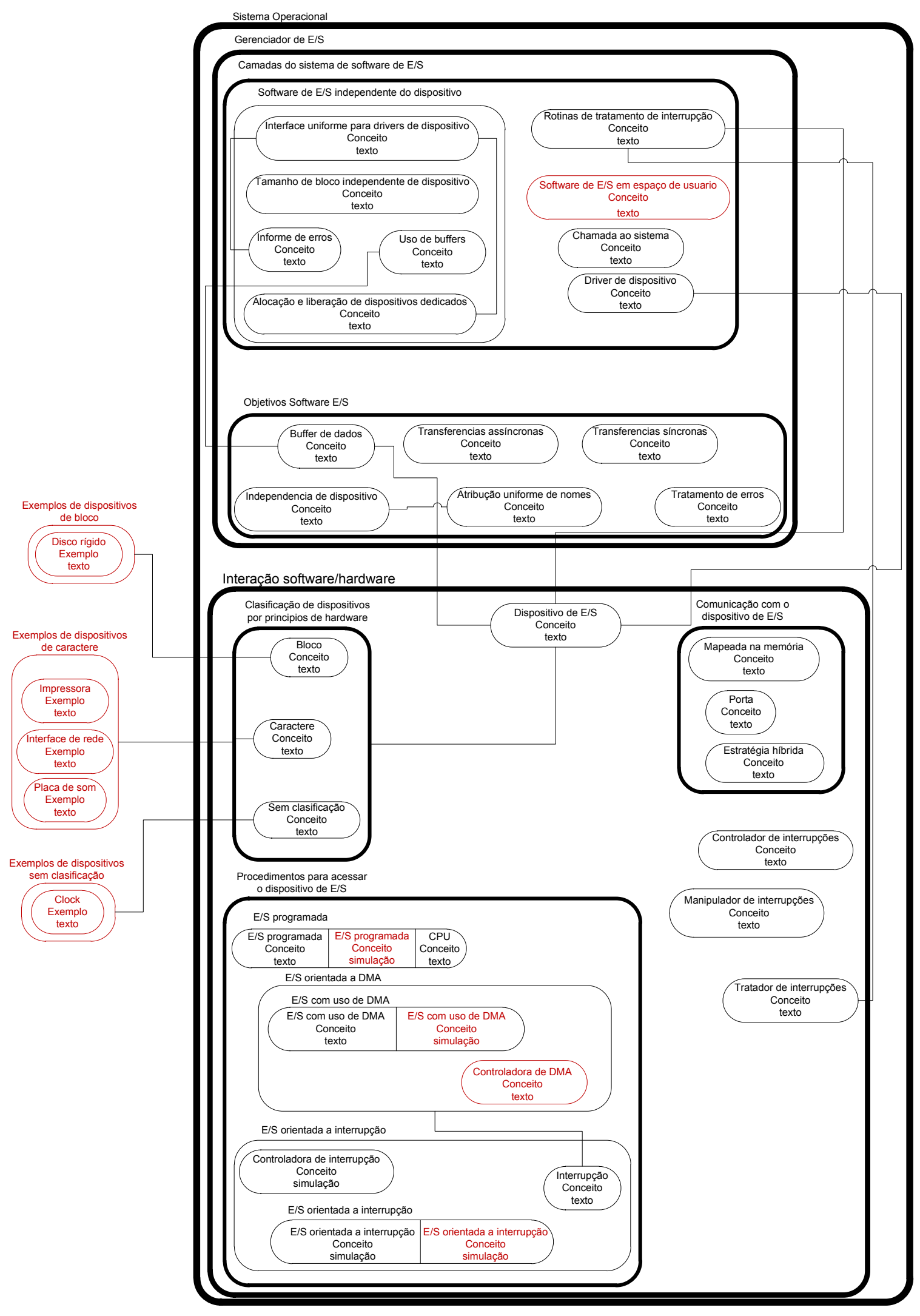

Figura 4.9: Diagrama instrucional do gerenciador de E/S 
A Figura 4.10 apresenta o modelo instrucional definido para o critério Sistemas de Arquivos, utilizando o HMBS/Instrucional mencionado no capítulo anterior, e também adicionando elementos que apoiam na comprensão dos conceitos estabelecidos em passos anteriores. A primeira etapa a ser feita é o reconhecimento de outras informações relevantes, com muita possibilidade de serem adicionadas ao modelo conceitual correspondente. Essas informações são:

1. Arquivos mapeados em mémoria:Conceito:texto;

2. Alocação com lista encadeada com FAT:Conceito:simulação;

3. MFT:Conceito:simulação;

4. Alocação com lista encadeada:Conceito:simulação;

5. Armazenamento de arquivos:Conceito:simulação;

6. Alocação contígua:Conceito:simulação;

7. I-Nodes:Conceito:simulação;

8. Armazenamento de forma contígua:Conceito:simulação.

Apresenta-se também associações entre os conceitos:

1. Alocação com lista encadeada com FAT:Conceito:texto e Alocação com lista encadeada com FAT:Conceito:simulação;

2. Arquivo:Conceito:texto e Chamada ao Sistema:Conceito:texto;

3. MFT:Conceito:texto e MFT:Conceito:simulação;

4. Alocação com lista encadeada:Conceito:textoe Alocação com lista encadeada: Conceito: simulação;

5. I-Node: Conceito:textoe I-Nodes:Conceito:simulação;

6. Armazenamento de arquivos:Conceitos:textoe Armazenamento de arquivos:Conceito:simulação;

7. Alocação contígua: Conceito:textoe Alocação contígua: Conceito:simulação;

8. Armazenamento de forma não contígua:Conceito:textoe Armazenamento de forma não contígua:Conceito:simulação. 


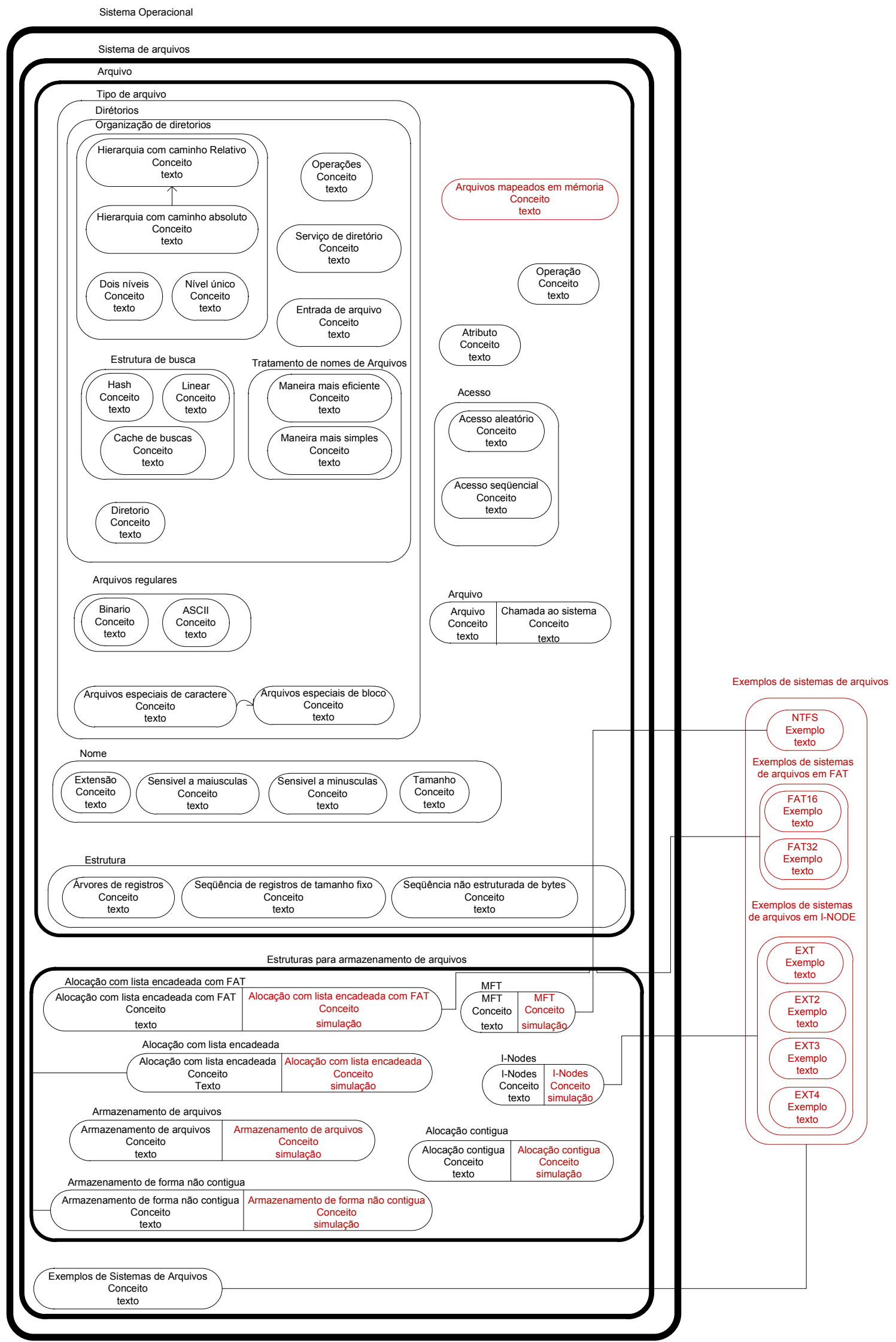

Figura 4.10: Diagrama instrucional do sistema de arquivos 
Finalmente são apresentados os elementos instrucionais do tipo explanatórios agrupados no Exemplos de sistemas de arquivos integrado por:

1. NTFS:Exemplo:texto e os grupos:

(a) Exemplos de sistemas de arquivos em FAT:
i. FAT16:Exemplo:textoe
ii. FAT32:Exemplo:texto.

(b) Exemplos de sistemas de arquivos em I-NODE
i. EXT:Exemplo:texto;
ii. EXT2:Exemplo:texto;
iii. EXT3:Exemplo:texto;
iv. EXT4:Exemplo:texto.

\subsection{Diagrama didáticos}

O modelo didático, tal como foi definido, estabelece a sequência de apresentação dos elementos definidos no modelo anterior (intrucional). Esta sequência pode ser definida pelo professor, instrutor ou instituição educativa.

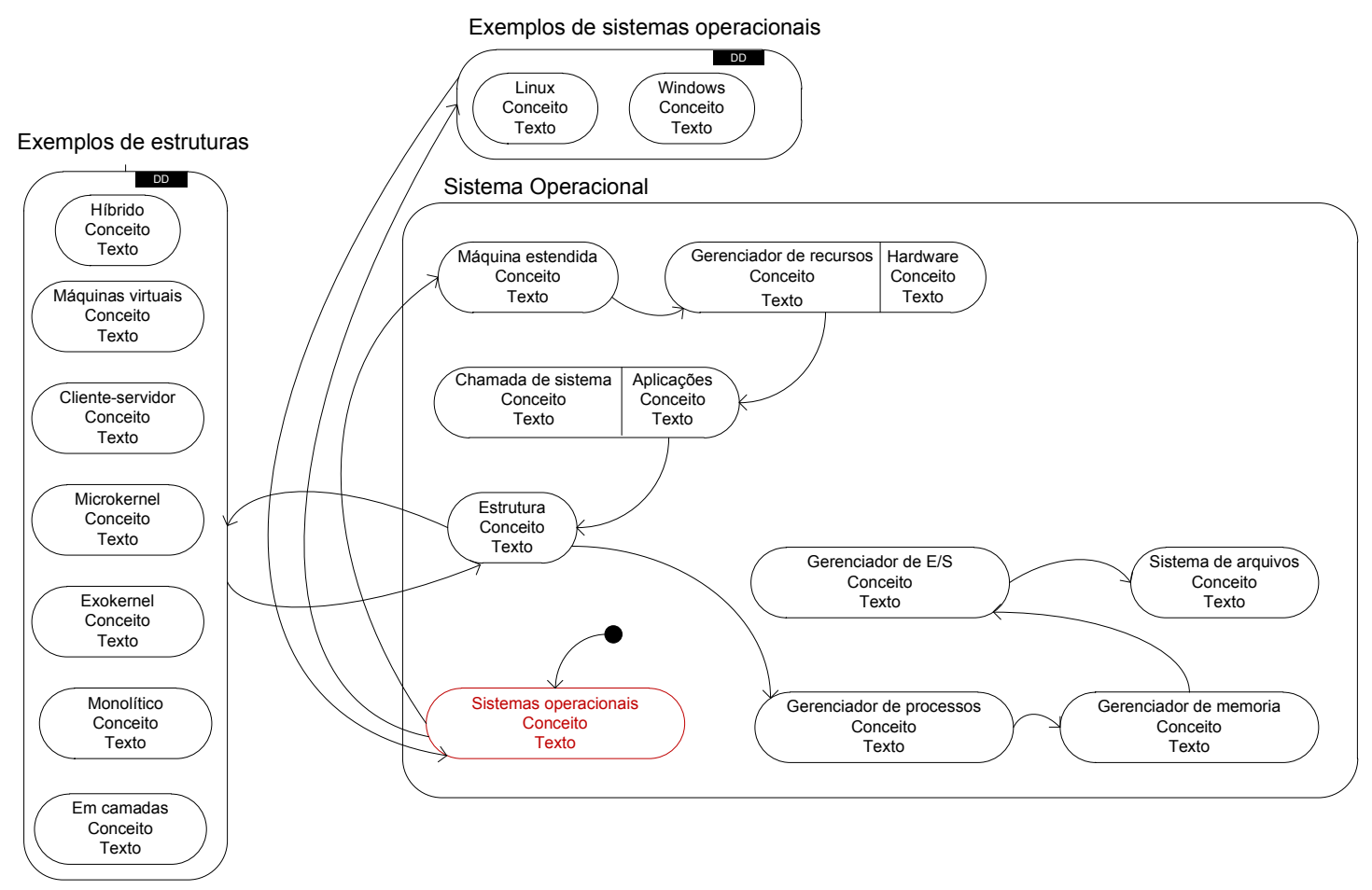

Figura 4.11: Diagrama didático de sistemas operacionais 
Na Figura 4.11 é apresentado o diagrama didático do tópico Sistemas Operacionais. O diagrama é um modelo didático fechado ${ }^{4}$, sendo aberto ${ }^{5}$ somente nos subconjuntos Exemplos de Estruturas e Exemplos de Sistemas Operacionais. A navegação no diagrama começa no elemento Sistemas Operacionais: Conceito: Texto destacado em vermelho na figura.

A Figura 4.12 ilustra o diagrama didático correspondente ao tópico gerenciador de processos. A navegação no diagrama começa no grupo Processo destacado em vermelho. A maioria dos elementos é apresentado em um estado DD (Dinamically Defined), podendo-se considerar um modelo aberto nos subconjutos:

- Ambiente de escalonamento;

- Exemplos de informações de hardware;

- Exemplos de informações de software;

- Exemplos de método de sincronização e comunicação;

- Exemplos de processo leve;

- Exemplos de algoritmos Iterativos;

- Exemplos de algoritmos Batch.

A Figura 4.13 apresenta o diagrama didático correspondente ao tópico gerenciador de memória. A navegação no diagrama começa no elemento Gerenciador de memória: Conceito: texto destacado em vermelho. Trata-se de um modelo fechado, apresentando estados DD somente nos elementos fora do domínio do conhecimento mais importante:

- Exemplos de algoritmo de alocação;

- Exemplos de algoritmo de alocação de segmentos;

- Exemplos de estratégia de busca de página;

- Exemplos de técnica para alocação de páginas.

A Figura 4.14 apresenta o diagrama didático do tópico gerenciador de $\mathrm{E} / \mathrm{S}$ e também é um modelo fechado em quase todos os elementos do diagrama, a exceção dos elementos do subconjunto Exemplos de dispositivos de caractere. A navegação no diagrama começa no elemento Dispositivo de E/S:Conceito:texto destacado em vermelho.

\footnotetext{
${ }^{4} \mathrm{Um}$ modelo é fechado quando todos os grupos que compõem o modelo didático não apresentam a característica de estado DD (Dinamically Defined).

${ }^{5}$ Considera-se um modelo aberto quando todos os grupos de elementos de um diagrama didático apresentam um estado DD (Dinamically Defined).
} 


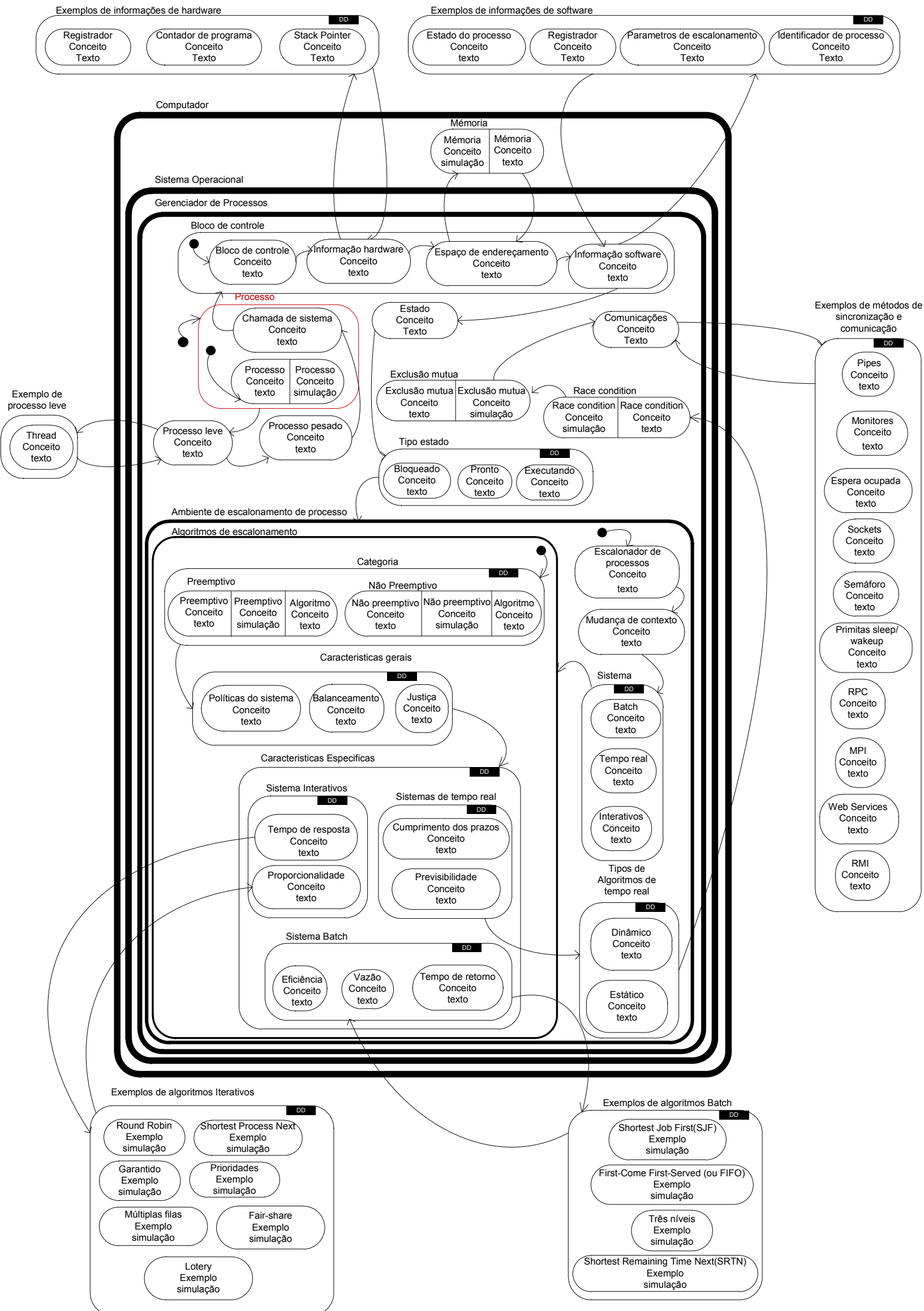

Figura 4.12: Diagrama didático do gerenciador de processos 


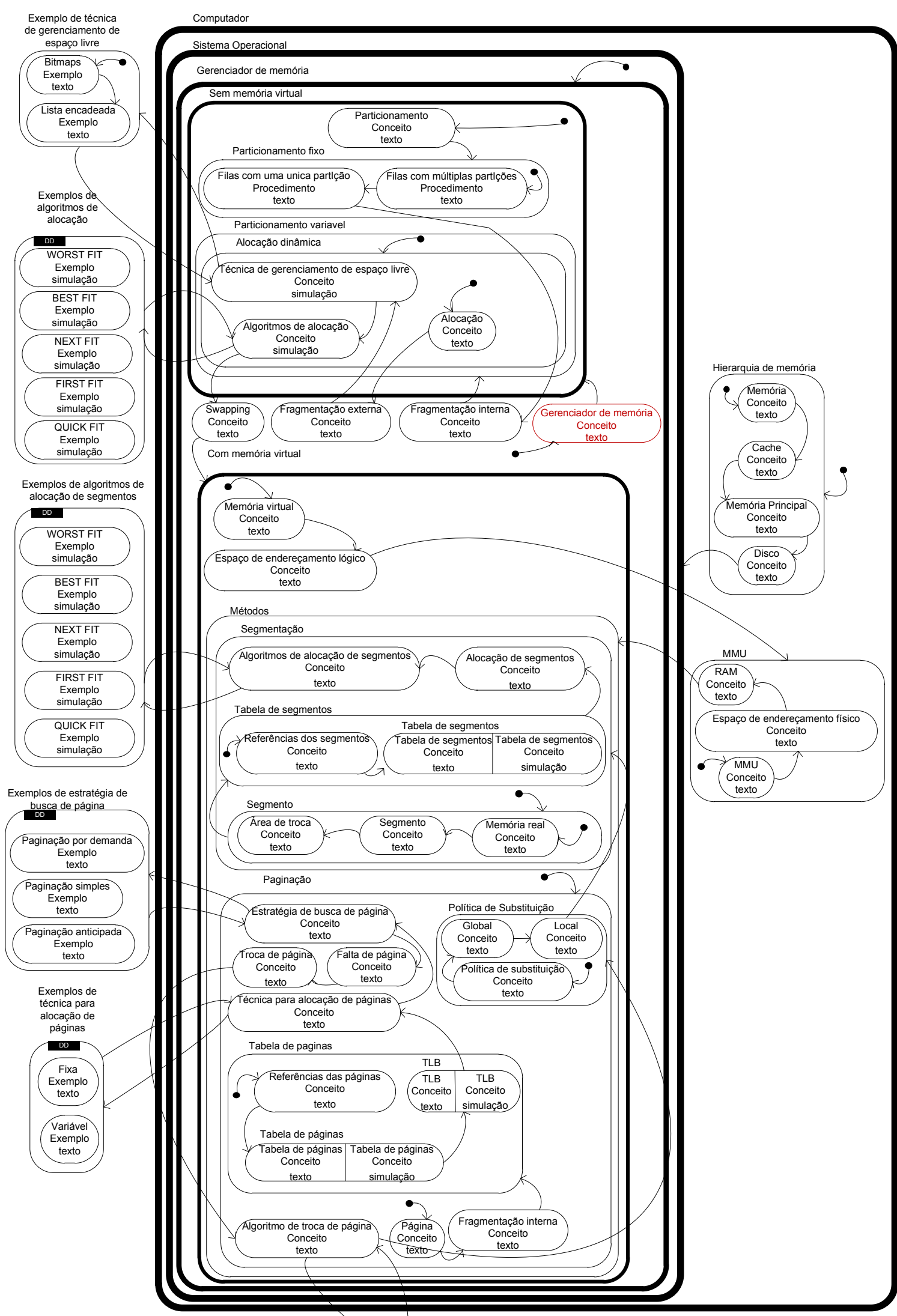

Exemplos de algoritmo de troca de página

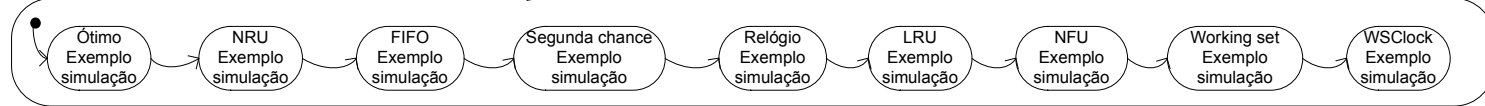

Figura 4.13: Diagrama didático do gerenciador de memória 


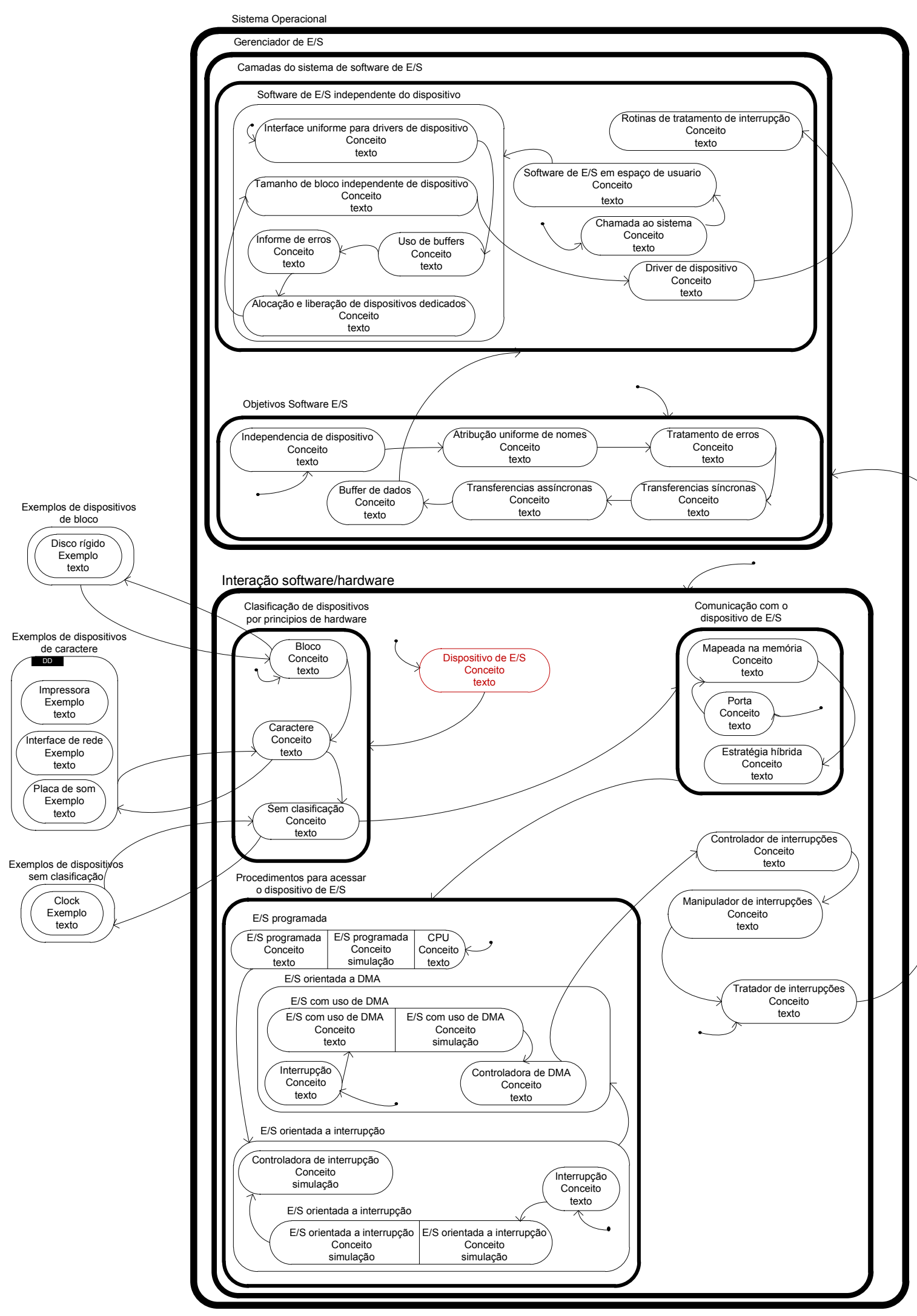

Figura 4.14: Diagrama didático do gerenciador de E/S 
Sistema Operacional

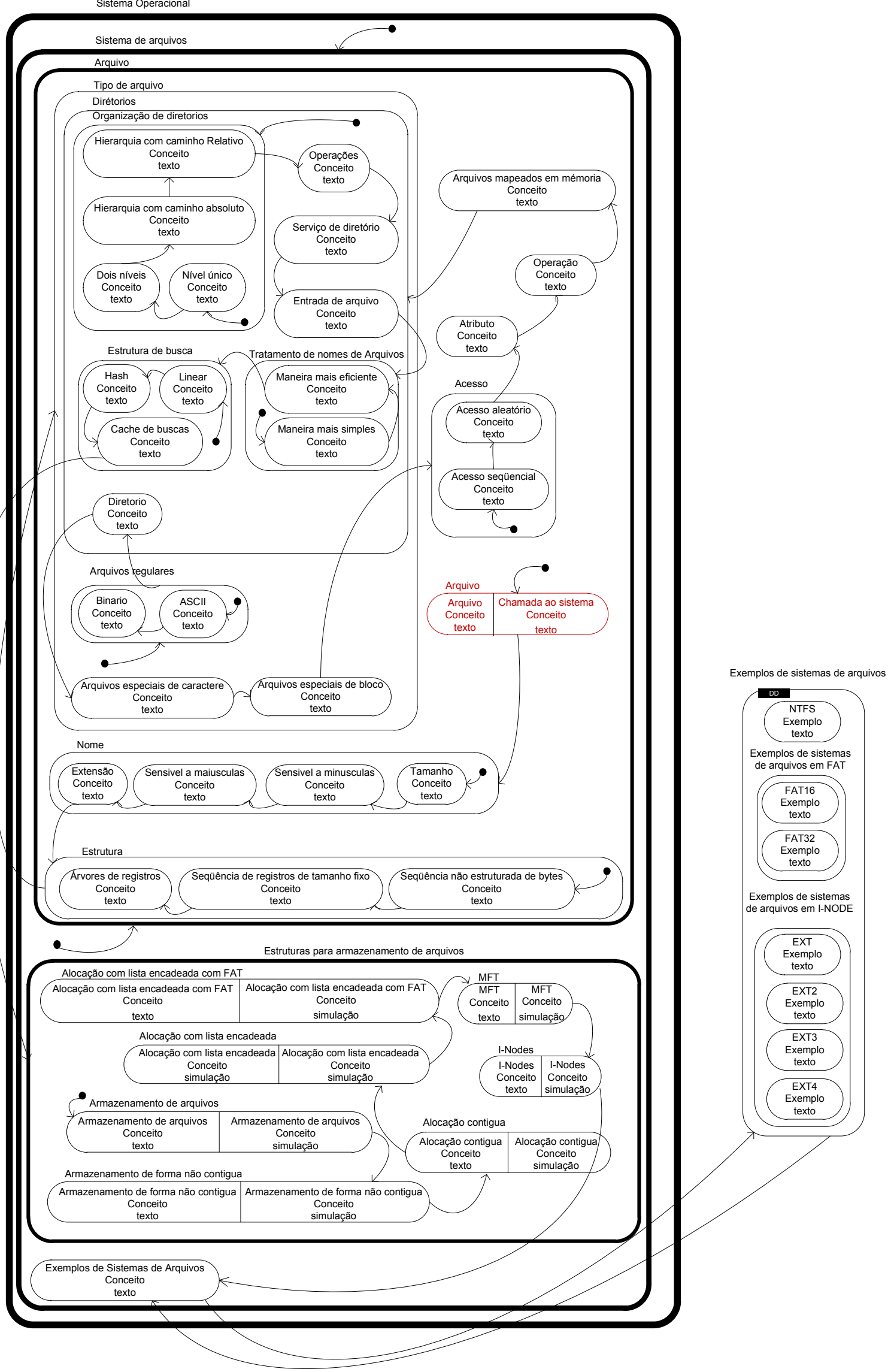

Figura 4.15: Diagrama didático do gerenciador de sistema de arquivos 
A Figura 4.15 apresenta o diagrama didático do tópico Sistemas de Arquivos, sendo um modelo quase totalmente fechado, a exceção de um subconjunto fora do domínio do conhecimento que apresenta estado DD, o subconjunto Exemplos de sistemas de arquivos. A navegação no diagrama começa no elemento composto Arquivo destacado em vermelho.

\subsection{Considerações Finais}

Neste capítulo foram abordados os diagramas conceituais, instrucionais e didáticos criados para este projeto. Sendo esta uma tarefa realizada sobre um grande conjunto de conceitos, é importante ressaltar a enorme dificuldade ao criar tais diagramas, o formato apresentado foi escolhido por ser o mais formal dentro os encontrados durante a pesquisa.

No próximo capítulo serão apresentados os passos e as técnicas utilizados na validação dos diagramas construídos, incluindo o desenvolvimento de um material didático para ser avaliado. 



\section{Validação dos modelos gerados}

\subsection{Considerações inicias}

Este capítulo descreve a metodologia de construção do material educativo correspondente aos diagramas definidos no capítulo anterior. Também são descritos os métodos utilizados para realizar a avaliação e validação do material educativo.

\subsection{Desenvolvimento de material educativo}

A validação dos diagramas definidos no capítulo 4 pode ser feito através do desenvolvimento de um material educativo que apresente as características dos modelos resultantes da aplicação da abordagem AIM-CID. Este material educativo deve ser submetido a uma avaliação através de questionários elaborados de acordo com o material educativo feito.

Dado a grande quantidade de diagramas desenvolvidos, optou-se pela construção de um material educativo referente ao tópico Gerenciamento de Processos. Um dos motivos desta escolha foi que segundo (Tanenbaum, 2009), um dos primeiros conceitos a serem ensinados em Sistemas Operacionais deve ser o ambiente de escalonamento. Assim, o material referente a este tópico foi desenvolvido e validado seguindo um sistema avaliador presente na literatura. Todos os outros diagramas podem ser validados da mesma maneira, no entanto, essas validações serão abordadas em trabalhos futuros.

O material educativo é composto por um conjunto de slides contendo os tópicos referentes ao gerenciamento e escalonamento de processos, como mudança de contexto, algoritmos, etc. 
Para o desenvolvimento dos slides foi utilizada a ferramenta de processamento de texto $\mathrm{LT}_{\mathrm{E}} \mathrm{X}$ e o pacote Beamer $\left(\mathrm{LT}_{\mathrm{E}} \mathrm{X}\right)^{1}$. Também foram acrescentados algumas funcionalidades que permitem navegação nos slides, uma característica do modelo didático da metodologia AIM-CID.

Para complementar o material didático, foi utilizado um simulador de apoio para o escalonamento de processos. Este simulador é denominado SOSIM, o qual foi desenvolvido para que o aluno tenha uma interação simples e fácil através de uma interface gráfica (Maia, 2001).

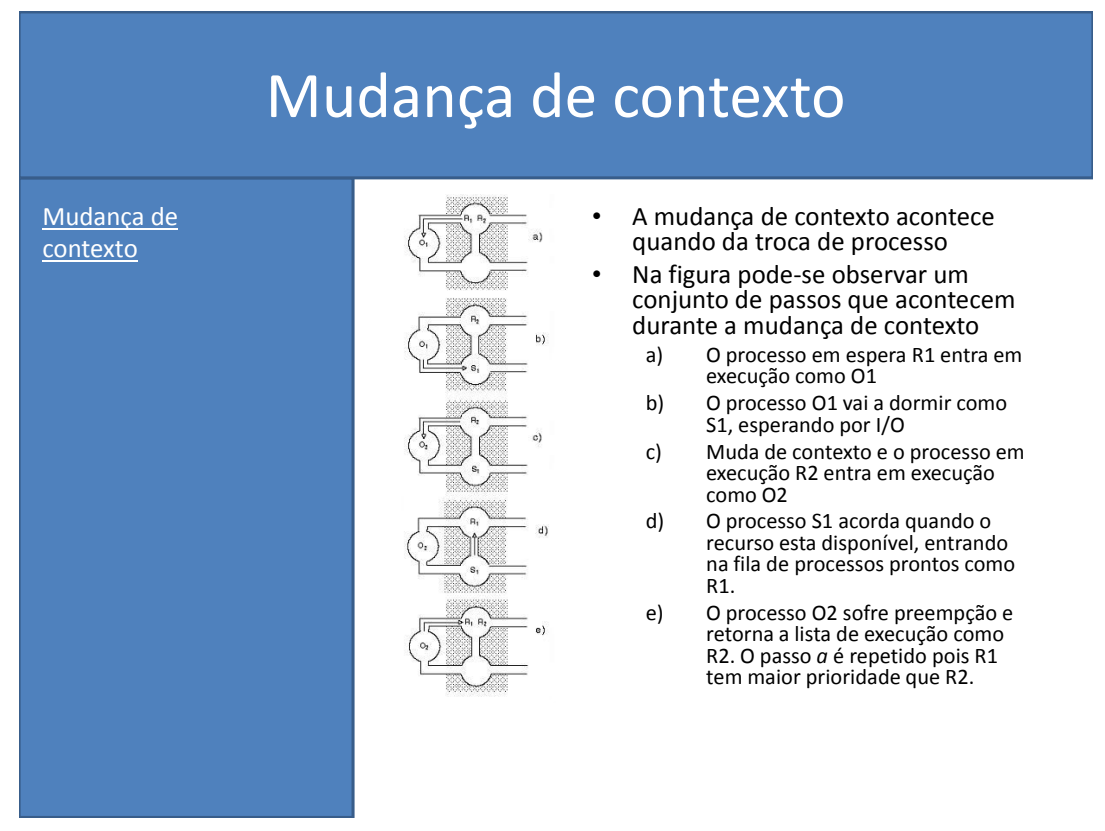

Figura 5.1: Exemplo de um slide do material didático

Todos os slides estão disponíveis no Apêndice, sendo que um dos slides pode ser observado na Figura 5.1. Para fazer a validação do material desenvolvido foi necessário a escolha de um conjunto de métricas que possam aferir a adequação e qualidade do material. O sistema escolhido e adaptado para a validação foi O Sistema Avaliador de Usabilidade em Softwares Pedagógicos, proposta por (Abreu, 2010).

\subsection{Sistema Avaliador de Usabilidade em Softwares Pe- dagógicos}

O objetivo principal do sistema é prover uma ferramenta avaliativa dos critérios técnicos e pedagógicos de um material de aprendizagem. O sistema utiliza um questionário para avaliar a usabilidade pedagógica, geral e voltada para web.

\footnotetext{
${ }^{1}$ https : //bitbucket.org/rivanvx/beamer/wiki/Home, Foi concebido para a criação específica de slides utilizando a sintaxe do IATEX
} 
As perguntas do questionário possuem pontuação que vão do 1 ao 5 (5 pontos):

- Concordo totalmente (1);

- Concordo parcialmente (2);

- Indeciso (3);

- Discordo parcialmente (4);

- Discordo totalmente (5).

As perguntas devem ser agrupadas em três categorias: Usabilidade Geral, Usabilidade para sites EAD (Ensino à Distancia) e Usabilidade pedagógica, segundo (Abreu, 2010).

- Usabilidade Geral: as questões referidas à usabilidade geral referem-se aos seguintes sete itens:

- Adequação a tarefa: este critério define que a interface permite a conclusão da tarefa correspondente de forma efetiva e eficiente;

- Autodescrição: o critério refere-se a capacidade da interface de satisfazer as necessidades do usuário de compreensão e de explicação;

- Controlabilidade: este principio descreve a capacidade do usuário de controlar a direção e o ritmo das interações ate chegar a seu objetivo final;

- Conformidade com as expectativas do usuário: a interface não contradiz os conhecimentos prévios do usuário o a experiência dele;

- Tolerância de erros: se for o caso de erro do usuário, o objetivo da aplicação poderá ser alcançado com pouca a nenhuma ação do usuário;

- Adequação a individualização: o critério fala da capacidade de adequação do material para os requerimentos das tarefas, individuais e habilidades individuais;

- Adequação ao aprendizado: o principio permite a guia e o apoio do material para a compreensão e memorização no uso do sistema.

- Usabilidade para sites EAD: as questões mostradas foram escolhidas para avaliar características próprias de websites educacionais, foram escolhidas por se adequarem ao sistema descrito, sendo:

- Simplicidade de navegação e estrutura: o site provê um mecanismo de navegação simples, permitindo que o usuário saiba onde ele está;

- Relevância do conteúdo do site para a aprendizagem: o quesito fala da qualidade do conteúdo referente a motivação, relevância e adaptado ao aluno. O conteúdo é de autores recomendados. 
- Usabilidade didática: estas perguntas foram escolhidas pois referem-se a fatores pedagógicos específicos para uma aplicação feita para o ensino:

- Controle do aluno: avalia o excesso na utilização da capacidade de memorização de conteúdo pelo aluno.

- Atividade do aluno: depende da didática, esta atividade pode ser melhorada em função de uma boa didática;

- Aprendizagem colaborativa/cooperativa: a interação entre os alunos permite chegar a cumprir os objetivos de aprendizado;

- Orientação a objetivos: estabelecer claramente quais são os objetivos e metas do que se esta ensinando para o aluno;

- Aplicabilidade: deve existir correspondência entre as habilidades e conhecimento do aluno que serão adquiridas no ensino para a realidade futura do aluno e também devem ser adquiridas estas habilidades e conhecimentos no ensino;

- Valor agregado: acrescentado através do uso criativo de mídia o de elementos tecnológicos;

- Motivação: o material deve motivar aos alunos através dos conteúdos e interatividade;

- Avaliação do conhecimento prévio: os conhecimentos antes obtidos pelo aluno sobre a matéria desenvolvida devem ser respeitados oferecendo uma revisão para obter um aprendizado geral;

- Flexibilidade: a capacidade que o aluno possui para utilizar o sistema e poder adequálo às suas necessidades.

- Feedback: o feedback do uso do sistema deve ser motivador para que o aluno entenda os problemas na sua aprendizagem.

\subsection{Adequação da metodologia}

Dado a natureza do material desenvolvido, no questionário elaborado para a validação seguindo a metodologia descrita não foi utilizada a parte de usabilidade para sites EAD. A Tabela 5.1 contém as perguntas referentes a usabilidade didática e a Tabela 5.2 contém as perguntas referentes a usabilidade geral.

O questionário foi implementado com o uso da ferramenta Googledocs, amplamente utilizada para elaboração de questionários, disponibilizada através do uso de uma conta no Google ${ }^{\circledR}$. A Figura 5.2 ilustra a interface definida pelo Googledocs para o questionário elaborado. 


\begin{tabular}{|l|l|}
\hline Pergunta & Critério de avaliado \\
\hline $\begin{array}{l}\text { No caso de uso dos slides por parte do aluno, } \\
\text { ele poderá concluir a simulações apresenta- } \\
\text { das? }\end{array}$ & Adequação a tarefa \\
\hline Os slides são facilmente explicáveis? & Autodescrição \\
\hline O material é facilmente controlavel? & Controlabilidade \\
\hline O material é facilmente direcionavel? & Controlabilidade \\
\hline $\begin{array}{l}\text { A interface do material educativo poderá ser } \\
\text { utilizada com base no conhecimento prévio } \\
\text { dos alunos? }\end{array}$ & $\begin{array}{l}\text { Conformidade com as expectativas do usuá- } \\
\text { rio }\end{array}$ \\
\hline $\begin{array}{l}\text { No caso da ocorrência de algum erro no uso } \\
\text { do material, pode-se dizer que o material } \\
\text { não cumprirá o objetivo de ensino? }\end{array}$ & Tolerância de erros \\
\hline $\begin{array}{l}\text { O usuario poderá modificar o material pre- } \\
\text { sente para seus proprios objetivos? }\end{array}$ & Adequação a individualização \\
\hline $\begin{array}{l}\text { O material oferece os elementos suficientes } \\
\text { para a memorização e comprensão do con- } \\
\text { teudo mostrado? }\end{array}$ & Adequação ao aprendizado \\
\hline
\end{tabular}

Tabela 5.1: Perguntas referentes a usabilidade didática.

\begin{tabular}{|l|l|}
\hline Pergunta & Critério de avaliado \\
\hline $\begin{array}{l}\text { O aluno pode entender esta quantidade de } \\
\text { informação oferecida no slide? }\end{array}$ & Controle do aluno \\
\hline $\begin{array}{l}\text { As Atividades podem ser extendidas com } \\
\text { este material? }\end{array}$ & Atividade do aluno \\
\hline $\begin{array}{l}\text { O material educativo permite que os alunos } \\
\text { interagem entre eles? }\end{array}$ & Aprendizagem colaborativa/cooperativa \\
\hline $\begin{array}{l}\text { O material educativo ajuda a cumprir as me- } \\
\text { tas da matéria? }\end{array}$ & Orientação a objetivos \\
\hline $\begin{array}{l}\text { O conhecimento está garantido através des- } \\
\text { ses slides? }\end{array}$ & Aplicabilidade \\
\hline $\begin{array}{l}\text { Acredita que o uso de um simulador agre- } \\
\text { gará conhecimento ao aluno? }\end{array}$ & Valor agregado \\
\hline $\begin{array}{l}\text { Você acredita que o uso desses slides é mo- } \\
\text { tivante? }\end{array}$ & Motivação \\
\hline Este material condiz com o material prévio? & Avaliação do conhecimento prévio \\
\hline $\begin{array}{l}\text { Você acredita que o aluno pode mudar al- } \\
\text { guma coisa do material em questão? }\end{array}$ & Flexibilidade \\
\hline $\begin{array}{l}\text { O material permite ao aluno discernir que } \\
\text { tais conhecimentos são necessários para sua } \\
\text { formação? }\end{array}$ & Feedback \\
\hline
\end{tabular}

Tabela 5.2: Perguntas referentes a usabilidade geral. 
O aluno pode entender esta quantidade de informação oferecida no slide?

$\begin{array}{lllll}1 & 2 & 3 & 4 & 5\end{array}$

Concordo totalmente $\bigcirc \bigcirc \bigcirc$ Discordo totalmente

As Atividades podem ser estendidas com este material?

$\begin{array}{lllll}1 & 2 & 3 & 4 & 5\end{array}$

Concordo totalmente $\bigcirc \bigcirc \bigcirc \bigcirc$ Discordo totalmente

O material educativo permite que os alunos interagem entre eles?

$\begin{array}{lllll}1 & 2 & 3 & 4 & 5\end{array}$

Concordo totalmente $\bigcirc \bigcirc \bigcirc$ Discordo totalmene

O material educativo ajuda a cumprir as metas da matéria?

$\begin{array}{lllll}1 & 2 & 3 & 4 & 5\end{array}$

Concordo totalmente $\bigcirc \bigcirc \bigcirc \bigcirc$ Discordo totalmente

Figura 5.2: Exemplo do questionário a ser aplicado

\subsection{Instruções para o preenchimento do questionário}

O questionário pode ser respondido de maneira simples e direta, tanto por alunos quanto por professores, bastando apenas que o usuário siga os passos:

1. Abrir o(s) arquivo(s) com os slides do material (disponíveis em formato .pptx);

2. Visualizar a sequência dos slides apresentados;

3. Preencher o questionário no Googledocs;

4. Confirmar o envio do formulário.

Para fazer esta pesquisa solicitou-se a dois professores que ministram aulas de Sistemas Operacionais para validar o modelo. Devido sua experiência no ensino de sistemas operacionais pode-se considerá-la como um elemento suficiente para validar os modelos apresentados em capítulos anteriores. O material educativo, mencionado anteriormente, foi encaminhado para os docentes por email. Através deste, também foram enviados os passos necessários para o preenchimento das 
questões da pesquisa de opinião. Após fazer a pesquisa de opinião utilizando as perguntas expostas anteriormente, o sistema apresentado foi adequado de acordo com as necessidades da pesquisa. O questionário foi respondido por apenas dois especialistas. Os resultados obtidos podem ser visualizados nas Tabelas 5.4 e 5.3 .

\begin{tabular}{|l|c|}
\hline Criterio avaliado & Média aritmética \\
\hline \hline Controle do aluno & 2 \\
\hline Atividades do aluno & 2 \\
\hline Aprendizagem colaborativa/cooperativa & 3,5 \\
\hline Orientação a objetivos & 2 \\
\hline Aplicabilidade & 4 \\
\hline Valor agregado & 1 \\
\hline Motivação & 3 \\
\hline Avaliação de conhecimento prévio & 2,5 \\
\hline Flexibilidade & 2 \\
\hline Feedback & 3,5 \\
\hline
\end{tabular}

Tabela 5.3: Respostas referentes a usabilidade didática.

\begin{tabular}{|l|c|}
\hline Criterio avaliado & Média aritmética \\
\hline \hline Adequação a tarefa & 1,5 \\
\hline Autodescrição & 2 \\
\hline Controlabilidade & 2,5 \\
\hline Controlabilidade & 2,5 \\
\hline $\begin{array}{l}\text { Conformidade com as expectativas do usuá- } \\
\text { rio }\end{array}$ & 2 \\
\hline Tolerância a erros & 3 \\
\hline Adequação a individualização & 2,5 \\
\hline Adequação ao aprendizado & 2 \\
\hline
\end{tabular}

Tabela 5.4: Respostas referentes a usabilidade geral.

\subsection{Conclusões dos questionários}

Dos resultados obtidos na parte da usabilidade didática sobre o material educativo desenvolvido, pode-se observar que os itens "Controle do aluno", "Atividades do aluno", "Valor Agregado", "Orientação a objetivos" e "Flexibilidade" têm a mais alta pontuação. Segundo os resultados obtidos nos quesitos antes mencionados, o impacto causado no aprendizado de aluno segundo a visão do professor, pode-se concluir que os slides são elementos importantes em relação à matéria de sistemas operacionais.

O quesito de "Avaliação de conhecimento prévio" também obteve um pontuação alta, mas menor que os quesitos descritos no parágrafo anterior. Do resultado conclui-se uma garantia do 
aprendizado do aluno sozinho ou em conjunto, permitindo ao aluno entender os objetivos do material educativo, para finalmente motivá-lo a resolver seus problemas no aprendizagem.

Dos itens de usabilidade geral do sistema recebe a máxima pontuação o quesito "Adequação a tarefa" do que se conclui que o material educativo permite cumprir com os objetivos dos alunos. Outros quesitos onde houveram alta pontuação foram os itens: "Autodescripção", "Conformidade com as espectativas do usuário" e "Adequação ao aprendizado" do que se conclui que a interface do material educativo é compreensível para o aluno, apresenta facilidade de ritmo de acordo com os conhecimentos do aluno, além de permitir um fácil aprendizado do seu uso.

O quesito que teve uma avaliação baixa foi "Tolerância a erros", sendo que neste quesito obteve-se uma resposta neutra, de onde não se pode tirar uma conclusão. Os quesitos "Controlabilidade" e "Adequuação a individualização" apresentam uma tendência a um valor neutro, também não se pode tirar uma conclusão. O objetivo final da avaliação foi verificar o senso didático do material criado para o modelo descrito no Capitulo 4 desta dissertação e se ele é adequado para o aprendizado da disciplina, sendo que o material educativo definido foca somente o tópico de ambiente de escalonamento. De acordo com a alta pontuação obtida na parte didática desta avaliação, pode-se dizer que este material educativo é adequado para ser utilizado em sala de aula.

\subsection{Considerações finais}

Neste capítulo foi apresentada a metodologia de validação dos modelos conceituais, instrucionais e didáticos desenvolvidos pela análise do material educativo elaborado. Para tanto, foi necessária à realização de uma pesquisa de opinião feita por um questionário, segundo os critérios estabelecidos na metodologia especificada neste capítulo. Sumarizando pode-se inferir que o material educativo feito em slides cumpre com os objetivos da matéria e possui uma interface aceitável para o aluno. Pelo qual se pode dizer que o modelo é um elemento didático válido para ser explorado nos outros conjuntos de conceitos presentes no domínio de conhecimento dos sistemas operacionais. 


\section{Conclusões e Trabalhos Futuros}

\subsection{Conclusões}

O desenvolvimento do material educativo é sugerido como uma tarefa obrigatória do professor encarregado de ministrar Sistemas Operacionais e, em consequência, deve estar em constante melhoria e ser constantemente avaliado. Independentemente se a quantidade de conceitos e outros elementos presentes em uma disciplina for muita ou pouca, a metodologia apoia no entendimento da complexidade dos conceitos.

A quantidade de conceitos da disciplina de Sistemas Operacionais é muito grande e aparentemente essa quantidade de conceitos vai-se acrescentando ano a ano. Devido a essa quantidade, a aplicação da metodologia AIM-CID teve seu grau de dificuldade. Na parte do desenho dos conceitos e suas inter-relações, apresentou-se uma dificuldade no desenho em si pois, ainda que utilizando a divisão dos conceitos de Sistemas Operacionais feita no livro Tanenbaum (Tanenbaum, 2009), também foram usadas algumas subdivisões sugeridas pelo mesmo livro e algumas outras subdivisões feitas para o melhor entendimento daqueles diagramas. O desenho dos diversos conceitos não foi uma tarefa trivial. Para a criação dos diagramas optou-se inicialmente pela utilização da ferramenta Graphviz $z^{1}$. A grande vantagem desta ferramenta foi que não houve necessidade de se trabalhar com uma interface gráfica, pois com um conjunto de comandos é possível desenhar tudo automaticamente. A desvantagem foi que a figura resultante não é atrativa e, em algumas situações, o resultado era confuso. Por esse motivo o Graphvi z não foi detalhado neste capitulo.

A solução encontrada foi a adoção da ferramenta Yed que obteve um melhor resultado e, portanto, foi utilizada para refazer todos os gráficos correspondentes aos diagramas conceituais

\footnotetext{
${ }^{1} h t t p: / / w w w . g r a p h v i z . o r g /$
} 
finais. Para os diagramas instrucionais e didáticos foi utilizada a ferramenta Mi crosoft Visio $2007^{\circledR}$ que na ocasião representava a melhor escolha disponível e adequada para a criação dos gráficos. A desvantagem e dificuldade de utilização desta ferramenta é que o Visio disponibiliza uma interface gráfica com pouco espaço para a criação e organização dos desenhos.

A pesquisa de novas ferramentas para o desenho de diagramas conceituais, instrucionais e didáticos deve ser continua com o objetivo de que no futuro seja possível a criação de desenhos de gráficos melhores e de forma mais rápida e sistemática.

A estrutura e divisão dos conceitos apresentados num livro não necessariamente têm que ser seguido por outros livros. A similaridade entre os conceitos não garante similaridade em outros aspectos sendo que, cada livro tem uma abordagem distinta, o qual não quer dizer que seja uma abordagem errada. O livro de Tanenbaum (Tanenbaum, 2009) apresenta muita similaridade em muitos conceitos presentes em diversos livros, o quais apresentam mais ou menos conceitos em relação ao livro do Tanembaum.

Na disciplina de Sistemas Operacionais, a execução de tarefas fora da realização de aulas expositivas tem um valor importante para o professor e o aluno (o objetivo principal do ensino). A procura por novos elementos e a inovação no ensino são obrigatoriedades para qualquer professor. Isto é uma tarefa constante no meio ambiente laboral, o qual se sugere deve ser uma constante no meio acadêmico também.

Os elementos auxiliares de uma aula de ensino não devem ser considerados como elementos que possam suplantar a aula expositiva, esta tem sua utilidade no ensino, como também são úteis as contribuições dos outros professores na área e também as opiniões dos alunos.

A metodologia AIM-CID na sua parte de desenho de conceitos, elementos instrucionais e elementos didáticos ajudam muito a entender e compreender as difíceis interações entre os conceitos presentes em um tema a ser ensinado. A metodologia também ajuda a entender a importância de alguns conceitos em relação aos outros conceitos, dizendo ao professor qual conceito é crítico. A aplicação da metodologia AIM-CID sobre a disciplina de Sistemas Operacionais deu uma visão sobre os conceitos importantes naquela disciplina e também deu uma visão sobre os diversos agrupamentos de conceitos presentes na disciplina. No grupo de conceitos do Gerenciamento de processos, Gerenciamento de Memória, Gerenciamento de Entrada/Saída e Sistemas de arquivos, além de visualizar a importância de alguns conceitos, estabeleceu quais conceitos são fundamentais e quais são secundarios, ou seja, que podem ser omitidos em caso de mudança de abordagem da disciplina, sempre respeitando a grade curricular dos diversos cursos de ciências de computação.

A metodologia AIM-CID, especificamente no caso do grupo de conceitos do Gerenciamento de processos, permitiu visualizar uma característica de modelo aberto nos conceitos, especialmente nos conceitos pertencentes ao conjunto do ambiente de escalonamento de processos, isto é dentro do domínio do conhecimento principal do Gerenciamento de processos.

No Gerenciamento de memória estabelece um modelo fechado em todos os grupos e subgrupos desta parte conceitual dos sistemas operacionais, sendo necessários elementos extras para o reforço 
na atividade do ensino, como é o caso do domínio do conhecimento do computador, o qual é muito maior que o domínio dos sistemas operacionais e, também do Gerenciamento de memória.

O gerenciamento de Entrada/Saída também apresenta um modelo fechado e, diferente dos outros modelos, não apresenta muitos exemplos como nos outros modelos. Acrescentou-se o nome de interação hardware e software para melhorar o entendimento dos diversos conceitos desta parte conceitual dos Sistemas Operacionais.

Finalmente sobre a parte conceitual dos Sistemas Operacionais conhecida como Sistema de Arquivos, também é um modelo fechado na parte principal deste domínio do conhecimento, somente apresenta um grupo de exemplos os quais também estão divididos internamente em três grupos para tornar mais fácil o entendimento destes em relação aos passos estabelecidos na metodologia AIM-CID.

As características de navegação apresentadas num diagrama didático também podem ser validadas através do uso de uma apresentação baseada em slides, que servem depois para realizar uma aula expositiva e também permite a avaliação de um docente em relação ao material educativo apresentado na forma de apresentação de slides.

Como conclusão dos resultados obtidos na pesquisa de opinião feita no capítulo de avaliação do modelo, pode-se concluir que o modelo cumpre com os objetivos traçados pelo professor da matéria de sistemas operacionais. Foram feitas algumas perguntas referentes à interface do material educativo, mas o foco da pesquisa de opinião foi a usabilidade didática, sendo que o resultado da usabilidade geral foi aceitável no que se refere ao usuário final. A pesquisa de opinião é um primeiro passo para futuras avaliações sobre os outros conjuntos de conceitos presentes no diagrama.

Os elementos presentes dentro dos diagramas gerados ao utilizar a metodologia AIM-CID para o domínio de conhecimento de Sistemas Operacionais mostram que nem todos os elementos precisam de simulação ou de outras formas de apoio ao ensino. A forma textual está presente naqueles elementos por ser considerada suficiente para a complexidade do conceito modelado dentro daquele domínio na suas partes agrupadas em conjuntos sugeridos pelo Tanenbaum (Tanenbaum, 2009).

\subsection{Publicações}

Durante a execução do mestrado o seguinte artigo relacionado a pesquisa desenvolvida foi publicado:

BRUSCHI, S. M.;ACEITUNO R. G. A. Aplicação da metodologia AIM-CID nos conceitos da disciplina Sistemas Operacionais, no domínio de gerenciamento de processos. In: Proccedings of the CSBC 2013 - WEI - XXI Workshop sobre Educação em Computação, Maceió, Brasil, 2013. 


\subsection{Contribuições}

A principal contribuição deste trabalho foi estabelecer uma hierarquização e classificação dos diversos conceitos presentes na disciplina de Sistemas Operacionais, sendo esta hierarquia produto da aplicação da metodologia AIM-CID.

Os diagramas gerados na presente pesquisa fornecerão um apoio ao professor na tarefa de determinar os conceitos importantes a serem ensinados na matéria de Sistemas Operacionais. Posteriormente o professor, dependendo da abordagem da grade curricular, poderá determinar quais conceitos são mais importantes no curso de ciências da computação onde esteja ministrando a matéria.

O presente trabalho pode também ser a base para o desenvolvimento de um ou mais simuladores de Sistemas Operacionais. Esses simuladores podem simular todo o Sistema Operacional ou uma parte, sendo que os modelos também podem ser modificados numa parte ou em todas as partes didáticas estabelecidas nos modelos feitos na presente pesquisa, podendo-se esperar uma grande variedade de software educativo.

\subsection{Trabalhos futuros}

A construção de um simulador de Sistemas Operacionais é a primeira sugestão de trabalho futuro para o presente trabalho, a qual pode ser feita em partes, não sendo preciso a construção do simulador. A metodologia permite a construção de simuladores de Gerenciadores de processos, Gerenciadores de memória, Gerenciadores de Entrada/Saída e de Sistemas de Arquivos.

A aplicação da metodologia AIM-CID deve ser aplicada a outras abordagens de outros livros de Sistemas Operacionais, utilizados em outros cursos de ciências da computação ou afins. Também sugere-se aplicá-lo sobre o material textual (seja apresentações em slides, apostilas ou outros) feito pelos professores encarregados de ensinar esta importante disciplina.

Os modelos feitos não devem ser tomados como modelo estático dentro do ensino de Sistemas Operacionais, sugerindo-se acrescentar os diversos diagramas gerados nesta metodologia. Mesmo utilizando o mesmo livro do Tanembaum (Tanenbaum, 2009), pode-se ter diversos diagramas gerados pelos diversos professores encarregados de ministrar esta disciplina, pelo que sugere a revisão, e a ampliação dos modelos apresentados nesta dissertação. Tudo isto com o objetivo de melhorar o ensino e o conhecimento do aluno.

A construção de software educativo nem sempre obriga a criação de simuladores. Também pode-se criar jogos para apresentar os diversos conteúdos dos Sistemas Operacionais, além de se fazer animações baseadas nos modelos e outros tipos de softwares que sejam necessários para aumentar a experiência do aprendizado para o aluno.

A tradução dos modelos apresentados em capítulos anteriores em outros idiomas aumentaria a aplicabilidade dos modelos em outras instituições de ensino superior relacionados com a ciência da 
computação, sugerindo-se principalmente que os diagramas sejam traduzidos aos idiomas espanhol e inglês. 

Abraham Silberschatz, P. B. G.; Gagme, G. Sistemas operacionais: conceitos e aplicações. Elsevier, 2004.

Abraham Silberschatz, P. B. G.; Gagme, G. Operating system concepts. John Wiley \& Sons, 2009.

Abreu, A. C. B. Avaliação de usabilidade em softwares educativos. Dissertação de Mestrado, Universidade Estadual do Ceará Instuto Federal de eduacação, ciência e tecnologia do Ceará, Fortaleza,CE, 2010.

Barbosa, E.; Maldonado, J.; Maidantchik, C. Padronização de processos para o desenvolvimento de módulos educacionais. In: XXIX Latin-American Conference on Informatics (CLEI 2003), 2003.

BARbosA, E. F. Uma contribuição ao processo de desenvolvimento e modelagem de módulos educacionais. Tese de doutorado, ICMC-USP, São Carlos, SP, 2004.

Barbosa, E. F.; Maldonado, J. C.; Ricarte, I. L. M. Learning materials: Towards the establishment of guidelines for domain modeling. In: Informatics Curricula, Teaching Methods and best practice Working Conference (ICTEM2002), 2002.

Bovet, C. P.; Cesati, M. Understandig the linux kernel. O'Reilly, 2000.

GAmA, C. L. G. Método de construção de objetos de aprendizagem com aplicação em métodos numéricos. Tese de doutorado, Métodos Numéricos em Engenharia da Universidade Federal do Paraná, Curitiba,PR, 2007.

KAWASAKI, E. I.;FERnAndes, C. T. Modelo para porjeto de cursos hipermídia. In: VII Simpósio Brasileiro de Informática na Educação (SBIE 96), 1996.

LEWINE, D. Posix programmers guide. O'Reilly Media, Incorporated, 1991. 
LOPES, V. R. P. Reutilização de conteúdo educacional no ambiente moodle ufba. Monografia, Departamento de Ciência da Computação, Instituto de Matemática, Universidade Federal da Bahia, Campus de Ondina, Salvador,BA, 2010.

Machado, F. B.; MAIA, L. P. Arquitetura de sistemas operacionais. LTC-Livros Técnicos e Cientificos Editora S.A., 2002.

MAIA, L. P. SOsim: simulador para o ensino de sistemas operacionais. Dissertação de Mestrado, Universidade Federal do Rio de Janeiro - UFRJ, Rio de Janeiro - RJ - Brasil, 2001.

Mayorga, J.; Verdejo, M.; Rodríguez, M.; Calero, Y.; ET Al. Domain modelling to support educational web-based authoring. Proceedings Telecommunications for Education and Training (TET 99), 1999.

Moreira, M. A.;BuChweitz, B. Mapas conceituais: Instrumentos didáticos, de avaliação e de análise de currículo, v. 1. São Paulo: Editora Moraes Ltda, 1987.

NiEnOw, A. L.; BEZ, M. R. Ferramenta de autoria para construção de objetos de aprendizagem para a área da saúde. Feevale: Novo Hamburgo, 2010.

Novak, J. Uma teoria de educação, v. 1. São Paulo: Editora Pioneira, 1981.

NovaK, J. Concept mapping: A useful tool for science education. Journal of research in science teaching, v. 27, n. 10, p. 937-949, 1990.

NovaK, J.; Gowin, D. Learning how to learn. Cambridge University Press, 1984.

Paul J. Deitel, H. M. D.; Choffnes, D. R. Sistemas operacionais. Pearson Prentice Hall, 2005.

Pimentel, M. Maphe: Metodologia de apoio a projetos de hipertextos educacionais. Simpósio Brasileiro de Informática na Educação, v. 8, p. 351-368, 1997.

Reigeluth, C. Instructional design theories and models: An overview of their current status, v. 1. Lawrence Erlbaum, 1983.

ReIS, F.; Costa, H. Tbc-so/web: Software educativo para aprendizagem de políticas de escalonamento de processos e de alocação de memória em sistemas operacionais. XX Simpósio Brasileiro de Informática na Educação-SBIE, 2009.

RocH, B. Monolithic kernel vs. microkernel. TU Wien, 2004.

Stallings, W. Operating systems : internals and design principles. Pearson Prentice Hall, 2005.

Tanenbaum, A. S. Sistemas operacionais modernos. Pearson Prentice Hall, 2003. 
Tanenbaum, A. S. Sistemas operacionais modernos. Pearson Prentice Hall, 2009.

Tarouco, L.; Fabre, M.; TAmusiunas, F. Reusabilidade de objetos educacionais. Novas Tecnologias na Educação, v. 1, n. 1, p. 1-11, 2003.

Turine, M.; OLIVEIRA, M.; MASIERo, P. Hyscharts: Um ambiente de autoria e navegação baseado no modelo hmbs. Simpósio Brasileiro de Sistemas Multimídia e Hipermídia (SBMIDIA'98), v. 4, p. 27-38, 1990.

Turine, M.; Oliveira, M.; Masiero, P. Designing structured hypertext with hmbs. In: VIII International ACM Hypertext Conference (Hypertext 97), 1997, p. 241-256.

TURINE, M. A. S. Hmbs: Um modelo baseado em statecharts para a especificação formal de hiperdocumentos. Tese de doutorado, IFSC-USP, São Carlos, SP, 1998. 

Ambientes de escalonamento de processos

Roni Guillermo Apaza Aceituno

Julho 2013

- Escalonador de processos

- Mudança de contexto

- Categoria

- Categorias de Ambientes

- Características gerais de algoritmos de escalonamento

- Características especificas dos algoritmos de escalonamento 


\section{Escalonador de processos}

Escalonador de processos
- O escalonador determina qual será o proximo processo a ser executado pela CPU.

- A função de escalonar processos não é uma tarefa simples pois deve aproveitar ao máximo o uso do processador.

- Exemplo de funcionamento de um escalonador através de um ambiente de simulação.

O simulador: programa

\section{Escalonador de processos}

Escalonador de processos
- O escalonamento é realizado com auxílio do hardware;

- O escalonador deve se preocupar com a eficiência da CPU, pois o chaveamento de processos é complexo e custoso;

- Afeta o desempenho do sistema e a satisfação do usuário;

- Toda vez que o escalonador é executado existe uma mudança de contexto 


\section{Mudança de contexto}

Mudança de contexto
- A tarefa feita pela SO para poder carregar um novo processo no CPU.

- Para que o CPU possa executar outro processo o SO deve guardar a informação do processo atual antes de poder carregar o novo processo.

\section{Mudança de contexto}

Mudança de contexto

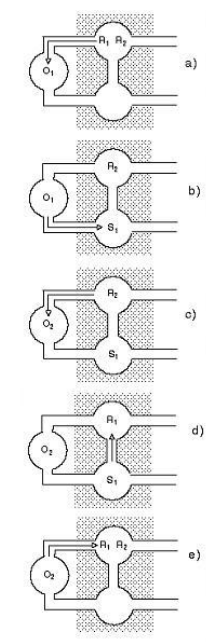

- A mudança de contexto acontece quando da troca de processo

- Na figura pode-se observar um conjunto de passos que acontecem durante a mudança de contexto

a) $O$ processo em espera $\mathrm{R} 1$ entra em execução como 01

b) O processo $\mathrm{O} 1$ vai a dormir como S1, esperando por I/O

c) Muda de contexto e o processo em execução R2 entra em execução como $\mathrm{O} 2$

d) O processo S1 acorda quando o recurso esta disponível, entrando na fila de processos prontos como R1.

e) $\mathrm{O}$ processo $\mathrm{O} 2$ sofre preempção e retorna a lista de execução como R2. O passo $a$ é repetido pois R1 tem maior prioridade que $\mathrm{R} 2$. 


\section{Categorias de algoritmos de Escalonamento}

Categorias de

algoritmos de

Escalonamento

Preemptivo

Não-preemptivo
- Os algoritmos de escalonamento podem ser divididos em duas categorias, dependendo de como as interrupções são tratadas:

- Preemptivo: escolhe um processo e o deixa executando por um tempo máximo;

- Não-preemptivo: estratégia que permite ao processo que está sendo executado continue sendo executado até ser bloqueado por alguma razão ( semáforos, operações de E/Sinterrupção) ou que libere a CPU voluntariamente

\section{Categorias de ambientes}

Categorias de

ambientes

Batch

Interativos

Tempo real
- Os sistemas operacionais podem ser classificados em 3 categorias.

- Batch: os usuários não esperam por respostas rápidas; os algoritmos de escalonamento são não-preemptivos ou preemptivos com longo intervalo de tempo;
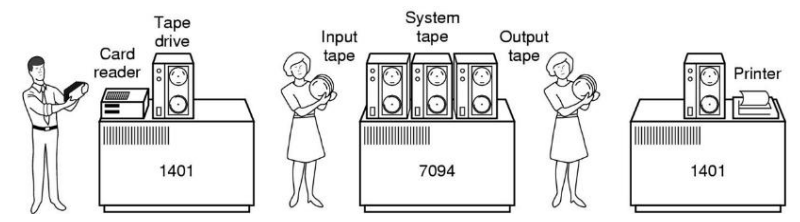


\section{Categorias de ambientes}

Categorias de

ambientes

Batch

Interativos

$\underline{\text { Tempo real }}$
- Tempo real: os processos são executados mais rapidamente; o tempo é crucial -> sistemas críticos;

- Interativos: existe interação constante com o usuário; os algoritmos são preemptivos; processo interativo -> espera comando e executa comando;

\section{Características gerais de algoritmos de escalonamento}

Características gerais $\underline{\text { Justiça }}$

Balanceamento

Politicas do $\underline{\text { sistema }}$
- Justiça: cada processo deve receber uma fatia justa de tempo da CPU;

- Balanceamento: diminuir o tempo ocioso do sistema;

- Politicas do sistema: respeita as prioridade de processos, de acordo com a política do sistema; 


\section{Características especificas}

Características especificas

Sistemas

interativos

Tempo de

resposta

Proporcio-

nalidade

Sistema Batch

Eficiência

Vazão

(throughput)

Tempo de

retorno

(turnaround

$\underline{\text { time) }}$

Sistema de tempo

real

Cumprimento

dos prazos

$\underline{\text { Previsibilidade }}$
- Sistemas Interativos;

- Tempo de resposta: tempo esperando para iniciar a execução;

- Proporcionalidade: satisfação dos usuários.

\section{Características especificas}

Características especificas

$\underline{\text { Sistemas }}$

interativos

Tempo de

resposta

Proporcio-

nalidade

Sistema Batch

Eficiência

$\underline{\text { Vazao }}$

(throughput)

Tempo de

$\underline{\text { retorno }}$

(turnaround

$\underline{\text { time) }}$

Sistema de tempo

real

Cumprimento

dos prazos

Previsibilidade
- Sistema Batch;

- Eficiência CPU: deve estar 100\% do tempo ocupado;

- Vazão (throughput): maximizar o número de jobs executados por hora;

- Tempo de retorno (turnaround time): tempo no qual o processo espera para ser finalizado; 

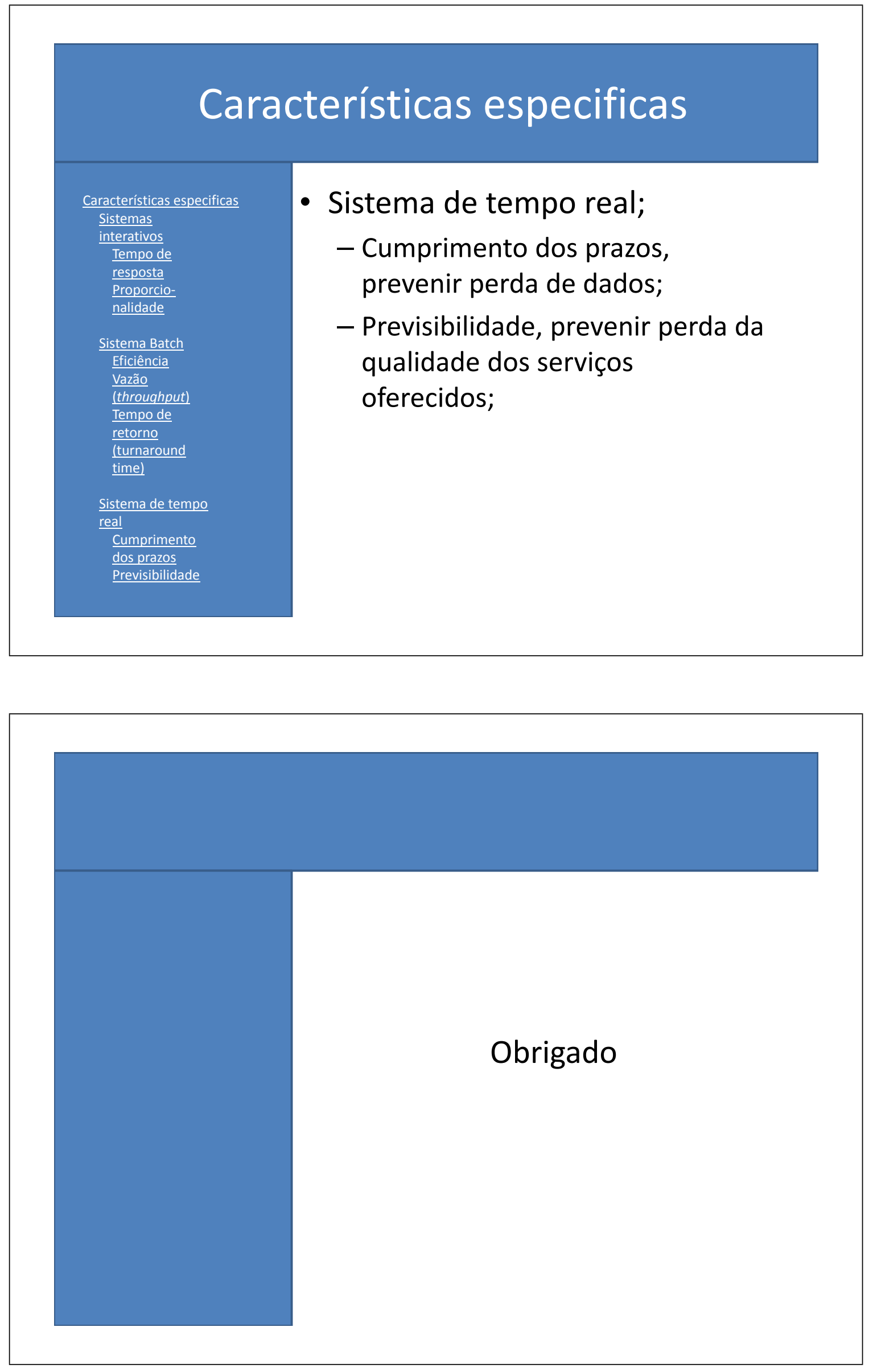


\section{Excercício}

- Criar um processo CPU-Bound ou I/O-Bound;

- Para realizar essa tarefa, selecionar a opção PROCESS -> CREATE, como é apresentado na figura abaixo.

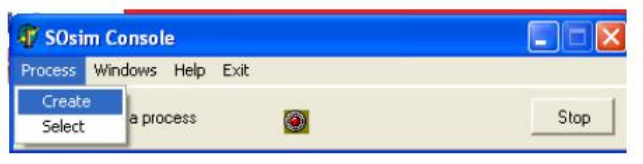

\section{Excercício}

- Em seguida, escolhe-se o tipo de processo;

- CPU_Bound;

- I/O_Bound; ou

- Misto;

- O padrão em "Num. of process" é o valor 1.

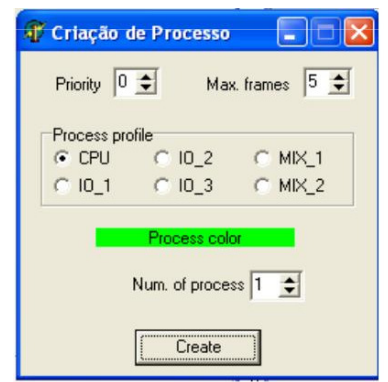




\section{Excercício}

- Na simulação se observa a mudança dos processos pelos diversos estados de um processo Running Ready Waiting.

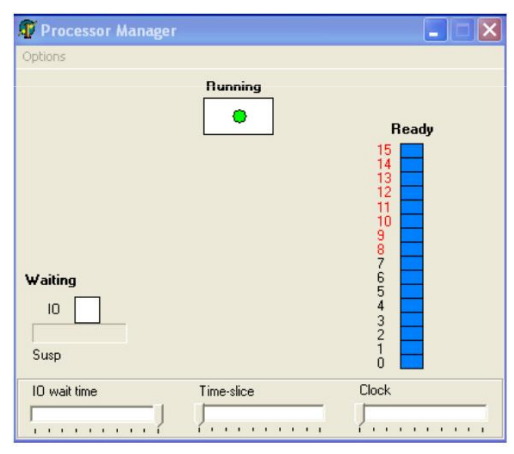

